\title{
INTERVENTION CHARACTERISTICS ASSOCIATED WITH IMPROVED PSYCHOLOGICAL DISTRESS IN ONCOLOGY FAMILY CAREGIVERS: A SYSTEMATIC REVIEW
}

\author{
by \\ Joyce Yuen-Ching Lo \\ BScN, Ryerson University, Canada, 2010
}

\begin{abstract}
A thesis
presented to Ryerson University

in partial fulfillment of the

requirements for the degree of

Master in Nursing

in the Program of Nursing
\end{abstract}

Toronto, Ontario, Canada, 2013

(C) Joyce Lo 2013 


\section{AUTHOR'S DECLARATION}

I hereby declare that I am the sole author of this thesis. This is a true copy of the thesis, including any required final revisions, as accepted by my examiners.

I authorize Ryerson University to lend this thesis to other institutions or individuals for the purpose of scholarly research.

I further authorize Ryerson University to reproduce this thesis by photocopying or by other means, in total or in part, at the request of other institutions or individuals for the purpose of scholarly research.

I understand that my thesis may be made electronically available to the public. 


\title{
INTERVENTION CHARACTERISTICS ASSOCIATED WITH IMPROVED PSYCHOLOGICAL DISTRESS IN ONCOLOGY FAMILY CAREGIVERS: \\ A SYSTEMATIC REVIEW
}

\author{
Abstract \\ by \\ Joyce Lo \\ Master of Nursing \\ Ryerson University, Toronto, 2013
}

Introduction: Caregiving for a loved one living with cancer can be distressing. Interventions to manage psychological distress may help family caregivers positively adapt to their situation.

Purpose: This review aims to describe the intervention characteristics that are effective in the management of psychological distress in oncology family caregivers. Specifically, the component, approach, mode and dose were examined.

Methods: For the purposes of this systematic review, articles which were primary research studies that evaluated an intervention aimed at oncology family caregivers, with psychological distress as an outcome, were included.

Results: A total of 23 articles were included. Effective interventions were primarily targeted, single-component, alternative therapies. These were mostly delivered in-person on an individual basis and varied in dose.

Implications/Conclusions: This study provides an understanding of intervention characteristics and provides a basis to help develop more effective and efficient programs, in an effort to address the issue of psychological distress among family caregivers. 


\section{ACKNOWLEDGEMENTS}

I would like to express my gratitude to my supervisor Dr. Suzanne Fredericks for your continued support, guidance and mentorship over the years. You have played a central role in my learning and have helped to open a multitude of opportunities for me. I really appreciate all that you have done for me.

I would also like to thank my committee members, Dr. Cristina Catallo and Dr. Elizabeth McCay for your encouragement and thought-provoking suggestions. I appreciate your enthusiasm and positivity, and I had a wonderful experience working with you.

To Dr. Lianne Jeffs, Dr. Souraya Sidani and my team, thank you for supporting my learning and education endeavors. Your patience and encouragement is much appreciated.

Lastly, to my family and friends, thank you for your unconditional love and confidence in me, I could not have done this without you. 


\section{TABLE OF CONTENTS}

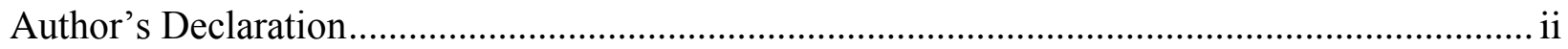

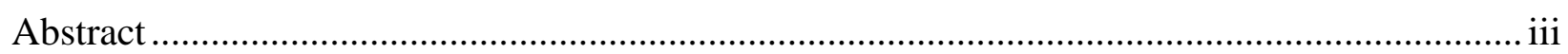

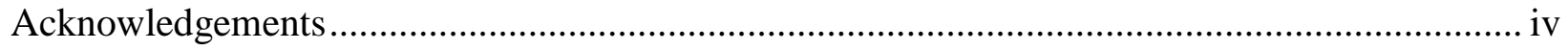

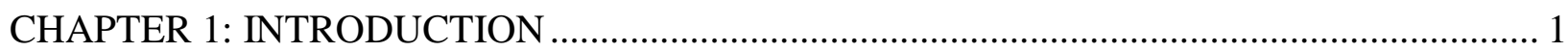

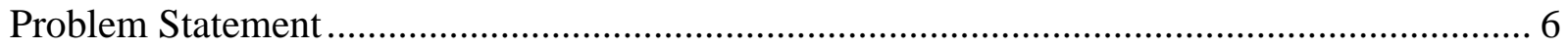

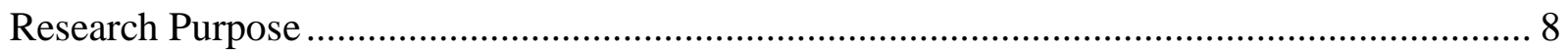

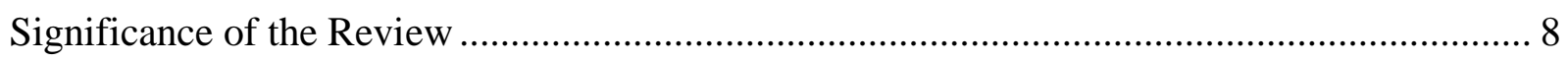

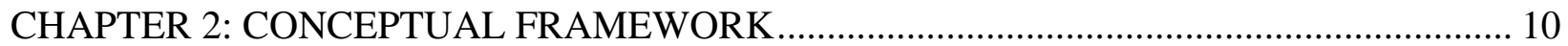

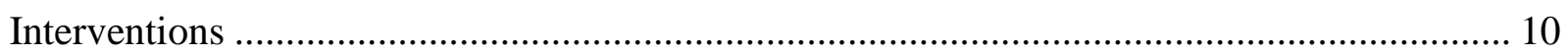

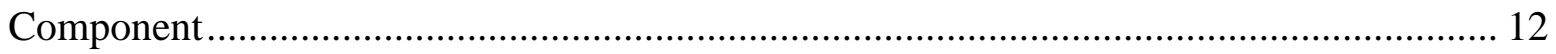

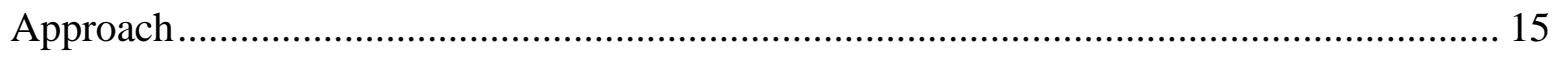

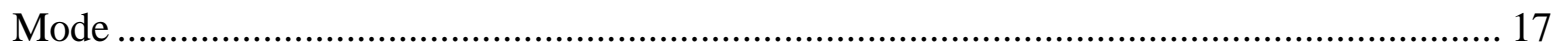

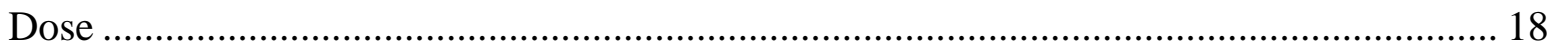

Outcome of Interventions: Psychological Distress ................................................................ 19

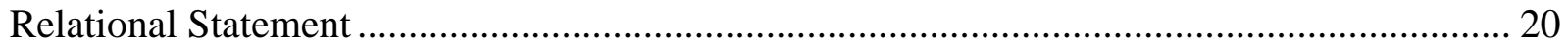

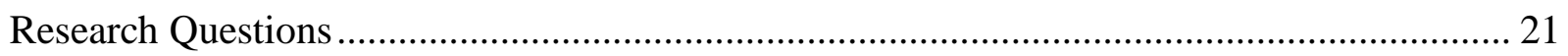

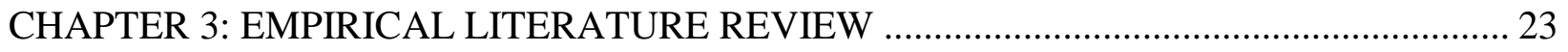

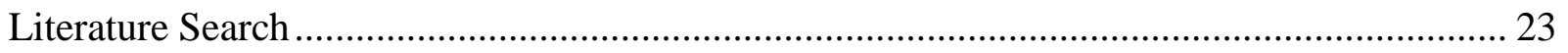

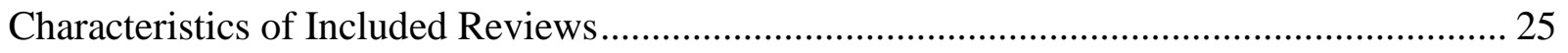

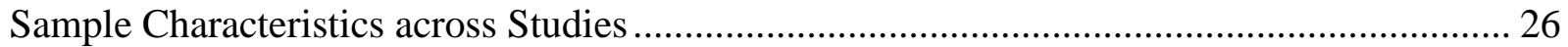

Intervention Characteristics - Component, Approach, Mode and Dose …………….............. 27

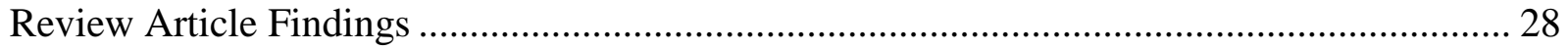




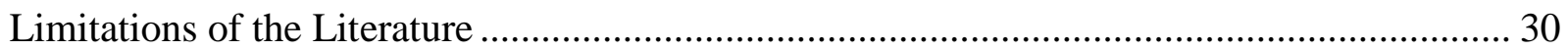

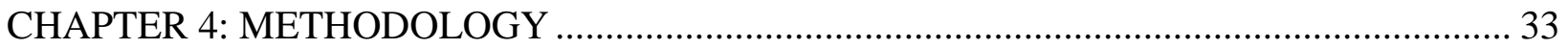

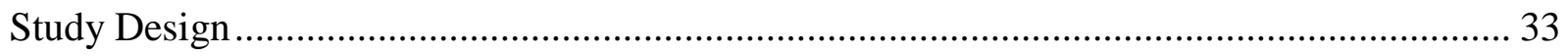

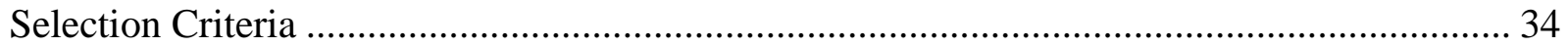

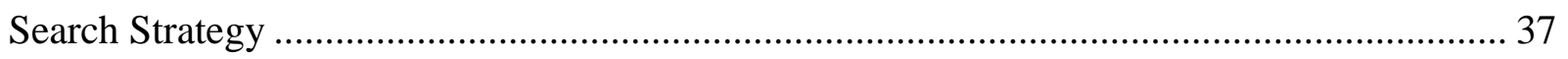

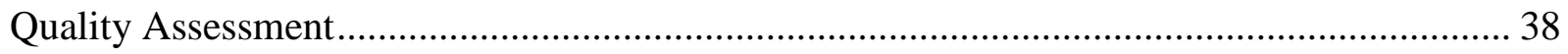

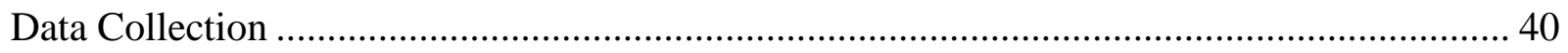

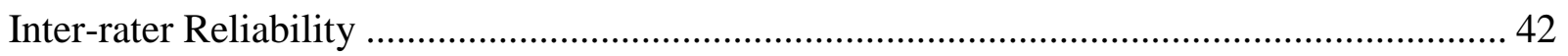

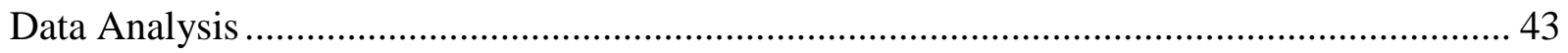

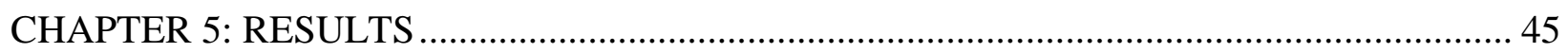

Research Question 1: Characteristics of Included Studies ..................................................... 45

Research Question 2: Characteristics of Individuals ........................................................... 49

Research Question 3: Findings Related to Psychological Distress........................................... 49

Research Question 4: Description of the Most Common Intervention Characteristics Across

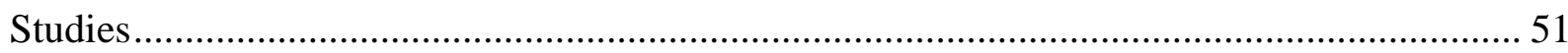

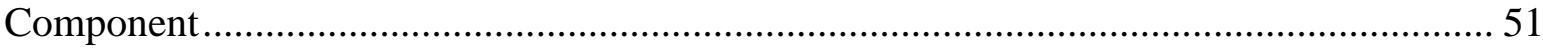

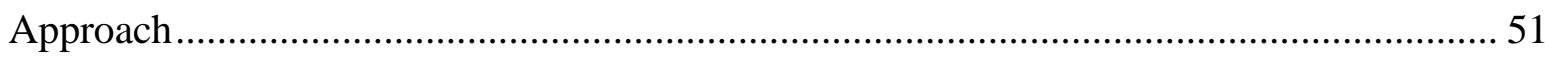

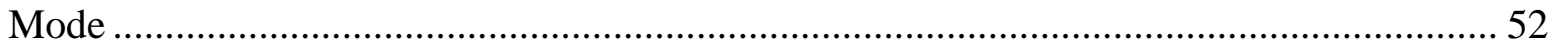

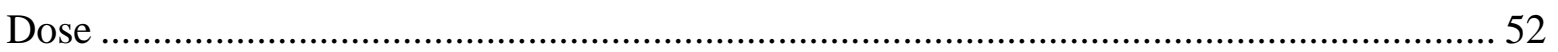

Interventions Producing Statistically Significant Psychological Distress Outcomes ............... 53

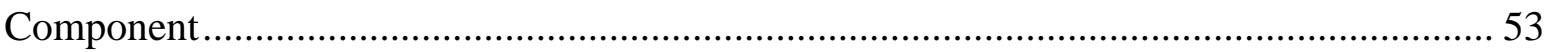

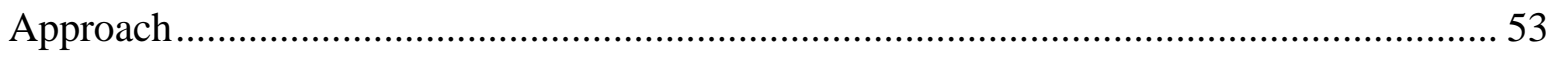

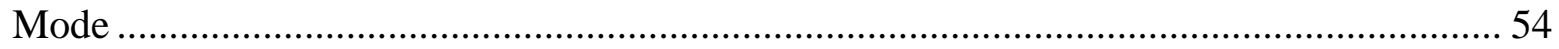


Dose

Research Question 5: Findings Related to Intervention Characteristics and Psychological

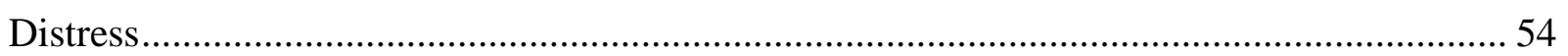

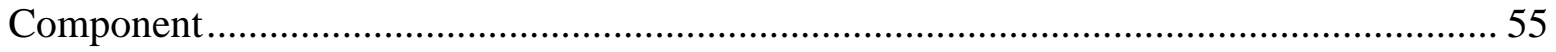

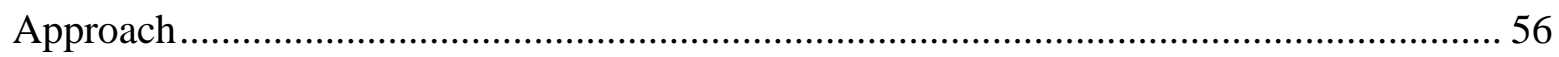

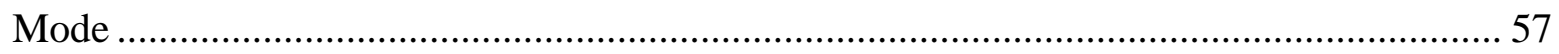

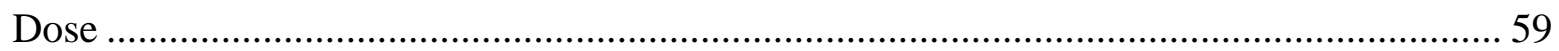

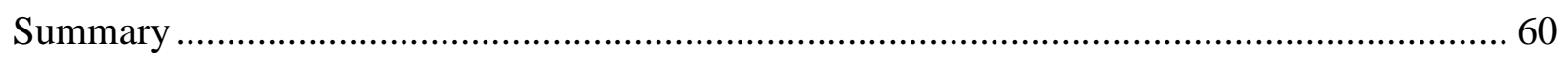

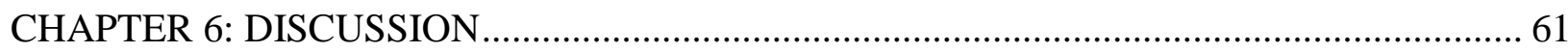

Research Question 1: Characteristics of Included Studies ............................................ 61

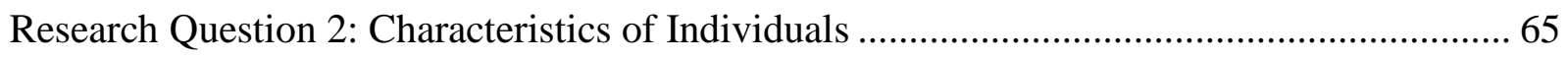

Research Question 3: Findings in Relation to Psychological Distress ................................ 68

Research Question 4: Description of the Most Common Intervention Characteristics Across

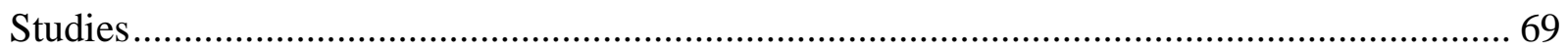

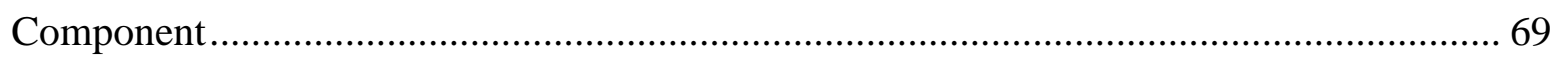

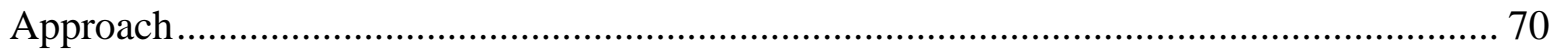

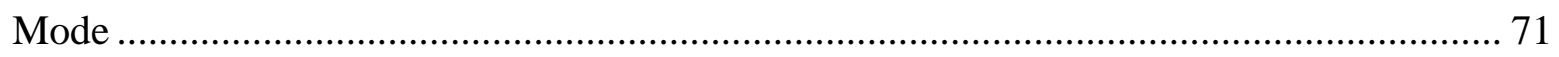

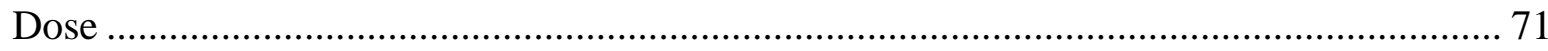

Research Question 5: Findings Related to Interventions Characteristics and Psychological

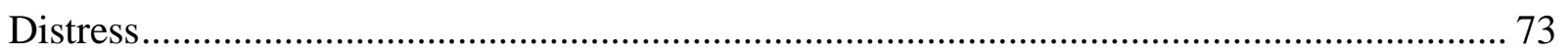

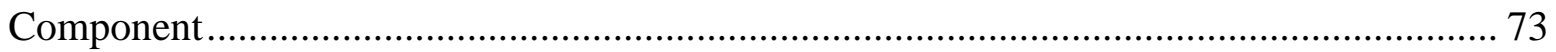

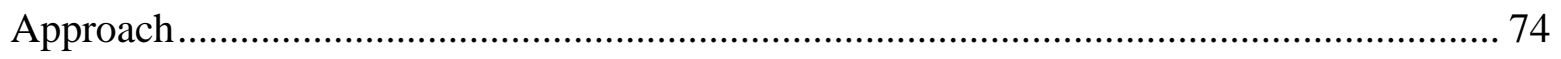

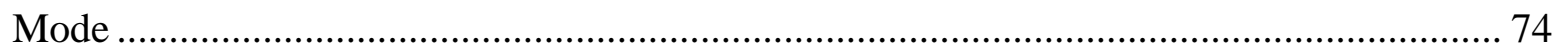


Dose

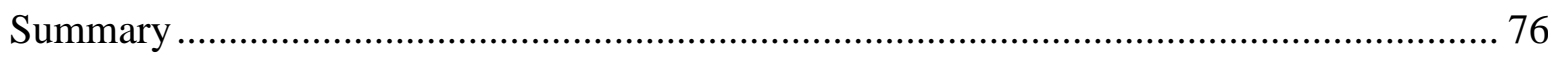

CHAPTER 7: IMPLICATIONS, LIMITATIONS, CONTRIBUTIONS AND CONCLUSION 78

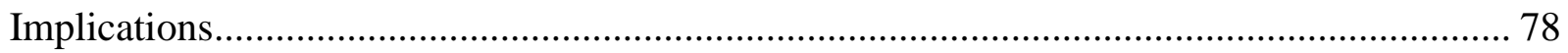

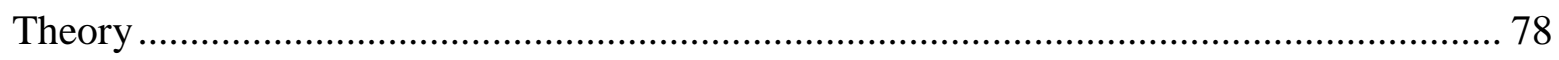

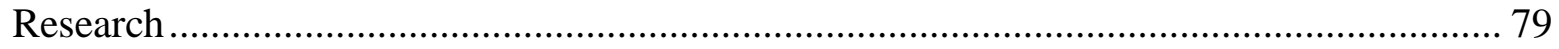

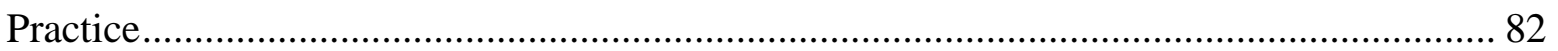

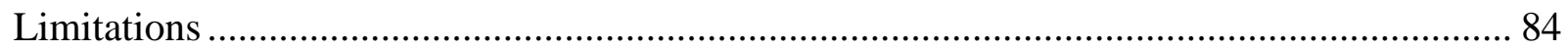

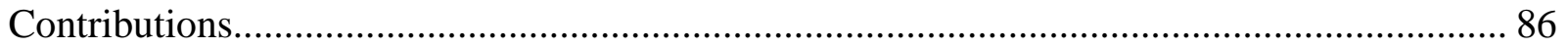

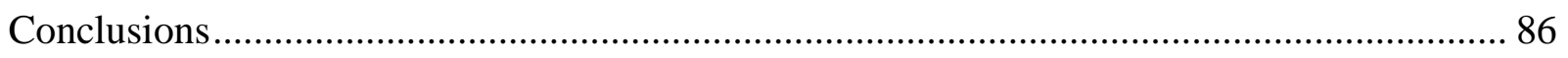

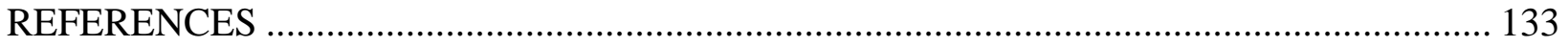




\section{LIST OF APPENDICES}

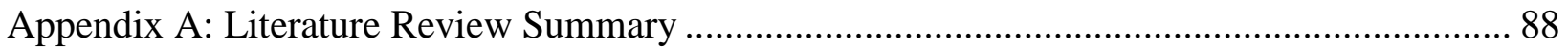

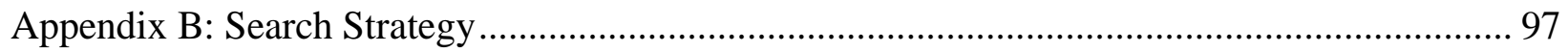

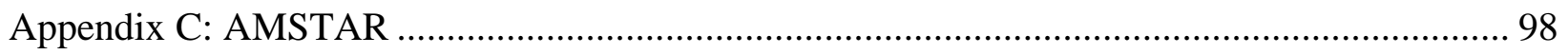

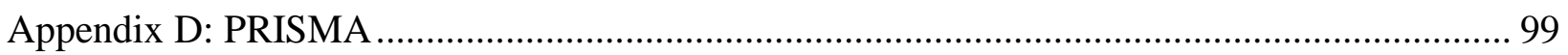

Appendix E: Quality Assessment Tool for Quantitative Studies: EPHPP ................................. 101

Appendix F: Quality Assessment Tool for Qualitative Studies: COREQ Checklist................... 105

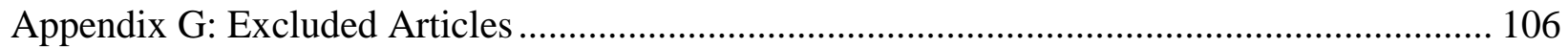

Appendix H: Table of Included Studies............................................................................... 108

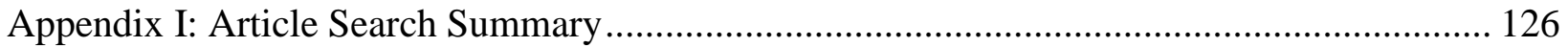

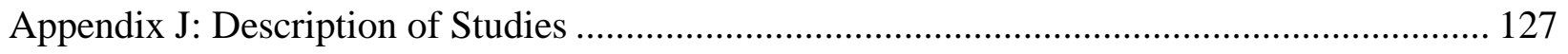

Appendix K: Strategies to Maintain Fidelity ......................................................................... 127

Appendix L: Standardized Tools Assessing Psychological Distress ........................................ 127

Appendix M: Component \& Mode Combinations..................................................................... 128

Appendix N: Studies Yielding Statistically Significant Psychological Distress Findings ......... 129 


\section{Chapter 1}

\section{Introduction}

Cancer refers to a broad group of diseases that involve an unregulated growth of abnormal cells (Lewis, Heitkemper \& Dirksen, 2006). Left untreated, its progression can lead to serious illness and even death (American Cancer Society, 2011). In Canada, it is estimated that approximately 177,800 new cases of cancer will occur in 2011, and 40\% of Canadian women and $45 \%$ of men are expected to develop this illness in their lifetime (Canadian Cancer Society, 2011). The cancer illness experience can be a significant source of distress for both the individual, as well as their loved ones (Hagedoorn, Sanderman, Bolks, Tuninstra \& Coyne, 2008; Manne \& Badr; 2008; Ussher, Wong \& Perz, 2010), and there is growing evidence in the literature that cancer has a negative psychological impact on family caregivers (McCorkle \& Pasacreta, 2001; Toseland, Blanchard \& McCallion, 1995).

As care for individuals with cancer shifts from the inpatient to outpatient setting, family members often assume caregiving responsibilities for their loved one (Kurtz, Kurtz, Given \& Given, 2005; McCorkle \& Pasacreta, 2001). In the oncology nursing literature, family caregivers are commonly defined as family members who attend to their loved one's care needs on an informal basis, including physical and emotional support (Cameron, Shin, Williams, \& Stewart, 2004; Grov, Dahl, Moum \& Fossa, 2005; Porter, Keefe, Garst, McBride \& Baucom, 2008). Family members' engage in a broad range of activities to support their family member, such as patient advocacy, supporting their loved one's adjustment and emotional needs, personal care, medication administration, symptom management, monitoring changes in health status, assistance in activities of daily living, patient transport, and managing previous activities and responsibilities of the patient (Blanchard, Albrecht, \& Ruckdeschel, 1997; Cameron et al., 2004; 
Given, Given \& Kozachik, 2001; Kurtz et al., 2005; Schumacher, Stewart, Archbold, Dodd \& Dibble, 2000; Swanson et al., 1997). Frequently, the patient's spouse, partner, or relative will undertake this supportive role (Grov, et al., 2005).

Advances in oncology treatments and supportive therapies have enabled individuals with cancer to prolong their lifespan despite experiencing ongoing complex health issues (Given et al., 2001; Kurtz et al., 2005; Lewis et al., 2006; McCorkle \& Pasacreta, 2001). As a result, family members are required to deliver unfamiliar complex care tasks to their loved one in order to meet their health needs (Cameron et al., 2004). Despite receiving little to no formal training, family caregivers engage in patient care activities surrounding the care of their loved one; playing a key role in the maintenance of the physical and emotional well-being of the patient (Hudson, 2004; Osse, Vernooij-Dassen, Schadé, \& Grol, 2006; Walsh, Martin, \& Schmidt, 2004). Furthermore, family carers have responsibilities outside of their care-giving role, such as employment, managing finances and other household and childcare commitments (Canadian Cancer Society, 2010a; McCorkle \& Pasacreta, 2001). Thus, balancing caregiving responsibilities in addition to existing roles may be challenging for the individual to manage, which may result in additional physical, emotional, social and economical strain (Blanchard et al., 1997, Canadian Cancer Society, 2010a; Hudson, 2004; McCorkle \& Pasacreta, 2001; Osse et al., 2006), leading to enhanced levels of stress (Blanchard et al., 1997).

Psychological distress refers to an unpleasant emotional state experienced by an individual in response to a stressor (Ridner, 2003). It is characterized by a perceived inability to cope with the stressor, a negative change in emotional status, discomfort with the distress, and harmful consequences to the individual as a result of being in distressed state (Ridner, 2003). Within the empirical literature, it is often measured in terms of anxiety, depression, psychosocial 
functioning, and mood/ affect (Blanchard et al., 1997; Kessler et al., 2002; Ridner, 2003; Veit \& Ware, 1983).

Empirical evidence suggests caregivers of family members living with cancer experience a significant amount of psychological distress, and have an increased risk of developing a number of psychological sequelae (Aranda \& Hayman-White, 2001; Carter \& Chang, 2000; Grov et al., 2005; Grunfeld et al, 2004; Haley, 2003; Harding \& Higginson, 2003; Hudson, 2004; Osse et al., 2006; Toseland et al., 1995). Many caregivers report that they require professional assistance to support their personal coping and to address spirituality and anxieties (Osse et al., 2006; Yates, 1999). Oftentimes, carers also experience increased rates of fatigue, impaired cognitive function and sleep disturbances as compared to their non-caregiving counterparts, and prolonged caregiving increases the strain that they experience (Northouse, et al., 2010). Many caregivers place their ill family member's health needs above their own, and are reluctant to report their own health care needs (Payne, Smith \& Glass, 1999). As such, caregivers may be at risk for poorer health outcomes as many do not seek help to address their own personal wellbeing and health needs at a preventative or early stage (Aranda \& Hayman-White, 2001).

Moreover, many family caregivers have personal health issues of their own as well, which may be further aggravated with the strains of caregiving (Northouse et al., 2010). These factors may have implications on caregivers' use of inpatient hospital facilities and readmission (Aranda \& Hayman-White, 2001).

The role of caregiver is important as it provides the much needed support and management to patients who may no longer have readily available access to health care once in the home environment. Distress from the caregiving experience can negatively affect the family carer's ability to attend to the patient, which can have implications for the quality of life of the 
care recipient (Cameron et al., 2004; Kurtz et al., 2005; Porter et al., 2008; Weitzner, Jacobsen, Wagner, Friedland, \& Cox, 1999). The degree to which caregivers are able to care for their family member can have an impact on their personal well-being (Aranda \& Hayman-White, 2001), wherein lower caregiver self-efficacy is often associated with adjustment issues, including a higher level of caregiver strain (Porter et al., 2008). Resources to address these needs may help to decrease the psychological burden carers experience (Cameron et al., 2004).

Interventions are designed to promote caregiver health as well as coping with their caregiving situation which may decrease psychological distress (Rider, 2003; Swanson et al., 1997). Interventions designed for oncology family caregivers are largely classified as being educational, cognitive-behavioural, or supportive in nature, while others may include a combination of these methods (Given, Sherwood \& Given, 2008; Honea et al., 2008; McCorkle \& Pasacreta, 2001; Suhonen, 2008). Educational interventions for family caregivers generally provide information to the caregiver about the illness, information to guide the provision of primary patient care, and about the management of caregiver's personal emotional and physical health (Bulechek, Butcher \& Dochterman, 2008; Northouse, Katapodi, Song, Zhange \& Mood, 2010; Northouse, Williams, Given \& McCorkle, 2012; Schumacher et al., 2000; Swanson et al., 1997). Caregivers frequently identify needing more support to increase their caregiving competence, including information on the disease process and symptom management of their loved one; as well as increased access to care and coordination of health services (Osse et al., 2006; Yates, 1999). Interventions using a cognitive-behavioural method seek to identify and adjust maladaptive behaviours and thoughts in efforts to develop caregivers' ability, preparedness, and/or competence (Uman et al., 2006; Honea et al., 2008; Matilla et al., 2009; Northouse et al., 2010). These interventions focuses on helping the individual identify and 
develop strategies and skills as a caregiver (Honea et al., 2008). Supportive interventions aim to provide psychosocial services to family caregivers and encourage the emotional expression of carers' thoughts and feelings regarding their caregiving experience (Honea et al., 2008;

McCorkle \& Pasacreta, 2001). This intervention style allows carers to share their experiences and receive emotional support (Honea, et al., 2008; Sorensen et al., 2002). Alternatively, many interventions may integrate several of these methods as part of the treatment.

Treatment is often provided to both the ill family member and their family caregiver, or to the family caregiver alone; and may be delivered in a variety of formats while varying in duration (Northouse et al., 2010). These interventions aim to assist family members to improve caregiver decision-making, manage cancer care or symptoms, and adapt to changes in their roles and routines, thus reducing feelings of distress (Blanchard et al., 1997; Carpenito-Moyet, 2006; Given et al., 2001; Whitley, 1992). Furthermore, the application of interventions that alleviate emotional distress in family caregivers may allow carers to provide more comprehensive and supportive care to their loved one (Trecartin \& Carroll, 2011; Raveis, Karus \& Siegel, 1998).

On examination of these interventions, the characteristics of these interventions are not consistent. (Blanchard et al., 1997; Cameron et al., 2004; Hudson, Aranda \& Hayman-White, Jepson, McCorkle, Adler, Nuamah \& Lusk, 1999; Kozachick et al., 2001; Rawl et al., 2005; Rexilius, Mundt, Erickson, Megel \& Agrawal, 2002; Scott et al., 2004; Toseland et al., 1995; Walsh, Martin \& Schmidt, 2004). Furthermore, the results of studies evaluating the effectiveness of interventions delivered to oncology family caregivers have reported inconsistent findings in relation to decreasing caregiver psychological distress (Blanchard et al., 1996; Hudson et al., 2005, Jepson, McCorkle, Adler, Nuamah \& Lusk, 1999; Kozachick et al., 2001; Kurtz et al., 2005; Lewis et al., 2008; Porter et al., 2011; Rawl et al., 2002; Rexilius, Mundt, Erickson, Megel 
\& Agrawal, 2002; Scott et al., 2004; Toseland et al., 1995). This may be due to the variability that is present in the design of these interventions. Variation in the characteristics of these interventions may in turn lead to inconsistent findings regarding treatment effectiveness (Sidani $\&$ Braden, 1998). This information is required to help determine intervention characteristics that are most efficient in improving psychological outcomes in this population, which can facilitate the design of such targeted interventions. To date, the specific characteristics of interventions that are most effective in reducing caregiver psychological distress is unknown.

\section{Problem Statement}

Studies have examined the effectiveness and efficacy of specific interventions designed to reduce psychological distress in family caregivers of individuals living with cancer (Cameron et al., 2004; Hudson et al., 2005; Kozachik et al., 2001; Kurtz et al., 2005; McCorkle, Robinson, Nuamah, Lev, Benoliel, 1998; Porter et al., 2011; Toseland et al., 1995; Walsh et al., 2004; Walsh, Radcliffe, Castillo, Kumar \& Broschard, 2007). However, a preliminary review suggests inconsistent findings related to the management of psychological distress within this population, which may be due to differences in the delivery characteristics of the intervention. Moreover, a preliminary overview of the literature suggests that there are inconsistencies in the reported characteristics of such interventions; namely the reported approach (which refers to how the intervention is given, i.e. individualized or standardized); component (ie: the type of activity(s) that make up the intervention), mode (i.e. in what format is the intervention given); and dose (i.e. length of time and frequency) of described interventions vary among different studies. This variability in treatment characteristics is problematic as variation influences the intervention's ability to produce desired outcomes (Sidani \& Braden, 2011). An intervention that is executed insufficiently or with an incorrect component, approach, mode or dose may lead to an inability to 
achieve the intended outcomes (Bellg et al., 2004). As such, variation in treatment delivery characteristics may lead to inconsistencies in the observed effectiveness of such interventions within the literature (Sidani \& Braden, 2011). A comprehensive review of the literature is needed to thoroughly explore and describe the treatment characteristics that are associated with improved psychological outcomes in oncology family caregivers.

Existing reviews have focused on the effect of interventions on family caregiver outcomes such as mental health, adjustment, quality of life, coping, physical functioning, knowledge, caregiver strain, and burden (Baik \& Adams, 2011; Cochrane \& Lewis, 2005; Harding \& Higginson, 2003; Honea et al., 2008; Hudson, 2004; McCorkle \& Pasacreta, 2001; Northouse, et al., 2012; Pasacreta \& McCorkle, 2000); however, few have examined how treatment characteristics may act as a factor into the effectiveness and efficacy of such interventions. Only three reviews briefly addressed intervention characteristics as potential moderators influencing the effectiveness of such interventions (Harding \& Higginson, 2003; Honea et al., 2008; Northouse et al., 2010). However, these review studies did not comprehensively explore specific intervention characteristics as a factor into the effectiveness of a given intervention as the primary focus of the review. A systematic review is warranted in order to ensure a rigorous synthesis of the existing evidence, and to allow more reliable results and conclusions to be drawn (Cochrane Collaboration, 2011). As well, understanding the specific characteristics of interventions that are effective in supporting family caregivers will allow for the design and implementation of future interventions to support these individuals as well as enhance the overall care being provided to individuals living with cancer. As such, the current systematic review aims to address this gap in knowledge by describing the treatment 
characteristics and their effectiveness in alleviating psychological distress in oncology family caregivers.

\section{Research Purpose}

The purpose of this systematic review is to describe the characteristics of interventions found to be most effective in the management of psychological distress in family caregivers of individuals living with cancer. In particular, the component, approach, mode and dose of interventions found to be most effective in reducing emotional distress will be examined. Specifically, this systematic review will add to the current body of knowledge by comparing the findings from the oncology family caregiver literature addressing psychological distress; provide a descriptive overview of the current literature and existing findings; and determine if relationships exist among these concepts, and the nature of these relationships. This information is required to guide the design of interventions that are both effective and efficient in producing improved emotional outcomes in the oncology caregiver population.

\section{Significance of the Review}

Knowledge of the specific component, approach, mode and dose of interventions found to be most effective in eliciting improved psychological distress has significance to practice and research. In terms of practice, clinicians are in a unique role to provide informational and emotional support for caregivers (Yates, 1999). This systematic review will provide useful information that can be used by clinicians to implement supportive interventions aimed at oncology family caregivers. Knowledge of the specific intervention characteristics associated with desired outcomes can facilitate clinicians' application of strategies to prevent or manage emotional distress when working with family caregivers of cancer patients. An understanding of which component, approach, mode and dose are associated with improved distress helps 
clinicians in their daily care to deliver interventions for this population in the most effective way. Similarly, such knowledge can also help in the development of programs and initiatives designed for oncology family caregivers to better meet their needs.

From a research perspective, this systematic review will address the existing gap in knowledge surrounding what specific intervention characteristics are associated with improved psychological outcomes for family caregivers of oncology patients. Such knowledge contributes to the current body of literature by examining the specific component, approach, mode and dose of interventions most likely to improve psychological distress in family caregivers within the oncology population. An enhanced understanding of what the ideal characteristics are for achieving reduced psychological distress will also be helpful in the design and evaluation of future interventions within this population. 


\section{Chapter 2}

\section{Conceptual Framework}

In this chapter, definitions of the key variables of interest will be considered. First, the variables of interest will be defined both conceptually and operationally, with a focus on intervention characteristics. This will be followed by a definition of psychological distress as a caregiver outcome, wherein conceptual and operational definitions will be provided.

\section{Interventions}

Interventions refer to treatments, therapies, procedures or actions carried out by health care professionals with patients to enhance health outcomes in a way that is beneficial to the client (Sidani \& Braden, 1998). Interventions may target individual persons, family members, as well as communities at large (Bulechek, Butcher \& Dochterman, 2008; Sidani \& Braden, 2011). Interventions can be therapeutic or preventative (Medical Research Council, 2000), and be physical, behavioural, psychological, cognitive or social in nature (Sidani \& Braden, 2011). Although the aim of a health intervention is to improve patient care, treatments may be directed towards individual clients or at healthcare professionals (MRC, 2000). Interventions may also be delivered at an organizational or population level in efforts to improve patient outcomes. The development and delivery of an intervention aims to address a presenting health problem that requires resolution, management or prevention (Sidani \& Braden, 2011). As such, the overall goal of health interventions is aimed at the promotion and/or maintenance of health.

Many healthcare interventions are complex in nature (Blackwood, 2006). These interventions consist of multiple interrelated and dependent elements, and encompass practitioners` behaviours, the frequency and timing of these behaviours, and strategies for organizing and delivering these behaviours (Blackwood, 2006; MRC, 2000). For instance, 
characteristics such as the expertise-level of the practitioner, practitioner type, setting, technologies available, and frequency of delivery, among others, all contribute to the design of an intervention. These intervention characteristics make up the active ingredients of a complex healthcare interventions and influence treatment effectiveness (MRC, 2000).

Within the oncology caregiver literature, interventions designed for family caregivers of individuals living with cancer are aimed at alleviating the negative effects of caregiving, including psychological distress (Haley, 2003), as well as to improve caregiver coping skills, knowledge and quality of life (Northouse, Williams, Given \& McCorkle, 2012). The literature identifies the positive psychosocial outcomes of these interventions for family caregivers, including reduced distress (Northouse, Katapodi, Song, Zhang \& Mood, 2010), burden (Martire, Lustig, Schulz, Miller \& Helgeson, 2004; Northouse et al., 2010; Sorensen, Piquart \& Duberstein, 2002), depression (Martire et al., 2004; Matilla, Leino, Paavilainen \& Astedt-Kurki, 2009, Sorensen et al., 2002), and improved mental well-being (Matilla et al, 200; Northouse et al., 2010; Sorensen, Piquart \& Duberstein, 2002).

The elements of an intervention include the type of intervention that is provided; how it is given; and how often it is presented (Müller-Staub, et al., 2007); and requires thought into its complexity, approach, mode, dose, and components (Lauver et al., 2002). For the purposes of this systematic review, the key intervention characteristics being examined include its components (educational, cognitive behavioural, or supportive), approach (standardized, targeted, tailored, or individualized), mode of delivery (medium and format) and dose (strength). Data pertaining to the key characteristics of interest were extracted from study articles by the researcher. 


\section{Component}

Conceptual definition of component. Conceptually, components of an intervention refer to the elements and activities that are aimed towards achieving treatment goals (Sidani \& Braden, 1998). These may be generally classified as being cognitive, behavioural, educational, physical, or social in nature, which will be further described in the section below.

Component types. Cognitive-behavioural training (CBT) interventions are common and merge both cognitive and behavioural components into the treatment. The cognitive portion aims to identify and alter maladaptive thoughts or feelings and reframe these into more positive beliefs, which in turn leads to more adaptive behavior and coping in the individual (Uman, McGrath \& Kisely, 2006; Sidani \& Braden, 2011). Similarly, the behavioural segment aims to change specific, targeted behaviors in efforts to prevent or reduce problem intensity (Uman et al., 2006; Forman \& Barakat, 2011). In interventions with a CBT technique incorporates both components; wherein practitioners work with individuals to identify and teach clients adaptive skills and behaviours (Uman et al., 2006; Honea et al., 2008).

Educational interventions aim to increase knowledge in the individual, where practitioners provide instruction to clients to address their learning and informational needs (Redman, 2001). Strategies involve classes, written materials, or demonstrations as part of the intervention (Sidani \& Braden, 1998).

Physical interventions target specific impairments (Harvey, Lin, Glinsky \& De Wolf, 2009) and include exercise, acupuncture, medication, surgery, and physiotherapy, among others (Harvey et al., 2009; Ruddy \& House, 2005). These interventions are often delivered by trained practitioners such as nurses, physiotherapists, occupational therapists, and medical practitioners (Harvey et al., 2009). 
Supportive or social interventions allow individuals to broaden social networks and receive support from others (Helgeson \& Cohen, 1996). In this type of intervention, individuals with a shared or common experience are provided a space to discuss their feelings, difficulties, and strategies (Sorenson et al., 2002). In doing so, supportive interventions allow participants to receive mutual support from peers as well as the opportunity to share and receive information from on another.

Simpler interventions may include only one component, whereas more complex interventions may consist of a multi-component design. In complex interventions, components of an intervention may work separately or interdependently to address treatment aims (MRC, 2000). Within the oncology caregiver literature, evaluating the effect component has on the achieving preferred outcomes has been limited. Review articles by Honea et al. (2008) and Hudson (2004) reported that multi-component interventions tended to be successful in producing favorable outcomes as opposed to single component interventions in oncology family caregivers. The result that multi-component interventions may be more likely to be effective in achieving desired outcomes may be attributed to the fact that multi-component interventions employ a number of various strategies to address family caregivers' needs. In spite of this, it is still unclear what type(s) of components are favourable in addressing psychological distress in oncology family caregivers.

Components for oncology family caregivers interventions. Interventions aimed at oncology family caregivers commonly include a psycho-educational, cognitive-behavioural or supportive component (Honea et al., 2008). Alternatively, interventions may also use a combination of these methods. 
Psycho-educational interventions are often information-based and provides education to the caregiver about the illness including the disease process, patient care, self-care, and informing caregivers about available resources and services (Honea et al., 2008; Northouse et al., 2010). The informational content is oftentimes delivered in a structured and standardized method, and may include lectures or written materials (Honea et al, 2008).

Another common intervention component type used with oncology caregivers is cognitive-behavioural training (CBT). Interventions with a cognitive-behavioural component aim to identify and adjust maladaptive behaviours, thought processes and feelings (Uman et al., 2006). This type of intervention aims to help develop caregivers' ability, preparedness, and/or competence to deal with distress (Honea et al., 2008; Matilla et al., 2009; Northouse et al., 2010). Cognitive-behavioural interventions may be delivered by a trained professional or therapist. The professional works with the individual to identify strategies, or teaches and develops the carer's personal skills (Honea et al., 2008). Examples of such cognitive-behavioural interventions include improving problem-solving abilities, challenging negative thoughts, and developing time management skills (Honea et al., 2008; Northouse et al., 2010).

Supportive interventions may be provided within a group or individual format and may be led by a healthcare professional or peer (Honea, et al., 2008; Sorensen et al., 2002). These interventions seek to build a relationship with carers to encourage emotional expression of their feelings and challenges regarding their caregiving experience (Honea et al., 2008; McCorkle \& Pasacreta, 2001). This type of intervention is therapeutic as it allows carers to share their experiences, as well as provide mutual support and share strategies with one another (Honea, et al., 2008; Sorensen et al., 2002). Multi-component interventions integrate or involve several of these components as part of the treatment. 
Operational definition of component. As such, component was operationalized by extracting whether a psycho-educational, cognitive behavioural, supportive, or a combination of these components were used from the article's description of the intervention activities. Treatments with a psycho-educational component were operationalized by any intervention that was described as having an informational or educative aspect to the program. This may be evidenced by training sessions, lectures or written materials as part of the intervention. Components using a cognitive behavioural method were operationalized in the current systematic review as any intervention that was identified within a cognitive-behavioural framework in the study. Supportive components were operationalized by any intervention that aimed to increase the social network of the individual as a means to receive emotional support. Lastly, multi-component interventions were those that included two or more of these components as part of the treatment. When interventions used multiple components, the types of components used in combination were recorded.

\section{Approach}

Conceptual definition of approach. Approach refers to the general strategy employed to carry out the intervention (Fredericks, Ibrahim, \& Puri, 2009). Complex interventions can be provided using targeted, tailored, or individualized approaches (Lauver, et al., 2002).

In the targeted approach, the intervention is aimed toward a group of individuals who share behavioural and/or socio-demographic characteristics. In this type of intervention, treatment delivery is standardized across participants and all patients receive the same treatment. Regardless of each participant's characteristics, personal circumstances or experiences, the treatment will be delivered with the same preselected content, components, mode, and dosage (Sidani \& Braden, 2011). In this approach, topics and subject matter related to oncology 
caregiving are pre-established and the health care professional delivers the same content to all intervention recipients. This is done without consideration to its relevance or appropriateness to the individual.

In contrast, interventions that use a tailored approach are more complex and are individualized to the personal needs of the patient (Lauver et al., 2002; Suhonen, Valimaki \& Leino-Kilpi , 2008). That is, each individual receives an intervention that is customized to the specific preferences, needs or characteristics of the patient (Lauver et al., 2002). Client characteristics that are taken into account include the individual's issue and readiness for change, general health status, socio-demographic status, resources and so on (Sidani \& Braden, 2011). With these in mind, specific activities or strategies are incorporated into the tailored intervention that is relevant to the individual's unique characteristics and situation to effectively address the presenting health problem or treatment goals. Participants may also have a choice over the type of information and care they receive from the intervention (Suhonen et al., 2008).

Individualized interventions are another approach that offers a highly customized treatment that is adapted to the individual and their personal situation (Lauver, et al., 2002). Interventions employing this approach may be so specific to the individual that oftentimes no two patients will receive the same treatment content as the other.

It has been hypothesized that standardized interventions may be not be as effective as treatments employing a tailored approach, since individuals tend to perceive the latter as being more personal or relevant to their experience (Dijkstra, 2005; Lauver et al., 2002; Sidani \& Braden, 2011). As such, clients may be more motivated to participate in the intervention, and information and skills may be more likely to be retained by the individual. 
Operational definition of approach. In this systematic review, approach was operationalized by whether the intervention was targeted, individualized or tailored; or if a combination of approaches were used. A targeted approach was evidenced by an intervention that remained constant across treatment recipients. A tailored approach was classified as a treatment that was organized for each individual participant within the sample in accordance with their needs and personal situation. Finally, an individualized intervention was identified by having an approach where the entire treatment was specifically customized to each individual carer. Interventions using a combination of these approaches were those that incorporated both targeted and tailored activities into the intervention program.

\section{Mode}

Conceptual and operational definitions of mode. Mode of delivery refers to the medium or process used to implement the intervention (Fredericks, et al., 2009; Suhonen, 2008). Mode is classified in terms of the strategy and format of the intervention.

Firstly, strategies refer to the medium or process that the intervention was delivered. In the current review, the intervention strategy was operationalized by whether the interventions used a telephone or face-to-face encounter, use of multimedia or technology, written materials, or a combination of several strategies as part of the program (Fan \& Sidani, 2009; Suhonen, 2008). Knowledge of the ideal medium helps to assess which strategies are more effective and appropriate to the intervention recipient.

Secondly, format refers to the how the intervention is provided to the participant, such as via one-to-one or group sessions, or a combination of both (Fan \& Sidani, 2009). Among family caregivers, interventions may also adopt a dyadic format, where the family caregiver and their loved one jointly receive the intervention (Northouse, Katapodi, Song, Zhang \& Mood, 2010). 
Programs delivered within different formats may have implications regarding the effectiveness of the intervention on the caregiver. Therefore, format was operationalized in the current study by identifying whether the intervention was provided to the family caregiver on a one-to-one basis, within a group setting, or if the treatment was delivered to both the caregiver and loved one. Ideally, the mode is thoughtfully selected as a means to optimize intervention delivery; for instance, an intervention utilizing a group session may help to facilitate interaction and discussion as part of the intervention (Sidani \& Braden, 2011). Within the literature, it is not clear which specific intervention strategies or format is ideal in producing favourable psychological outcomes among oncology caregivers.

\section{Dose}

Conceptual definition of component. Dose refers to the strength to which the intervention is given in order to achieve desired outcomes (Sidani \& Braden, 1998). Variability in the prescribed dose of an intervention may effect the treatment's ability to reach intended outcomes. Specification of the dose of an intervention is vital to determining the required strength needed to produce favourable outcomes. Furthermore, knowledge of the dose of an intervention allows for analysis into level of the intervention that is most acceptable and appropriate for producing positive outcomes for individuals. As discussed in the literature review, there are few studies that evaluated the relationship between effectiveness of varying intervention dose levels and psychological distress within the oncology caregiver population. The results of one meta-analysis indicated that longer interventions with more hours and treatment sessions were associated with improved coping in cancer caregivers (Northouse et al., 2010), however it is not well known what intervention dose levels are effective in addressing psychological distress in this population. 
Operational definitions of dose. In this study, the intervention dose was operationalized in terms of the amount, frequency, and duration of the intervention. Amount refers to the total length of time of the intervention per session. Frequency was measured by the rate to which the intervention session was delivered over a specific period of time. Finally, duration consists of the total time period that the intervention was delivered from commencement to its conclusion.

\section{Outcome of Interventions: Psychological Distress}

Conceptual definition of psychological distress. The key outcome of interest in this systematic review is psychological distress. Psychological distress is conceptually defined as the "unique discomforting, emotional state experienced by an individual in response to a specific stressor or demand that results in harm, either temporary or permanent, to the person" (Rider, 2003, p. 539). It is characterized by a perceived inability to cope with the stressor, a negative change in emotional status, discomfort with the distress, and harmful consequences to the individual as a result of being in a distressed state (Rider, 2003). Psychological distress occurs within a continuum, where symptoms range in severity from a normal level of fear or sadness, to a maladaptive level of distress, which may be debilitating to the individual (Carlson \& Bultz, 2003; Ridner, 2003). Within the oncology literature, psychological distress extends to the unpleasant emotional experience that is psychological, spiritual or social in nature, which may in turn impede the individual's ability to cope with the illness experience (National Comprehensive Cancer Network, 2012).

In the literature, psychological distress is often used in as an umbrella term, applied within the contexts of stress, strain and distress (Rider, 2003); and is often used interchangeably with the term 'emotional distress' (Kessler, 1979). Indicators of psychological distress may 
include anxiety, depression, hopelessness, sadness, fearfulness, irritability, and tearfulness (Ridner, 2003). Within the empirical literature, psychological distress is most frequently measured by anxiety and depression (Blanchard et al., 1997; Carlson \& Bultz, 2003; Ensel \& Lin, 1991; Holahan \& Moos, 1981; Kessler et al., 2002; Strong et al., 2007; Ridner, 2003; Veit \& Ware, 1983; Zabora, Brintzenhofeszoc, Burbow, Hooker \& Piantadosi, 2001), although it also frequently included in other measures such as psychosocial functioning, mood/ affect, and worrying (Blanchard et al., 1997; Carlson \& Bultz, 2003; Kessler et al., 2002; Ridner, 2003; Veit \& Ware, 1983; Zabora et al., 2001).

Operational definition of psychological distress. For the purposes of this systematic review, psychological distress was operationally defined as the level of change in an indicator or symptom of psychological distress in the sample, either between or within groups, following the intervention. Examples of such referents may include anxiety, depression, hopelessness, psychosocial functioning, mood/ affect, and worrying. This was obtained by assessing whether the intervention led to a statistically significant change in the psychological distress indicator. This information was acquired from the results section of the study article.

\section{Relational Statement}

Family caregivers of a loved one living with cancer are at a higher risk of experiencing increased levels of psychological distress (Cameron, Franche, Cheung \& Stewart, 2002). Psychologically-based interventions have been designed to aid family caregivers in efforts to improve psychological well-being in this population (Selwood, Johnston, Katona, Lyketsos \& Livingston, 2006), however, these intervention characteristics vary, including the component, approach, mode and dose of such treatments. Such variation may affect the intervention's ability to achieve positive outcomes in the individual (Reed et al., 2007; Sidani \& Braden, 2011). The 
optimal characteristics of effective psychological interventions are unknown (Harding et al., 2004), and specifically, the ideal delivery circumstances to which family caregiver interventions are provided in order to address psychological distress are still not well known. The current systematic review was conducted to seek a better understanding of the relationship between specific intervention characteristics and improved psychological outcomes for family caregivers of oncology patients. Such knowledge will contribute to increased insight into the specific intervention component, approach, mode and dose most likely to improve psychological distress in family caregivers within the oncology population. Furthermore, an enhanced understanding of what the ideal characteristics are necessary for achieving reduced psychological distress will also facilitate the design and evaluation of future interventions within this population.

\section{Research Questions}

In order to gain perspective on the relationship between interventions characteristics and psychological outcome, the primary research question of this systematic review aims was to identify and address the association between the approach, component, mode and dose of an intervention with psychological distress and other relevant psychological outcome indicators. Identification of the most common intervention characteristics was also examined. Additionally, descriptive data was extracted on characteristics of the study, participants, and findings across the included studies. Specifically, the conduct of this study was guided by six research questions:

1. What are the characteristics of intervention studies that examined psychological distress among oncology family caregivers; such as study design, quality, sample size, and setting?

2. What are the characteristics of individuals included across studies, such as average age, gender, and martial status? 
3. What are the most common characteristics related to psychological distress, such as the measures and tools used to assess psychological distress?

4. What are the most common intervention characteristics aimed to reduce psychological distress in oncology family caregivers? Specifically:

a. What is the most common approach presented?

b. What is the most common component presented?

c. What is the most common mode presented?

d. What is the most common dose presented?

5. What is the relationship between psychological distress and intervention characteristics? Specifically, which intervention characteristics are associated with a statistically significant change in psychological distress? 


\section{Chapter 3}

\section{Empirical Literature Review}

In this chapter, a review of the oncology family caregiver intervention literature was conducted to assess the existing evidence and identify limitations. Attention will be given to what is known in terms of the study and sample characteristics across studies, with particular emphasis on the intervention characteristics and findings in relation to these characteristics. The intervention characteristics reviewed included the component (elements of the intervention, ie: educational, skills training, or supportive), approach (general strategy of the intervention, ie: individualized, tailored, targeted or standardized), mode (medium or process used to implement the intervention, ie: encompasses the strategy and format of delivery) and dose (the strength to which the intervention is given, ie: amount, frequency, and duration) across interventions. This synthesis will be followed by a critique of the literature and how the current systematic review aims to address these limitations.

\section{Literature Search}

A search of the literature was conducted to identify review articles that examined interventions designed for family caregivers of patients diagnosed and living with cancer. Existing systematic and meta-analytic review articles were included in this literature synthesis. The outcomes of interest were intentionally kept broad, as no reviews specifically examined interventions focused on psychological distress as its sole outcome. The following databases were searched: Medline, CINAHL, EMBASE, HealthStar, and COCHRANE. Boolean operators such as OR and AND, and truncation symbols such as “*” and "+" were used to facilitate the search. The search was guided by the following keywords: cancer, oncology, caregiv*, family caregiver, informal caregiver, intervention, program, treatment, systematic review, meta-analysis, 
literature review, and review article. A supplemental search within the reference lists of retrieved articles were also manually reviewed for additional studies. The search was limited to articles written in the English language; however no limitation on year of publication was established to be inclusive of the literature.

Articles were deemed relevant for this literature review if they met the following inclusion criteria: 1) the report was a systematic review, meta-analysis or literature review; 2) the sample consisted of family caregivers of persons with a diagnosis of cancer; 3 ) both the caregiver and loved one with cancer were adults (18 years of age or older); and 4) the review article focused on non-pharmacological interventions aimed towards family caregivers. References yielded from the electronic and manual searches were assessed for relevancy to the literature review. Questions that guided the relevancy screening included: 1) Was the article a literature review, systematic review or meta-analysis?; 2) Did the sample consist of family caregivers?; 3) Was the sample specific to oncology? 4) Did the article explore interventions; 5) Was the intervention aimed at the caregiver?; 6) Are the interventions relevant to nursing practice?; and 7) Were caregiver outcomes reviewed? Initially, article titles and/or abstracts were reviewed for potential eligibility. If five out of the seven (75\%) relevancy questions were addressed, articles were then obtained and more thoroughly reviewed for inclusion into the literature review. Once reviewed, the article had to address all the relevancy questions and inclusion criteria to be incorporated in this literature review.

The electronic search resulted in 51 references, of which 44 articles were excluded after screening for relevancy. Reports were excluded if the article was not a peer-reviewed report; a systematic review, meta-analysis, or literature review; if it was not a review of interventions; if interventions were not aimed towards the family caregiver; and if the study population was not 
specific to oncology. Seven articles met the relevancy screening and full-text versions were obtained and further screened for eligibility using the inclusion criteria. Seven articles were deemed relevant and included in this literature review. The supplemental search of references also yielded two additional studies. As a result, nine review articles examining interventions for family caregivers of oncology patients were identified and included in this literature review (Baik \& Adams, 2011; Cochrane \& Lewis, 2005; Harding \& Higginson, 2003; Honea et al., 2008; Hudson, 2004; McCorkle \& Pasacreta, 2001; Northouse et al., 2010; Northouse, Williams, Given \& McCorkle, 2012; Pasacreta \& McCorkle, 2000). Please refer to Appendix A for a table summarizing these articles.

\section{Characteristics of Included Reviews}

Of the nine reviews selected, two were literature reviews (Hudson, 2004; McCorkle \& Pasacreta, 2001), six used a systematic review design (Baik \& Adams, 2011; Cochrane \& Lewis, 2005; Harding \& Higginson, 2003; Honea et al., 2008; Northouse et al., 2012; Pasacreta \& McCorkle, 2000), and one was a meta-analytic study (Northouse et al., 2010). Sample sizes of primary studies ranged from four to 29 included studies. The majority of the articles included primary research studies that used various research design methodologies in their sample, such as randomized control trials, quasi-experimental, and case study designs (Baik \& Adams, 2011; Cochrane \& Lewis, 2005; Harding \& Higginson, 2003; Honea et al., 2008; Hudson, 2004; McCorkle \& Pasacreta, 2001; Pasacreta \& McCorkle, 2000). One meta-analysis only included randomized controlled trials in its sample (Northouse et al., 2010). Another systematic review exclusively limited its sample to meta-analyses (Northouse et al., 2012).

Most articles were inclusive of the types of oncology family caregiver interventions under review, however several limited their review to specific types of treatment, such as only 
examining interventions that were psychosocial (Baik \& Adams, 2011; Northouse et al., 2012), supportive (Hudson, 2004), or social/cognitive/behaviourally-based (Northouse et al., 2010). Among these nine articles, most did not specify a particular caregiver outcome of interest in their review. Rather, the majority of these reviews reported intervention effects on a range of caregiver outcomes reported across included study articles (Baik \& Adams, 2011; Harding \& Higginson, 2003; Hudson, 2004; McCorkle \& Pasacreta, 2001; Northouse et al., 2010; Northouse et al., 2012; Pasacreta \& McCorkle, 2000). Examples of such outcomes include mental health, adaptation, quality of life, coping, physical functioning, knowledge and burden. Alternatively, several review studies focused on specific outcome variables of interest, such as adjustment (Cochrane \& Lewis, 2005) and family caregiver strain and burden (Honea et al., 2008). Six articles addressed psychological distress as an outcome in their study (Baik \& Adams, 2011; Cochrane \& Lewis, 2005; McCorkle \& Pasacreta, 2001; Northouse et al., 2010; Northouse et al., 2012; Pasacreta \& McCorkle, 2000), although psychological outcome was not the sole or primary outcome of interest in any of these studies. Additionally, several reviews dedicated large sections within the article detailing the limitations of the literature as well methodological issues within the intervention literature for oncology family caregivers (Baik \& Adams, 2011; Hudson, 2004; Pasacreta \& McCorkle, 2000).

\section{Sample Characteristics across Studies}

Two articles limited their review to individual studies evaluating interventions with partner-caregivers only (Baik \& Adams, 2011; Cochrane \& Lewis, 2005), while others reviewed interventions aimed at family caregivers in general. Three review articles focused their sample on family caregivers of loved ones who were in the palliative stage of cancer (Harding \& Higginson, 2003; Hudson, 2004; McCorkle \& Pasacreta, 2001), while the rest included various 
caregivers of family members at various stages of the illness. In terms of diagnosis, most included studies with various diagnoses of cancer into their sample (Baik \& Adams, 2011; Harding \& Higginson, 2003; Honea et al., 2008; Hudson, 2004; McCorkle \& Pasacreta, 2001; Northouse et al., 2010; Northouse et al., 2012; Pasacreta \& McCorkle, 2000). In the two reviews aimed at partners, one review exclusively studied caregivers of breast cancer patients (Cochrane \& Lewis, 2005), while the other primarily included breast and prostate cancers within their sample (Baik \& Adams, 2011). Information pertaining to participant age, gender, race, marital status, level of education and employment status were not generally provided among these review articles.

\section{Intervention Characteristics - Component, Approach, Mode and Dose}

Across these review articles, researchers commonly classified interventions as having an educational, skills-building/cognitive-behavioural or supportive type component. Generally, interventions with an educational component focused on topics including information on symptom management and the physical aspects of cancer, or tasks of patient care. Skills-building or CBT type interventions generally focused on caregiver coping, and developing communication among couples or problem-solving skills. Supportive interventions addressed concerns of the family member, whether it be related to caregiving or any other general concerns they are experiencing. Across the review articles, the majority of interventions included educational or skills-building/CBT content as its primary component.

In terms of approach, details pertaining to the approach of the included interventions often were not described in most of the review articles. Only one article clearly reported that their included studies evaluated interventions that were either structured or tailored to the participants`situation or dynamic (Cochrane \& Lewis, 2005). 
Likewise, mode was often not clearly described or consistently reported both across the studies in this literature review, as well as within each article`s description of its` included primary studies. For those articles that included detailed descriptions as to the mode; face-to-face and telephone contact were the most common delivery strategies (Baik \& Adams, 2011; Northouse et al., 2012; Northouse et al., 2010). Furthermore, a group format of delivery was most commonly identified across studies, however, individual and dyadic focused interventions were also identified.

The dose of interventions was also infrequently reported on within these review studies. For studies that reported details related to the dose of the interventions, the range between the amount, frequency and duration of the interventions varied widely among different treatments. This is well exemplified in Northouse et al. (2010)`s meta-analysis, which reported that the total length of time of the included interventions spanned between 1.7 to 18 hours; the total number of sessions ranged from two to 16 contacts; while the duration ranged from within a time frame of several days to a period of 18 months.

Collectively, the description of the approach, component, mode and dose of interventions were not well described or consistently reported on across studies. Furthermore, for studies that did provide this information, treatment characteristics varied greatly in terms of the reported components, approach, mode and dose of the intervention delivered (Baik \& Adams, 2011; Cochrane \& Lewis, 2005; Harding \& Higginson, 2003; Hudson, 2004; McCorkle \& Pasacreta, 2001; Northouse et al., 2010; Northouse, et al., 2012).

\section{Review Article Findings}

Across these review articles, interventions generally resulted in an overall improvement on a number of family caregivers outcomes (Baik \& Adams, 2011; Cochrane \& Lewis, 2005; 
Hudson, 2004; McCorkle \& Pasacreta, 2001; Northouse et al., 2010). In terms of statistical significance, the results of Northouse et al. (2010) indicated that interventions for oncology family caregivers significantly reduced burden, and improved coping, self-efficacy and quality of life in the caregiver, and results of later a systematic review of meta-analyses by Northouse et al., (2012) showed significantly less burden, depression and distress. However, results pertaining to the effectiveness of interventions in addressing psychological distress in family caregivers were mixed among review article results (Baik \& Adams, 2011; Cochrane \& Lewis, 2005; McCorkle \& Pasacreta, 2001; Northouse et al., 2010; Northouse et al., 2012; Pasacreta \& McCorkle, 2000).

Among these nine review articles, five articles described observed associations between specific intervention characteristics and measured outcomes (Harding \& Higginson, 2003; Honea et al., 2008; Hudson, 2004; Northouse et al., 2010; Northouse et al., 2012). Specifically, connections were drawn between the components, mode and dose of interventions, and improved family caregiver outcomes in several reviews. Two review articles commented that multicomponent interventions tended to be more likely to improve caregiver outcomes as opposed to single-component interventions (Honea et al., 2008; Hudson, 2004).

In terms of mode, three reviews reported varying results pertaining to the format of treatment delivery on outcomes. One systematic review reported that programs delivered to individuals were more likely to be effective than those delivered in a group format (Honea et al., 2008). In contrast, another meta-analysis reported that group interventions were favourable in improving outcomes (Northouse et al., 2010). Likewise, a third review study also reported opposing results; that when examining studies that utilized one-to-one or group interventions, studies in both categories produced mixed results pertaining to the effectiveness of the interventions (Harding \& Higginson, 2003). Moreover, results of two studies that commented on 
whether treatments delivered to the caregiver alone versus those delivered to both the caregiver and family member also exhibited contradictory results (Northouse et al., 2010; Northouse et al., 2012)

Regarding the dose, the results of one meta-analysis indicated that longer interventions with more treatment sessions were associated with improved coping (Northouse et al., 2010), which is a finding supported by Northouse et al. (2012). However, in the same article, Northouse et al. (2010) also reported that interventions that are longer in length and have more treatment sessions are associated with more negative outcomes, such as caregiver burden, depression, and negative family relationship outcomes. None of the articles discussed the influence that intervention approach may have as a potential moderator in treatment outcomes.

\section{Limitations of the Literature}

On examination of these studies, several limitations of the literature were identified. First, the design characteristics of included interventions were not consistently designed across studies. In particular, the reported components, approach, mode and dose of these treatments vary (Baik \& Adams, 2011; Cochrane \& Lewis, 2005; Harding \& Higginson, 2003; Hudson, 2004;

McCorkle \& Pasacreta, 2001; Northouse et al., 2010; Northouse, et al., 2012). This observed variability in treatment delivery across populations is problematic because variation influences the intervention's ability to produce desired outcomes (Sidani \& Braden, 2011). An intervention that is designed with an inadequate or an incorrect component, approach, mode or dosage level may lead to erroneously rejecting a potentially effective intervention (Bellg et al., 2004). The discrepancy within reported intervention characteristics within the literature may indicate the lack of awareness of the treatment elements and dosage strength associated with the achievement of desired outcomes. 
Second, authors of reviews of the oncology intervention literature focusing on family caregivers have summarized or described relevant interventions and/or their effect on various caregiver outcomes (Baik \& Adams, 2011; Cochrane \& Lewis, 2005; Harding \& Higginson, 2003; Honea et al., 2008; Hudson, 2004; McCorkle \& Pasacreta, 2001; Northouse et al., 2010; Northouse, et al., 2012; Pasacreta \& McCorkle, 2000), however, few have comprehensively explored the relationship between the specific intervention characteristics as a factor into the effectiveness of a given intervention. These reviews did not clearly examine how treatment characteristics may contribute to the attainment of preferred outcomes. Designing an intervention with ideal characteristics must be done in order to allow for the active elements of the treatment to trigger the mechanisms involved to attain outcome changes (Sidani \& Braden, 2011). The application of the most ideal intervention elements are required to achieve positive outcomes in the most effective and efficient way.

Although some reviews briefly described the influence of several treatment characteristics in their report, none have incorporated a thorough exploration of multiple interventions characteristics on family caregiver outcomes. These reviews provide a fragmented view of the role that treatment characteristics have in their contribution to intervention effectiveness, and a comprehensive examination of intervention characteristics is lacking in the literature. Such knowledge is needed to facilitate the design and implementation of effective yet efficient interventions for oncology family caregivers.

Finally, the existing literature has largely assessed broad outcomes in oncology family caregiver interventions, while none have focused primarily on psychological distress as the main outcome of interest. A systematic review has not yet been done to comprehensively explore intervention characteristics that specifically address psychological distress as a primary outcome 
in family caregivers. To date, a gap in the literature exists regarding the specific intervention characteristics that are most effective in addressing psychological distress in oncology family caregivers is unknown.

Therefore, this systematic review will contribute to the current body of knowledge as there previously has not yet been any review studies done to comprehensively examine the characteristics of interventions aimed to address psychological distress in family caregivers of cancer patients. A systematic review will allow for a rigorous critical appraisal and synthesis of the existing evidence.

The results of this review will add to the existing body of literature on the characteristicoutcome response relationship that may exist, and demonstrate the influence intervention elements have as potential moderators in achieving desired treatment outcomes. Furthermore, the results of this review will contribute to what is currently known about which specific component, approach, mode and dose of an intervention is associated with improved psychological distress within the oncology family caregiver population. This will in turn aid the development of effective and efficient interventions in the oncology family caregiver population. Additionally, this systematic review will employ a rigorous approach that will help to provide a preliminary overview of the evidence base as well as a critical appraisal of the existing literature. This will further support the development of future research in this field by building foundational work for studies and new interventions (Burns \& Grove, 2009). 


\section{Chapter 4}

\section{Methodology}

In this section, consideration will be given to the methods and procedures used in this review. Specifically, details relating to the design, selection criteria, data collection and data analysis are described below.

\section{Study Design}

A systematic review was used to address the purpose this study. A systematic review is warranted as it allows for a rigorous method of assessing the effectiveness of different interventions (Bero et al., 1998; Boaz, Baeza, Fraser \& the European Implementation Score Collaborative Group, 2011; Higgins \& Green, 2011). This is achieved through a systematic and explicit appraisal of studies to minimize bias within the review and identify the best evidence on different strategies. This procedure helps to facilitate the appraisal and interpretation of evidence across studies, in efforts to support the application of reliable research findings into the practice setting. Moreover, this process includes both narrative and statistical means of analysis (Burns \& Grove, 2009). This approach allows for both the objectivity of having a statistical measure, as well as an in-depth narrative analysis of the results.

This review was guided by the AMSTAR tool (Shea et al., 2007) and the PRISMA statement (Moher, Liberati, Tetzlaff, Altman, 2009) (see Appendix C and D). The AMSTAR tool assesses the methodological quality of systematic reviews, while the PRISMA statement is a 27-item checklist and flow diagram. Items on these tools will be used to guide the conduct of this systematic review to ensure clear and transparent reporting (Moher et al., 2009), as well as reinforce a structured process that is methodologically sound (Shea et al., 2007). 
Guided by these two tools, this systematic review included several steps. Initially, selection criteria were established, including the specification of explicit study and participant characteristics of eligible articles. Secondly, a thorough search of the literature was performed; using specific eligibility screening criteria followed by a quality assessment of relevant studies. Data was then extracted from the included articles as part of the data collection process, and inter-rater reliability was assessed. Lastly, data synthesis and analysis took place. A more detailed description of each stage is provided below.

\section{Selection Criteria}

\section{Inclusion Criteria:}

Criteria for inclusion in this systematic review required studies to be: 1) written in English; 2) published in a peer-reviewed, scholarly journal within the last decade; 3) was a primary qualitative, quantitative or mixed methods study; 4) examined adult family caregivers of an adult living with cancer; 5) evaluated an intervention aimed at family caregivers, and 6) assessed psychological distress as an outcome of the intervention. These are further described in this section.

\section{Types of Studies}

It was a requirement that the study report be written in English to allow for ease of use. Articles published outside of the English language are less widely disseminated, and it was not feasible to access such articles with limited distribution (Polit \& Beck, 2008). As well, translation services were not accessible to the writer. Articles were also required to have been published in a peer-reviewed scholarly journal. It was decided to only include study reports published in peer-reviewed journals as these articles have undergone evaluation and critical appraisal as part of the peer-review process. This will maintain the level of quality of the selected 
articles at a scholarly level, which may also have implications on the articles' quality and credibility of their findings (Polit \& Beck, 2008). Finally, reports of studies were required to be published within the last ten years in order to be relevant and reflective of current knowledge in the literature.

Moreover, the design of the study had to be qualitative, experimental, or quasiexperimental design in order to be included. For studies with a qualitative methodology, results pertinent to the research objectives were extracted in narrative format. For quantitative studies, relevant data were extracted and entered into a data collection table. In studies utilizing a mixed methods approach, quantitative outcomes were be subjected to quantitative analysis, whereas qualitative results were recorded as a narrative description.

In order to address the research questions, included studies were also required to have evaluated an intervention aimed at oncology family caregivers. Additionally, eligible studies must have assessed psychological distress as an outcome of the study. This also includes behaviours, symptomology and mood indicators related to psychological distress as an outcome of the study, as guided by definitions presented in Chapter 2 .

\section{Types of Participants}

In order to address the research questions, this systematic review included studies that examined adult (defined as 18 years of age or older) family caregivers of an adult living with a diagnosis of cancer. Such caregivers may be partners, adult children, siblings, or parents to the individual with cancer. A sample consisting of adult family carers of an adult cancer patient was selected as an inclusion criterion for this study in order to specifically focus on caregivers within the adult cancer population as opposed to caregivers for children living with cancer. Although there are commonalities among caregiving for a family member with cancer, there are unique 
needs and experiences associated with caring for an adult family member versus caring for an ill child (James et al., 2002). Characteristics also differ between the family caregivers of pediatric and adult cancer patients (Carter \& Chang, 2000; Santo, Gaíva, Espinosa, Barbosa, \& Belasco, 2011). For instance, the majority of children's family carers are their parents, while family carers of adults with cancer are often their partner or adult children (Carter \& Chang, 2000; James et al., 2002). As a result of these differences, the decision to focus on studies that specifically examined family caregivers of an adult living with cancer was made to account for differences in the patient-caregiver relationship (Mancini et al., 2011) and variations in caregiving experiences (James et al., 2002).

Included studies consisted of participant samples from both in-patient and out-patient settings. Interventions for family caregivers of a loved one with cancer may occur in a variety of community and hospital based settings, such as in inpatient units, outpatient agencies, in the home setting, or occur a combination of these settings (Kurtz et al., 2005; Northouse, 2007; Northouse, Kershaw, Mood \& Schafenacker, 2005; Porter, 2011; Walsh et al., 2004). As such, this review included studies that assessed an intervention delivered within an in-patient or outpatient setting. To remain inclusive of the literature and diversity of this population, no limitations were placed on income, race, level of education, or any other social determinant of health.

\section{Exclusion Criteria}

Excluded study characteristic criterion comprised of articles that were not peer-reviewed, unpublished work, abstracts, news columns, editorials and letters. Generally, unpublished articles and non-peer reviewed articles may not have undergone critical evaluation. As such, the article's quality may be uncertain, which can have implications on the credibility of their findings (Polit 
$\&$ Beck, 2008). Articles that were not published were also excluded due to the practicality involved with retrieving such reports. In addition, systematic reviews and meta-analyses were not included in the sample. The exclusion of review articles was done to prevent the overlap in articles included in systematic reviews and/or meta-analyses and the primary research studies to be examined in the current systematic review. In terms of participant type, studies examining family caregivers within the pediatric oncology population were excluded. A list of excluded studies is provided (see Appendix G).

\section{Search Strategy}

A search of the literature was conducted to identify relevant articles that evaluated an intervention aimed at oncology family caregivers designed to address psychological distress, wherein psychological distress was measured as a primary outcome. The systematic search for pertinent literature was performed using five electronic databases including CINAHL, EMBASE, Medline, Proquest Nursing, and PsychINFO. A professional librarian assisted in testing potential search strategies.

A general search strategy was carried out and applied to each database (see Appendix B). Specifically, the steps in this general search strategy were as follows: Keywords relating to oncology, including "cancer" and "oncology" were entered and combined with the operator OR. In a separate search, key terms relevant to family caregivers (caregiv*, partner, "family caregiver", and "informal caregiver") were also conducted, using the operator OR to separate each keyword. Another search was done for key terms related to psychological distress (anxiety, depression, "caregiver burden", emotion*, "emotional distress", hopelessness, mental, psychological, "psychological distress", psychosocial and stress). Finally, a fourth search was done with key words related to interventions (intervention, program, and treatment). The results 
of these four separate searches was then combined using the operator AND to yield a total number of potential articles to review for relevance to this systematic review. This search strategy was repeated for each research index. A supplemental search of the reference lists of retrieved articles was conducted manually for relevant studies. Articles were limited to papers written in English, and published within the last decade.

Titles and abstracts yielded from both the electronic and manual search were then assessed for relevancy to this systematic review. Questions that guided the relevancy screening included: 1) Was the article written in English?; 2) Was the article a primary qualitative, quantitative, or mixed methods study?; 3) Did the study examine oncology family caregivers as its population of interest?; 4) Did the study evaluate an intervention?; 5) Did the intervention target family caregivers?; and 6) Was one of the measured outcomes related to psychological distress? Guided by these criteria, the researcher reviewed titles and abstracts yielded from the initial search results. If all relevancy questions are met, the complete full-text article were obtained and more thoroughly read to ensure its agreement with the inclusion criteria. Full-text articles were further reviewed by a second rater, an experienced quantitative researcher, in order to assess for inter-rater agreement on article relevance and inclusion into the systematic review. Ineligible articles and the rationale as to why the article was excluded are listed in Appendix G.

\section{Quality Assessment}

In the current study, quality assessments were made for eligible studies by critically appraising each article (Polit \& Beck, 2008). A quality assessment is warranted in order to examine the rigour of the study design, whether key information on the sample and intervention were clearly and adequately described, and that study outcomes were adequately reported. The assessment was also conducted to maintain a minimum level of quality amongst the included 
studies, as well as to ensure that key information could be systematically extracted from the included articles. Articles that used a quantitative or qualitative research methodology were each evaluated by different tools designed to fit the quality assessment requirements of the study design. The researcher assessed the quality of all relevant studies that met the inclusion criteria, and a second independent rater evaluated ten percent of these studies to ensure inter-rater agreement (Higgins \& Green, 2011).

Relevant quantitative articles were appraised using the Effective Public Health Practice Project (EPHPP) Quality Assessment Tool (2010) (see Appendix E), which was specifically designed for the assessment of methodological quality of intervention study designs, and may be used to examine quality in studies with an experimental or non-experimental design (ArmijoOlivio, Stiles, Hagen, Biondo \& Cummings, 2010). This quality assessment tool includes six domains, which include selection bias, study design, confounders, blinding, data collection method, and withdrawals/ drop-outs. This tool has been reported to demonstrate content and construct validity. Most items within each domain are scored between one to three, wherein a score of one indicates a stronger rating, while a score of three indicates a weaker rating. The combined average score among the six domains yield a final rating. Scores ranging from 1.00 to 1.50 indicate a study with higher methodological quality; 1.51 to 2.5 as having a moderate level of quality; and scores of 2.51 to 3.00 indicating a less rigorous report.

Qualitative studies were be assessed for quality by utilizing the Consolidated criteria for reporting qualitative research (COREQ) checklist (Tong, Sainsbury \& Craig, 2007) (see Appendix F). This tool is a 32-item checklist designed specifically to promote comprehensive reporting in qualitative research studies. Items are organized into three domains, including research team and reflexivity; study design; and data analysis and reporting. Each domain 
contains between eight to 15 items, with a total potential score that ranges between zero and 32 , where a lower count connotes a weaker report, and higher scores signify a methodologically stronger article.

\section{Data Collection}

A data extraction template was developed to mine data from the included articles, in which variables were coded to allow for analysis. The items in the table reflected demographic data to describe participant characteristics as well as characteristics of the study, including a quality assessment of the articles. To address the key research questions, the template included items to mine characteristics of the intervention, and psychological distress outcomes from the intervention. For the main variables of interest, extracted items were guided by the operational definitions and objectives of this study.

\section{Study and Participant Characteristics and Quality Assessment}

Data was collected to describe the characteristics of the included studies, and comprised of the study design, country where the study was conducted, year of publication, sample size, and study setting. Additionally, an assessment of article quality and fidelity was done for each included article. Article quality was represented categorically into strong, moderate and lower quality.

Demographic data was also extracted to describe the family caregiver participant samples in the included studies. The demographic variables collected for this systematic review included caregivers' age, gender, level of education, and relationship to the patient. Data was also extracted pertaining to the patients' diagnosis type and stage of cancer.

\section{Psychological Distress Outcomes}


Data was collected on psychological distress outcomes from each study, including indicators used to represent psychological distress in the study, as well as tools used to assess psychological distress. Indicators and tools that were used to measure psychological distress in the included studies were complied and described in a narrative format.

Key findings pertaining to psychological distress were also recorded in the data extraction table. Specifically, whether the presence of statistical significance between groups or over time was obtained. This was coded as $0=$ non-statistically significant, and $1=$ statistically significant. Furthermore, a narrative portion was also included to supplement the extracted data in order to ensure a breadth of data was achieved.

\section{Intervention Characteristics}

Data was extracted from the articles to describe key elements of the intervention, comprising of the component, approach, mode and dose. Qualitative information, in the form of a narrative, was also included in order to enhance or extend the depth of the extracted data. This information inlcuded further description of the reported characteristics and intervention contents, ie: the component, approach, mode and dose.

\section{Component.}

The type of component utilized in the intervention was extracted from the study article. This identified whether the intervention applied an educational, skills-training, therapeutic counselling intervention, or encompassed a combination of two or more components. This was coded as $1=$ psycho-educational, $2=$ cognitive-behavioral/skills training, $3=$ supportive/ therapeutic counselling, or $4=$ combination.

Approach. 
In this systematic review, approach was measured by indicating whether the intervention was standardized across all participants, tailored to the individual, or created specifically for each participant. This was coded as $1=$ targeted, $2=$ tailored, and $3=$ individualized.

Mode.

The mode of delivery was operationalized in terms of the strategy and format of the intervention. Extracting data pertaining to intervention strategy identifies the medium to which the intervention was delivered, and was categorized by $1=$ face to face, $2=$ telephone, $3=$ audiotape, $4=$ booklet, or $5=$ combined. The delivery format includes $1=$ one-to-one, $2=$ group session, or $3=$ dyadic.

Dose.

As dose has been operationalized in terms of the amount, frequency and duration of the intervention; the following data was extracted:

1) the total reported amount of time to deliver each intervention session, quantified in minutes to determine amount

2) the frequency of intervention delivery over a month to determine intervention frequency

3) total time period allocated to the delivery of the intervention will be used to assess duration.

\section{Inter-rater Reliability}

Data was extracted from each included article into the data collection table. In order to address inter-rater reliability in the current review, another qualified and experienced reviewer was approached to independently extract data from ten percent of the included articles. These articles were selected at random. The second rater was trained by providing verbal and written 
guidelines to facilitate data collection. A kappa score was calculated to demonstrate the interrater agreement between the reviewers, and a value of 0.8 or greater was considered acceptable in the current review (Burns \& Grove, 2009). The primary and second reviewer extracted data should yield $100 \%$ agreement between raters. If complete agreement was not achieved, the two reviewers collaborated to determine how and why differences occurred; make the necessary revisions to the data extraction process; and then repeat the inter-rater reliability assessment using another set of articles randomly selected from the sample. Ultimately, the inter-rater reliability was $100 \%$ among the two independent reviewers.

\section{Data Analysis}

SPSS PASW Statistics 19 was used to organize and perform analysis on collected data. To prepare for data analysis, the researcher also audited ten percent of entered data to ensure that data had been inputted correctly. Missing data was addressed in the current study by contacting the study investigator of the included article in efforts to retrieve information that was not included in the publication. For continuous variables, missing data was replaced by imputing the mean of the observed values for that specific variable. That is, the average was taken for all available data for the variable, and each missing value was substituted by this mean value for that specific variable. Additionally, field notes were made to indicate the number of studies that had missing data for each variable. To address missing data for categorical variables, an extra category was added for nominal level variables to indicate missing values. This technique is appropriate as missing data is expected to be missing at random. Additionally, this method allows for only the available data to be analysed, which is appropriate for categorical variables. The researcher also recorded the ratio of missing data for each variable.

\section{Study and Participant Characteristics and Quality Assessment}


For data analysis, descriptive statistics was be used to report the study and participant characteristics of the included studies, as well as to report results of the quality assessment. Nominal and ordinal data were expressed as percentages, whereas interval and ratio data were presented using measures of central tendency and dispersion.

\section{Psychological Distress Outcomes}

Descriptive statistics were also used to describe the types of psychological distress indicators and tools used to represent and measure this outcome. A list of relevant indicators and tools were compiled and presented as percentages.

\section{Intervention Characteristics}

The most commonly reported intervention approach, component, mode and dose among the included studies were outlined using descriptive statistics. These were presented as percentages during analysis.

\section{Relationship Between Psychological Distress/ Indicators of Psychological Distress and Intervention Characteristics}

Initially, a two-sample chi-square test was used to determine the association between specific intervention characteristics and the presence of statistically significant differences in psychological distress and indicators of psychological distress. In the event an inadequate number of articles occurred, which precluded the conduct of a chi-square analysis, a descriptive analysis was planned to describe associations between intervention characteristics and psychological distress. 


\section{Chapter 5}

\section{Results}

In this chapter is a presentation of the study findings as framed by the research questions identified in Chapter 2. First, an overview of the characteristics of the included studies will be provided. Second, sample characteristics of the individuals across the included studies will also be given. This will be followed by a summary of the findings related to psychological distress. A description of the most common intervention characteristics of treatments aimed to reduce psychological distress in oncology family caregivers will follow; specifically, the most common component, approach, mode and dose will be identified. Finally, key findings based on the relationship between the intervention characteristics and psychological distress will be presented. (see Appendix $\mathrm{H}$ for a summary of the included articles).

Various indicators of psychological distress (such as mood, stress, hopelessness, and negative emotion) were not frequently measured throughout the studies. As such, all psychological outcome indicators (anxiety, depression, psychological distress, mood, stress, hopelessness, negative emotion) were grouped together into a general psychological distress cluster during analysis. Additionally, due to the overall small number of articles that assessed each psychological distress indicator, a chi-square analysis could not be used to detect relationships between intervention characteristics and psychological distress. Therefore, a narrative synthesis of the results is provided.

\section{Research Question 1: Characteristics of Included Studies \\ Description of studies}

In the search for the eligible studies, 956 article titles and/or abstracts were screened using the relevancy criteria (see Appendix I for a detailed description of the search process). Of 
these, 58 articles were identified for a more detailed review of the full-text regarding study eligibility. Based on the relevancy criteria, 12 articles were not eligible and 25 articles were duplicates. Additionally, a manual search yielded two suitable articles. Therefore, 23 articles met the inclusion criteria and were included in this systematic review. The year of publication ranged between 2002 to 2013 . The majority of these studies were quantitative ( $n=21,91.3 \%)$, with approximately $52.4 \%(n=11)$ of quantitative studies having a randomized control design. Studies were primarily conducted in the United States $(n=12,52.2 \%)$ and Canada $(n=6,26.1 \%)$, with participants being recruited from outpatient and/or clinic settings ( $n=20,86.9 \%)$ (see Appendix $\mathrm{J})$.

\section{Quality assessment}

A quality assessment was conducted to examine study quality of the included articles. All 21 quantitative articles were assessed for study quality using the Effective Public Health Practice Project's (EPHPP) quality assessment tool. The single mixed methods article was also assessed using the EPHPP as the study was primarily quantitative in methodology. The qualitative article included in this review was assessed using the COREQ checklist for reporting qualitative research. Overall, among all of the 23 included articles, most $(n=11,47.8 \%)$ articles were moderate in quality, while $30.4 \%(n=7)$ were strong and $27.1 \%(n=5)$ were weak in quality.

Among the 22 quantitative and mixed methods articles, studies were judged based on six dimensions: selection bias; study design; confounders; blinding; data collection method; and withdrawals and drop outs. The first domain assessed selection bias in the study, and most $(\mathrm{n}=$ $10,45.5 \%)$ studies obtained a weak score in this domain, while eight (36.4\%) received a moderate score, and four $(18.2 \%)$ had a stronger score. The selection bias scoring was based on two criteria: the likelihood to which individuals were representative of the targeted population, 
and the percentage of individuals that agreed to participate in the study. In most of the included studies, participants were very likely $(n=12,54.4 \%)$ or somewhat likely $(n=9,40.9 \%)$ to represent the target population, as participants were randomly selected $(n=12,54.4 \%)$ or systematically referred from a source (such as a clinic) $(n=9,40.9 \%)$. Participation rates were relatively low among the included studies. Half of the included studies reported participation rates of $60 \%$ or less $(n=6,27.3 \%)$, or did not report participation rates at all $(n=5,22.7 \%)$. Only $27.3 \%$ of the included studies reported participation rates of $80-100 \%$.

Most of the included studies received a strong $(n=11,50 \%)$ or moderate $(n=10,45.5 \%)$ quality score in the study design dimension. This score was based on whether randomization occurred and if the method of randomization was reported. Most studies $(n=13,59.1 \%)$ included an element of randomization, while $36.4 \%(n=8)$ provided details of the selected method of randomization.

Within the confounder dimension, the majority of the included articles $(n=18,81.8 \%)$ received a strong quality rating. Confounders were assessed by determining if important differences were identified at baseline in the study. Most $(n=19,86.4 \%)$ studies did not have any significant differences between groups.

Sixteen $(72.7 \%)$ studies reported a moderate score within the blinding dimension, while four $(18.2 \%)$ were strong and two $(9.1 \%)$ were assessed to be weak in this category. Six $(27.3 \%)$ studies reported that outcome assessors in the study were aware of the intervention status of participants, while outcome assessors were blinded to participant status in $27.3 \%$ of these studies. Most studies (45.5\%) did not report blinding in their study.

Of the 22 quantitative and mixed method studies, most $(n=13,59.1 \%)$ obtained a strong quality score in the data collection methods domain. This is due to the high number of articles 
that reported the validity $(n=19,86.4 \%)$ and reliability $(n=14,63.6 \%)$ of data collection tools used in the study.

Within the withdrawals and drop-outs domain, half (50\%) of the included articles scored high quality scores. This rating was influenced by the high number $(n=21,95.5 \%)$ of articles that reported participant attrition rates. Also, more of the included studies reported completion rates of over $80 \%$, while close to half $(45.5 \%)$ had completion rates of less than $79 \%$.

This review included one qualitative study (Arnaert, Theresa, Gabos, Ballenas \& Rutledge, 2009). Quality was assessed within three domains in the COREQ checklist: research team and reflexivity; study design; and analysis and findings. Based on this checklist, this study was assessed to be strong in quality, as it achieved an overall score of $81.3 \%$. In the first domain, the research team and reflectivity dimension, this article reported on $62.5 \%$ of the eight recommended items in the checklist. The three items that were not reported in the article included details of the researchers' experience and training, participants' level of knowledge of the researcher, and characteristics of the interviewer (such as their pre-existing assumptions and interests in the study topic). This article scored high in the remaining assessment domains; reporting scoring $93.3 \%$ in the study design domain and $88.9 \%$ in the analysis and findings domain.

Eleven $(47.8 \%)$ of the included articles described intervention fidelity, however approximately $3.0 \%(n=7)$ of the included articles reported the results of their efforts to ensure fidelity. Among these eleven articles, the most commonly reported strategies to ensure treatment fidelity was training $(n=9,81.8 \%)$, having a protocol/manual $(n=9,81.8 \%)$, and reviewing audiotaped/videotaped treatment sessions $(n=8,72.7 \%)$. (see Appendix K for additional strategies to ensure fidelity). 


\section{Research Question 2: Characteristics of Individuals}

The 23 articles contained a total of 1565 caregivers. On average, the caregivers were 54.0 years old $(\mathrm{SD}=4.9)$, female $(72.2 \%)$, Caucasian $(85.0 \%)$, and had a post-secondary education (47.5\%). The majority of studies examined family caregivers in general in their sample $(n=14$, $60.9 \%$ ), which largely consisted of partners, adult children, and parents. The remaining studies specifically limited their examination to partner-caregivers only $(n=9,39.1 \%)$. Across the 23 studies, most studies included caregivers of family members experiencing a variety of cancer related diagnoses in their sample $(n=15,65.2 \%)$, while others limited their inclusion to caregivers of patients with a specific type of cancer, such as breast $(n=2,8.7 \%)$ or prostate $(n=2$, 8.7\%) cancer. Likewise, most articles studied oncology populations that included patients at various stages of cancer $(n=12,52.2 \%)$. Approximately one third of studies $(n=8,34.8 \%)$ also limited their examination to family caregivers of patients at an advanced stage of cancer.

\section{Research Question 3: Findings Related to Psychological Distress}

Among the 22 quantitative studies, psychological distress was most commonly conceptualized as depression $(n=14,63.6 \%)$ or anxiety $(n=10,45.5 \%)$; followed by hopelessness $(n=4,18.2 \%)$, mood $(n=4,18.2 \%)$, psychological distress $(n=4,18.2 \%)$, stress $(n=2$, 9.1\%), and negative emotion $(\mathrm{n}=1,4.5 \%)$. Among the included studies, the most commonly used standardized instruments to assess these indicators of psychological distress were the Center for Epidemiological Studies-Depression Scale (CES-D) ( $\mathrm{n}=7,31.9 \%$ ), Profile of Mood States (POMS) ( $\mathrm{n}=5,22.7 \%)$, and Beck Hopelessness Scale (BHS) $(\mathrm{n}=4,18.2 \%)$ (see Appendix L for a complete list of tools). Although psychological distress was most commonly conceptualized as depression and anxiety, there was variability in the type of instruments used to measure these outcomes. 
Among all of the included studies, most $(n=12,52.2 \%)$ did not achieve a statistically significant time or group effects related to the psychological outcome(s) of interest as a result of the intervention. Across the included studies, interventions aimed at family caregivers were most likely to improve anxiety. Eighty percent $(n=8)$ of interventions that measured anxiety as a study outcome resulted in significant improvements in anxiety score. Despite these results, most interventions also did not result in a statistically significant difference in other related psychological distress measures. Of the 14 interventions examining depression as an outcome, only $28.6 \%$ of studies showed a statistically significant improvement in depression. Two out of four of interventions measuring mood resulted in statistically significant results, and a only a quarter of studies measuring hopelessness reported significant findings. All of the studies examining stress and psychological distress did not report significant improvements. In the only study measuring negative emotion as an outcome, there was a significant improvement as a result of the intervention (Walsh et al, 2004).

Two studies (Anaert et al., 2010; Lewis et al., 2008) presented qualitative data that suggested the interventions were instrumental in minimizing caregiver stress, while promoting healing. A theme that emerged from these studies was that of "enduring effects: emotional and spiritual healing" (Anaert et al., 2010). This theme captured caregivers' perception of the effectiveness of the intervention in promoting emotional and spiritual healing during and after treatment. 


\section{Research Question 4: Description of the Most Common Intervention Characteristics}

\section{Across Studies}

\section{Component.}

Within the included articles, interventions most commonly used a combination of two or more components $(n=11,47.8 \%)$. Among these eleven interventions, the most common component combinations were psycho-educational and supportive $(n=5,45.5 \%)$; cognitivebehavioral and psycho-educational $(\mathrm{n}=3,27.3 \%)$; and a blend of cognitive behavioral, psychoeducational and supportive $(\mathrm{n}=2,18.2 \%)$ (see Appendix M for additional component combinations).

Of the intervention studies that used a single component to guide their treatment, cognitive-behavioural therapy $(n=5,21.7 \%)$ was the most common component type employed. A number of alternative interventions $(n=5,21.7 \%)$ were also commonly used as the sole component in five studies. The alternative interventions described within the included studies consisted of: art $(n=2,8.7 \%)$, meditation $(n=1,4.3 \%)$, music $(n=1,4.3 \%)$ and massage therapy $(n=1,4.3 \%)$.

Although psycho-educational $(n=1,4.3 \%)$ and supportive $(n=0,0 \%)$ component types were not commonly used in single-component interventions, psycho-education was used in combination with other treatment components in $47.8 \%(n=11)$ of the included studies. Likewise, a supportive component was used in conjunction with other component types in $34.8 \%(n=8)$ of the included studies.

\section{Approach.}

Across the 23 studies, most interventions used a targeted approach $(n=18,78.3 \%)$, while fewer utilized a tailored approach $(n=2,8.7 \%)$. Tailored interventions customized the program 
to align with the needs and circumstances of the caregiver, such as patient symptomology, symptom severity, type of received treatments, time since initial diagnosis, and level of caregiver involvement (Kurtz et al., 2007; Porter et al., 2011). Two (8.7\%) interventions both used both targeted and tailored approaches to the intervention content. In these studies, the intervention contained core topic areas that were targeted to all participants, but also contained content that was specific to the needs of the participant (Northouse et al., 2005; Northouse et al., 2007).

\section{Mode .}

The majority $(n=21,91.3 \%)$ of the interventions incorporated a face-to-face method as the intervention mode. Ten (43.5\%) articles used face-to-face as their sole mode of delivery, whereas eight $(34.8 \%)$ used a face-to-face method in conjunction with another mode of delivery. These included written materials (such as information sheets or booklets), audiotapes, and telephone/verbal delivery. Regarding the format of delivery, most interventions included the both the caregiver and patients and were dyadic $(n=11,47.8 \%)$ in nature, while $43.5 \%(n=10)$ were delivered in a one-on-one format with the caregiver only (see Appendix $\mathrm{M}$ for additional multimodal combinations).

\section{Dose.}

In terms of the amount, intervention sessions averaged $67.8(\mathrm{SD}=25.9)$ minutes in length. The frequency of intervention sessions ranged from being delivered one to six times a month, and were delivered at an average of $2.6(\mathrm{SD}=1.5)$ times per month. The duration of these interventions tended to span an average of 66.0 days $(\mathrm{SD}=65.2)$, and ranged from lasting one day to eight months. Among the included articles, dose was the least commonly reported item, and dose information was missing in eight $(34.8 \%)$ of the studies. 


\section{Interventions Producing Statistically Significant Psychological Distress Outcomes}

Ten interventions produced statistically significant findings. Of the articles that reported significant improvements, seven were of strong (Cameron, Chin, Williams \& Stewart, 2004;

Northouse et al, 2007) or moderate article quality (Lai et al., 2011; Lewis et al., 2008; McLean et al., 2008; Porter et al., 2011; Walsh et al., 2007b), and three (Birnie, Garland \& Carlson, 2010; Rexilius, Mundt, Erickson \& Agrawal, 2002; Walsh, Martin \& Schmidt, 2004) were assessed to be weak in quality. The characteristics of these significant interventions are described (see Appendix N).

\section{Component.}

Across the statistically significant interventions, more treatments used a single component $(n=5,50 \%)$ than a combination of components $(n=4,40 \%)$. It was unclear what type of component was used in one $(10 \%)$ of these interventions. Five treatments used a single intervention approach, of which most were focused on alternative techniques $(n=4,80 \%)$, while one used a cognitive-behavioural approach (20\%). Among the significant treatments that used multiple components, education was the most commonly combined approach; and all the multicomponent treatments included an educational aspect to the intervention. Education and support was the most common multi-component combination $(n=5,50 \%)$ (Lewis et al., 2008; Northouse et al, 2007).

\section{Approach.}

Of the ten interventions that produced significant improvements, most used a targeted approach $(n=7,70 \%)$, whereas one used a tailored approach (10\%), and another used both targeted and tailored approaches $(n=1,10 \%)$. In one article it was unclear whether the intervention used a targeted or tailored approach (10\%). 


\section{Mode.}

In terms of format, interventions that resulted in significant improvements in psychological distress were primarily delivered with the family member on a one-on-one basis $(n=6,60 \%)$. Regarding the strategy, $90 \%(n=9)$ of these treatments were delivered face-to-face with family members, either as the sole method of delivery (Lewis et al., 2008; McLean et al., 2008; Rexilius et al., 2002; Walsh et al., 2004; Walsh, Radcliffe, Castillo, Kumar \& Broschard, 2007) or in combination with other strategies (Birnie et al., 2010, Cameron, et al., 2004; Lai, Li \& Lee, 2011; Northouse et al, 2007; Porter et al., 2011).

\section{Dose.}

Significant interventions averaged $63.9(\mathrm{SD}=31.9)$ minutes per session. The frequency of treatment sessions ranged from one to six times per month; averaging $2.8(\mathrm{SD}=1.8)$ sessions per month. The duration of significant interventions varied greatly; this ranging from one day and up to eight months for treatment completion. On average, these interventions took 71.6 (SD=78.9) days to complete.

\section{Research Question 5: Findings Related to Intervention Characteristics and Psychological}

\section{Distress}

This section will present findings related to the influence of intervention characteristics on psychological distress. As previously stated, since many indicators of psychological distress were not frequently measured throughout the studies, all psychological indicators (anxiety, depression, psychological distress, hopelessness, stress, mood, negative emotion) were grouped together into a general psychological distress cluster during analysis. Additionally, due to the small number of articles that assessed each psychological distress indicator, a chi-square analysis 
could not be used to determine the relationship between intervention characteristics and psychological distress. Therefore, a narrative synthesis of the results is provided.

Interventions that were significant in improving the psychological distress cluster was primarily targeted, single-component, alternative therapy interventions. Significant interventions mostly incorporated a one-on-one strategy, and were delivered face-to-face with participants. These programs usually lasted an average of one hour per session and were delivered two to three times per month. In terms of duration, significant treatments ranged from lasting as little as one day, spanning up to eight months; averaging 71.6 days in total duration. These are further discussed below.

\section{Component.}

Approximately $95.7 \%(\mathrm{n}=22)$ of studies described the component(s) that comprised the intervention. Nine of these studies yielded a significant effect on the psychological distress cluster. Specifically, eight of these interventions reported a statistically significant improvement in anxiety (Birnie et al., 2010; Cameron et al., 2004; Lai et al., 2011; Lewis et al., 2008; Porter et al., 2011; Rexilius et al., 2002; Walsh et al., 2004; Walsh et al., 2007b) and four were significant in reducing depression (Lai et al., 2011; Lewis et al., 2008; Rexilius et al., 2002). One article reported significant reductions in hopelessness (Northouse et al, 2007) while another intervention was effective in improving negative emotion (Walsh et al., 2004).

Interventions that were significant in improving the psychological distress cluster were most likely to be a single-component, alternative therapy intervention. Among the significant interventions, five described using a single component in the treatment (Cameron et al., 2004; Lai et al., 2011; Rexilius et al., 2002; Walsh et al. 2004, Walsh et al., 2007); of which four used a alternative technique (Lai et al., 2011; Rexilius et al., 2002; Walsh et al., 2004; Walsh et al., 
2007). Lai et al. (2011) tested an alternative music intervention, wherein participants either listened to a live musical piece on a Chinese violin with nursing presence, or a pre-recorded music piece. Pre- and post-tests demonstrated that both of these music interventions led to significant improvements in anxiety and depression. Another study by Rexilius et al. (2002) also tested a single component intervention. Rexilius et al. (2002) compared two relaxation interventions with usual nursing care. In one of the interventions, patients received massage therapy, and the second intervention group received a therapeutic healing touch treatment. Results only showed significant reductions in anxiety and depression in family caregivers in the massage therapy group. Two significant interventions used a single component, creative arts based intervention (Walsh et al. 2004, Walsh et al., 2007). Both of these interventions invited family caregivers to participate in art- making activities in efforts to improve anxiety (Walsh et al. 2004, Walsh et al., 2007b), stress (Walsh et al., 2007b), mood (Walsh et al. 2004) and negative emotions. These interventions were only effective in reducing anxiety and negative emotion in family members (Walsh et al. 2004; Walsh et al., 2007).

\section{Approach.}

Of the 23 included articles, most $(n=22,95.7 \%)$ reported the approach of the intervention. Most ( $\mathrm{n}=17,73.9 \%)$ interventions used a targeted approach (Arnaert et al., 2010; Birnie et al., 2010; Cameron et al., 2004; Carter, 2006; Lai et al., 2011; Lewis et al., 2008; Hudson et al., 2005;

Rexilius et al., 2002; Kuijer et al. 2004; Lengacher et al., 2012; Manne et al., 2010; McLean et al., 2013; Scott et al., 2004; Walsh \& Schmidt, 2003; Walsh et al., 2004; Walsh et al., 2007b; Walsh et al, 2007a). Interventions that were significant in improving the psychological distress cluster most commonly used a targeted approach (Birnie et al., 2010; Cameron et al., 2004; Lai et al., 2011; Lewis et al., 2008; Rexilius et al., 2002; Walsh et al., 2004; Walsh et al., 2007b). 
Specifically, statistically significant improvements in anxiety were found in seven of these studies (Birnie et al., 2010; Cameron et al., 2004; Lai et al., 2011; Lewis et al., 2008; Rexilius et al., 2002; Walsh et al., 2004; Walsh et al., 2007b); three demonstrated improved depression (Lai et al., 2011; Lewis et al., 2008; Rexilius et al., 2002); two improved mood (Walsh et al., 2004; Birnie et al., 2010) and another intervention was effective in improving negative emotion (Walsh et al., 2004).

Of the $12(52.2 \%)$ studies that did not yield significant results, most used a targeted approach $(\mathrm{n}=10,83.3 \%)$ as well (Carter, 2006; Hudson et al., 2005; Kuijer et al. 2004; Lengacher et al., 2012; Manne et al., 2010; McLean et al., 2013; Porter et al., 2009; Scott et al., 2004; Walsh \& Schmidt, 2003; Walsh et al, 2007a).

\section{Mode}

Most significant interventions incorporated a face-to-face strategy, and were delivered oneon-one with participants.

\section{Strategy}

Twenty-two $(95.7 \%)$ of the included articles reported both the strategy and format of the intervention. Of the interventions that were effective in improving the psychological distress cluster, all used a face-to-face strategy when delivering the intervention. Half $(n=11)$ of these interventions delivered the intervention solely using a face-to-face strategy (Lewis et al., 2008; McLean et al., 2008; Rexilius et al., 2002; Walsh et al., 2004; Walsh et al., 2007b), while the other half used used a combination of strategies (Birnie et al., 2010; Cameron et al., 2004; Lai et al., 2011; Northouse et al, 2007; Porter et al., 2011). Cameron et al. (2004) used multiple strategies to deliver the intervention, such as using a face-to-face strategy while they were attending a hospital visit with their family member, as well as delivering a slide presentation 
using a laptop or flipchart. Lai et al. (2011) also provided the music intervention in a face-to-face format via nursing presence, as well as delivered a live performance of a musical piece. Participants also received the music intervention by listening to a pre- recorded CD. Another study delivered the intervention face-to-face during home visits, and also had telephone sessions with couples (Northouse et al., 2007). An intervention described by Birnie et al. (2010) was given face-to-face with participants during program classes and during a weekend retreat. A supplementary booklet and audiotape was also given. Porter et al. (2011)'s intervention also provided training to participants on a face-to-face basis, and supplemented these sessions with written materials and a CD or audiotape.

Within the studies that reported non-significant treatment effects in the psychological distress cluster, all (100\%) incorporated a face-to-face delivery strategy into the intervention.

\section{Format}

Across the included studies, all of these articles reported the treatments' format of delivery. Most significant interventions were delivered one-on-one with participants. Among the ten interventions that resulted in significant improvements in the psychological distress cluster, most (60\%) delivered the intervention using a one-to-one format with the caregiver (Cameron et al., 2004; Carter, 2006; Lai et al., 2011; Lewis et al., 2008; Walsh et al., 2004; Walsh et al., 2007b). Thirty percent of these interventions were delivered dyadically (McLean et al., 2008; Northouse et al, 2007; Porter et al., 2011). In interventions studied by Northouse et al. (2007) and McLean et al. (2008), treatments were provided specifically to partner/spouse and patient dyads, whereas Porter et al. (2011) provided treatments dyadically to both the patient and any family caregiver. Only one (10\%) was given in a group format, where both the partner caregiver and loved one with cancer were included (Birnie et al., 2010). 


\section{Dose.}

Interventions that were significant in improving the psychological distress cluster lasted an average of one hour per session and were delivered two to three times per month. In terms of duration, significant treatments ranged from lasting as little as one day, spanning up to eight months; averaging 71.6 days in total duration.

\section{Amount}

Among the included studies, fifteen $(65.2 \%)$ reported the amount of the intervention dose. Within the ten studies that reported significant improvements, most $(n=8,80 \%)$ described the treatment amount (Birnie et al., 2010; Cameron et al., 2004; Lewis et al., 2008; Lai et al., 2011; Porter et al., 2011; Rexilius et al., 2002; Walsh et al., 2007b). The dose of each intervention session averaged approximately one hour (63.9 minutes, $\mathrm{SD}=31.9)$ and ranged from 30 minutes and lasted up to two hours in length.

Interventions that were not effective in reducing psychological distress averaged 72.5 $(\mathrm{SD}=18.0)$ minutes per session, and ranged from 52.5 minutes to 94.0 minutes in length.

\section{Frequency}

Sixty-five percent of the included studies described the frequency to which the intervention was given. Among treatments that yielded significant results, $80 \%$ reported the frequency of the intervention. Effective interventions averaged $2.8(\mathrm{SD}=1.8)$ sessions per month, and ranged from being delivered once a month up to six times a month.

Within the twelve studies reporting non-significant treatment effects, eight $(66.6 \%)$ reported the frequency to which the intervention was given. Intervention sessions were delivered an average of $2.8(\mathrm{SD}=1.1)$ times a month, and ranged from being delivered once a month up to four times in a month. 


\section{Duration}

Most (69.6\%) of the included studies described the treatment duration. Within the interventions that resulted in significant improvements in psychological distress, $80 \%$ adequately described the duration of the intervention (Birnie et al., 2010; Cameron et al., 2004; Lai et al., 2011; Lewis et al., 2008; McLean et al., 2008; Northouse et al, 2007; Porter et al., 2011;

Rexilius et al., 2002). Interventions lasted as little as one day, and spanned up to eight months in duration. On average, effective treatments lasted 71.6 days $(\mathrm{SD}=78.8)$.

Nine $(75 \%)$ interventions without significant treatment effects described the duration of the program. These treatments ranged from lasting 21 days up to six months in duration, averaging 68.1 days in length $(\mathrm{SD}=55.2)$.

\section{Summary}

In sum, among the included studies, caregiver interventions tended to be comprised of multiple components, and were mostly psycho-educational or supportive in nature. Most interventions were targeted, used a face-to-face strategy, and were delivered dyadically with both the caregiver and patient. These intervention sessions tended to last approximately one hour in length, and were delivered an average of 2.6 times a month. Treatment duration varied greatly across the included studies, spanning from programs that lasted just one day, up to eight months.

In comparison, interventions that were significant in improving the psychological distress cluster was primarily targeted, single-component, alternative therapy interventions. Significant interventions mostly incorporated a one-on-one strategy, and were delivered face-to-face with participants. These programs usually lasted an average of one hour per session and were delivered two to three times per month. In terms of duration, significant treatments ranged from lasting as little as one day, spanning up to eight months; averaging 71.6 days in total duration. 


\section{Chapter 6}

\section{Discussion}

A discussion of the results of this systematic review is presented in this chapter. In this chapter is an examination of study findings as framed by the research questions and a comparison to existing literature. First, the characteristics of the included studies and of the family members included across the studies will be discussed. Following this, a discussion of the findings related to psychological distress will be presented and most common intervention characteristics considered. Finally, a discussion of the key findings between intervention characteristics and psychological distress will ensue, focused mainly on the influence of the component, approach, mode and dose of the included interventions.

\section{Research Question 1: Characteristics of Included Studies}

Across the included studies, the majority of studies used a quantitative approach, while one used a qualitative design. One article used a mixed methods design, however this study was primarily quantitative in nature. Among the quantitative and mixed methods studies, most were moderate in quality, while seven were of strong quality and five were assessed to be weak. The only qualitative article was assessed to be of strong quality. The large number of quantitative articles suggests the need for more qualitative or mixed methods research to be conducted within this field. Although quantitative methods are most commonly used in intervention research, this method does not provide insight into the context and viewpoints of participants (Streubert \& Carpenter, 2011). Qualitative inquiry is particularly valuable in intervention research as it provides deeper insights and clarifies quantitative findings (Needleman \& Needleman, 1996). For instance, a qualitative investigation may provide insights into participants' perceptions and preferences with interventions, or reasons for completing or dropping out from the study. To 
further support the importance of qualitative work in this population, it has been suggested that including a qualitative component in studies may improve recruitment and retention rates in intervention research, as qualitative inquiry facilitates trust with participants (Murphy et al., 2007).

Sample sizes ranged among the included studies. A small number of studies (Lai et al., 2011; McLean et al., 2013; Rexilius et al., 2002; Walsh et al., 2007a) described their sample size calculation based on a power analysis. The lack of integration of a power analysis is problematic as it provides structure and consistency in determining the power needed to adequately demonstrate whether changes in outcome were due to the effects of the intervention. (Burns \& Grove 2009). As such, it is of interest that most non-significant studies did not report performing a power analysis, since these negative results may be attributed to inadequate sample size. In particular, studies that do not have an appropriate sample size calculated may be prone to type II error, wherein an insufficient sample size is unable to detect differences, which may produce false negatives in the results of a study (Nayak, 2010). A more accurate interpretation of results may be drawn when there is an appropriate sample size with sufficient statistical power.

Articles were primarily of moderate to strong quality. This rating was reflective of the large number of studies that used a randomized control trial design or a quasi-experimental design, which are considered to be more objective and inferential methodologies (Burns \& Grove, 2009). Among the stronger articles, higher quality ratings were due to most studies reporting that there were not any baseline between-group differences prior to the intervention, as well as adequately describing data collection process and tools. The high number of moderate and strong quality articles helps to ensure that the results of the included studies are valid in the current systematic review (Higgins \& Green, 2011). 
Among the quantitative articles, approximately half used a randomized controlled trial design. These designs are considered to be the most powerful means to examine causality (Burns \& Grove, 2009). Although quasi-experimental research also identifies causal relationships and the significance of such relationships, experimental designs are regarded as more rigorous and considered to be stronger evidence in intervention research. Randomized control trials rigorously control the variables of interest, contain a control and treatment group, and include an element of randomization. This type of experimental design aims to control threats to the validity, which minimizes errors in study outcome. Treatment manipulation and randomization to groups also help to ensure study findings will be representative and generalizable the population of interest. As this methodology allows for the analyses of causality, the randomized control trial is considered to be the most powerful method of quantitative design.

In light of this, it is important to note that studies with non-significant results had a higher number of moderate to high quality articles $(n=10)$ than studies that yielded a significant reduction in psychological distress $(n=7)$. Additionally, the majority of non-significant studies were RCTs, whereas only a small number of the significant articles used a RCT design. This trend is reflected in the work of Majumdar, Lipton and Soumerai (2011) who posit that welldesigned RCTs tend to show no intervention effects, whereas RCTs that are less adequately controlled are more likely to report significant intervention effects.

Furthermore, almost all of the non-significant studies compared the intervention to a control group. In most of these studies, participants in the comparison group received standard care. In contrast, few significant articles had a comparison group; rather, most of the significant articles only showed the time effects of the intervention within one group of participants. In essence, this shows that across all the included studies, significance was primarily achieved 
when examining time effects of the intervention, whereas analysis for group effects tended to yield non-significant psychological distress findings. This finding may be due to limitations associated with using usual care practices as a comparison group. As discussed in the work of Thompson and Schoenfled (2007), usual care is oftentimes highly variable and inconsistent across settings and clinicians. As such, usual care may be inferior or superior to the intervention being tested, and it may be difficult to compare and interpret the effect that each group has on the outcomes of interest. In light of this, having a comparison group increases the study's ability to accurately detect differences between groups (Burns \& Grove, 2009). As such, significant findings from studies with no control group are limited as they were not able to demonstrate that the improvement in psychological distress was due to the intervention and not other factors.

Many studies scored a weak rating in the selection bias dimension of the quality assessment. This was largely due to the low participation rates of individuals during recruitment as well as relatively high attrition rates. Low participation rates are problematic as it becomes a challenge to determine the generalizability of study findings (Gross, Mallory, Heiat \& Krumholz, 2002 ). The issue of low participation rates and higher levels of attrition found in this systematic review are reflective of the difficult nature of recruiting and retaining participants from the cancer caregiver population (Northouse et al., 2006). Higher refusal rates during recruitment are common, as family caregivers may be reluctant to spend time away from their loved one (Murphy et al., 2007). In interventions aimed to benefit the caregiver, family members often times experience guilt and feelings of selfishness which effect their willingness to enter into the study. Lack of interest or time are also frequent reasons for refusal (Northouse et al., 2006). Meanwhile, common reasons for participant attrition include lack of time, loss of interest, illness and treatment demands (Cooley et al., 2003). 
Half of the included studies reported methods to ensure treatment fidelity. The low number of articles that reported strategies used to ensure fidelity is reflective of the general research literature (Bellg et al., 2004). It is important for researchers to verify that measures to ensure treatment fidelity are put in place to safeguard from drawing inaccurate conclusions (Horner et al., 2006; Sidani \& Braden, 2011). Enhanced fidelity strengthens study findings that examine the intervention-outcome relationships, as it allows for improved internal and external validity (Horner et al., 2006). Deviation from the intervention protocol yields differences in the treatment received among participants, which in turn effect intended outcomes and response from the treatment (Sidani \& Braden, 2011).

\section{Research Question 2: Characteristics of Individuals}

Sample characteristics were similar to other intervention research investigating oncology family caregivers. Specifically, the samples in this systematic review are comparable to oncology family caregiver samples in the descriptive literature in that they were primarily Caucasian, female, and the partner or spouse of the patient (Northouse, Katapodi, Song, Zhang, \& Mood, 2010; Northouse, Williams, Given, \& McCorkle, 2012)

The findings indicate that the majority of participants were Caucasian. Although the studies were largely conducted in North America, the underrepresentation of different cultures is problematic as it does not depict a culturally diverse sample that is characteristic of Canada and the US (Government of Canada, 2011). This is also a concern as it does not broaden our understanding of how caregivers respond to caregiving and related interventions. Different cultural values and norms influence individual practices and perceptions of caregiving (Dilworth-Anderson, Williams \& Gibson, 2002). The caregiver literature supports that caregiver experiences and outcomes are different among racial and ethnic groups. For instance, caregiver 
research has shown that caregivers from different cultural groups draw on differing social support networks, vary in terms of the formal support services seek, and have different perceived needs (Dilworth-Anderson et al., 2002). Additionally, individuals from different cultural backgrounds may experience various levels of psychological distress. This may be an area of concern as most interventions that are designed and tested within a primarily Caucasian sample population may not account for differences in experience and perception among non-Caucasian caregivers. In relation to this, significant interventions may not produce the intended outcomes among diverse and non-Caucasian populations. As such a need for more attention to caregiving among diverse populations is warranted.

Results also suggest most caregiver participants were the intimate partner of the individual with cancer. In spite of this, most interventions were not targeted specifically at partner- caregivers; rather, the majority of treatment programs were aimed at any family caregiver of the patient. This is congruent in the descriptive oncology caregiver intervention literature (Harding \& Higginson, 2003; Honea et al., 2008; Hudson, 2004; McCorkle \& Pasacreta, 2001); Northouse et al., 2010; Pasacreta \& McCorkle, 2000). Partners, by virtue of their intimate relationship with the patient, may experience challenges or have needs that are different from other family members. Couples often play an important role in each other's wellbeing when confronted with a stressful situation, and partners are often viewed as the most crucial source of social support (Badr et al., 2010; Scott, Halford \& Ward, 2004). Among couples, partners cope both individually and together as a unit when faced with a shared stressor (Badr, Carmack, Kashy, Cristofanilli \& Revenson, 2010), and couples will oftentimes become interdependent and jointly cope, (Badr et al., 2010). When faced with stress, each person's involvement can positively or negatively effect the stress management of the other. Therefore, 
coping among couples is a reciprocal process which in turn affects their personal coping ability and well-being. As the cancer illness experience effects both the individual as well as their partner, it would be valuable to examine the concept of coping specifically as it pertains to patient-partner couples using a relational perspective in order to gain an in-depth understanding of the phenomenon (Kayser, Watson \& Andrade, 2007). As couples share this unique bond, interventions that tap into this phenomenon may be best suited for improving psychological outcomes in partner-caregivers than interventions that are more generalized for all family members. In light of these different experiences and the important role they play in their loved ones well-being, it may be beneficial to further build interventions that are aimed specifically at couple dyads or partners caring for a loved one with cancer.

Furthermore, findings suggest most oncology caregiver interventions are not specialized to cancer type. Approximately, two-thirds of the included studies tested an intervention that was not targeted at a specific type of cancer. Just over a third of interventions were designed specifically for a specific cancer type, namely breast and prostate cancers. Although different types of cancer may have commonalities, cancer- specific experiences and responsibilities exist as well, such as body image, sexuality issues, symptom management, and treatment; among others (Bruner \& Boyd, 1999; Osse, Vernooig-Dassen, Schade \& Grol, 2006; Zabora, Brintzenhofeszoc, Curbow, Hooker \& Piantadosi, 2001). Different types of cancer can also impact caregiver psychological distress levels (Kim, Wellisch, Spillers \& Crammer, 2006). As different types of cancer have may have varying care needs, it may be valuable to tailor intervention content according cancer type in order to improve the effectiveness of such interventions. 


\section{Research Question 3: Findings in Relation to Psychological Distress}

Overall, the levels of quality among the significant and non-significant articles were evenly distributed. The articles that reported significant psychological outcome comprised of five studies of moderate quality, three of high quality, and three of weaker quality. Similarly, articles reporting non-significant outcomes were assessed to have six articles that were moderately scored, four studies of strong quality, and two of weaker quality.

Psychological distress was most commonly conceptualized as anxiety or depression; a finding that is congruent with the literature (Blanchard et al., 1997; Carlson \& Bultz, 2003; Ensel \& Lin, 1991; Holahan \& Moos, 1981; Kessler et al., 2002; Strong et al., 2007; Ridner, 2003; Veit \& Ware, 1983; Zabora, Brintzenhofeszoc, Burbow, Hooker \& Piantadosi, 2001). A smaller number of studies examined other measures, such as hopelessness, psychological distress, stress, mood, and negative emotion. In the caregiving literature, depression and anxiety are some of the most commonly measured emotional outcomes in research within this population (DilworthAnderson et al., 2002; Stenberg, Ruland \& Miaskowski, 2010). However, less is known about the psychological experience beyond anxiety and depression. The effect of psychosocial interventions on other distress measures is not well studied and is required to have an improved understanding of the emotional experience family caregivers have beyond anxiety and depression.

Among the included studies, interventions seemed to be most effective in reducing anxiety; in fact two-thirds of interventions that measured anxiety as an outcome reported significant improvements following treatment. However, although depression was one of the most commonly measured outcomes, only a low proportion of intervention studies reported significantly improved depression scores. In general, interventions were not effective in reducing 
the other psychological outcome measures; for instance, only two inventions improved mood, one treatment improved hopelessness, and one was effective in improving negative emotion. None of the interventions were effective in alleviating the psychological distress or stress indicators. Overall, most of the empirical studies included in this review did not report significant time or between-group difference in the psychological distress cluster. The mixed results obtained in this systematic review are comparable to some of the caregiver distress literature (Baik \& Adams, 2011); Knight, Lutzky, Macofsky-Urban, 1993; Harding \& Higginson, 2003) and the course of caregiver distress over time is not well understood (Knight et al., 1993). It is important to note that among the studies that indicated significant improvement in the psychological distress cluster, most did not have a comparison group, but rather found significant improvements over time in the same group of participants. In contrast, most of the nonsignificant interventions examined between group and/or time effects of the intervention. Caregivers sometimes improve without intervention; and without a comparison group, these significant studies may simply be showing positive change over time that is not attributed to the intervention (Knight et al., 1993). Therefore, as many of these studies lack a comparison group, it is difficult to draw conclusions on the true effectiveness of these interventions.

\section{Research Question 4: Description of the Most Common Intervention Characteristics}

\section{Across Studies}

\section{Component.}

Overall, interventions most commonly included more than one component type in the treatment design. Researchers may have included the use of multiple components, as more components may have synergistic properties as a means to improve the effectiveness of the 
intervention, a method that has been previously supported in the literature (Blue \& Black 2005;

Fan \& Sidani, 2009; Honea et al., 2008).

Although the most common types of components identified in the caregiver intervention literature have been cited to be psycho-educational, supportive or cognitive-behavioural (Honea et al., 2008), another commonly reported component type in this review were alternative interventions, which included non-conventional treatments such as massage, music, and artistic approaches. Previous reviews of the literature have not highlighted these alternative component types and the effectiveness of such interventions (Honea et al., 2008). As discussed earlier, the literature has historically shown mixed results pertaining to the effectiveness of psychosocial caregiver interventions (Knight et al., 1993). As this systematic review included more recent studies from the last decade, the prominence of these alternative types of treatment may be researchers' attempts to explore and be creative in building new interventions beyond traditional component types for oncology family caregivers. Additionally, as evidenced in this systematic review, the positive effect that these alternative treatments have on psychological distress offers promise in the design of future interventions for oncology family caregivers.

\section{Approach.}

Among the included studies, a targeted design was the most popular approach. These interventions delivered standardized content to all participants without regard to individual needs. Almost all tested interventions in this review used a standardized, targeted design, whereas only four used a tailored approach. This is expected, as intervention research most commonly requires the treatment program to be delivered in a standardized way as a means to minimize variation and improve validity (Burns \& Grove, 2009). Unfortunately, this may not contribute to the understanding of tailored and individualized approaches for interventions aimed at the oncology 
caregiver population. Furthermore, the literature has generally supported that intervention content that is more tailored to be of relevance to individual needs are more effective than targeted and standardized programmes (Dijkstra, 2005; Fredericks, Guruge \& Wan, 2010; Lauver et al., 2002; Sidani \& Braden, 2011).

\section{Mode: Strategy and Format.}

Interventions in this review most often incorporated a face-to-face strategy to deliver the intervention, either as its sole method of delivery or in combination with another strategy such as written materials, audiotapes, or telephone sessions. In terms of format, interventions were either delivered one-on-one with the caregiver, or provided dyadically with both the caregiver and the patient. The general use of face-to face strategies across the tested interventions may not contribute to our understanding of the influence alternative intervention modes have on psychological outcome. Participants, particularly within the caregiver population, may be reluctant to participate due to caregiving and personal responsibilities, difficulty arranging alternative help, inaccessible meeting places, or scheduling conflicts, and as such face-to-face strategies may not be ideal or preferred (Czaja \& Rubert,, 2002; Murphy et al., 2007).

Another concern with the overall homogeneity of treatments is individuals have different learning styles, and may not be responsive or best suited to face-to-face programs. As individual learning style influences ones' preference and receptiveness to particular delivery modes (Buch \& Bartley, 2002), congruence between learning style and intervention mode may facilitate treatment success. Building and testing treatments that use alternative strategies may provide a richer understanding of how caregivers respond with different mode types.

\section{Dose: Frequency, Amount and Duration.}


Across the included articles, the amount, frequency and duration of interventions varied greatly; in fact, no two interventions provided their treatment programme at the same dosing strength. The great variation among dose strength is reflected within the oncology caregiver intervention literature (Baik \& Adams, 2011; Harding \& Higginson, 2003; Hudson, 2004; McCorkle \& Pasacreta, 2001; Northouse, Katapodi, Song, Zhang, \& Mood, 2010; Northouse, Williams, Given, \& McCorkle, 2012). Furthermore, the rationale for how the specific intervention dose was built was not provided in these articles, which has implications for the integrity of such interventions (Sidani \& Braden, 2011). It may also be difficult to compare the effectiveness of interventions with such a wide variation in dose, as non-significant interventions may simply have been given at an inadequate dosing level to produce significant improvement in psychological distress.

Furthermore, among the intervention elements being reviewed, dose information was the least frequently reported among the included articles; in fact, over a third of articles were missing information related to the amount, frequency or duration of the treatment program. Descriptions of intervention dose were occasionally brief and vague in nature. This lack of clarity and reporting of treatment dose information is of concern as it does not provide adequate guidance to replicate the intervention (Sidani \& Braden, 2011). Dose specification is imperative in monitoring the fidelity of intervention implementation. Without knowing the dosing strength to which the treatment should be carried out, the intended program outcomes may not be achieved. 


\section{Research Question 5: Findings Related to Interventions Characteristics and Psychological}

Distress

\section{Component.}

Overall, adequate descriptions of the treatment component(s) were reported in most of the included articles. Among the ten interventions that yielded statistically significant improvements in psychological distress, nine reported details of the intervention component. From the small number of articles, it was difficult to decipher patterns and linkages between component type and significance in psychological distress. Slightly more single component interventions demonstrated significance than multi-component interventions. The literature has generally supported that multi-component interventions are more effective than single component interventions among caregivers (Honea et al., 2008; Hudson, 2004; Sorenson et al., 2002). Interventions that have more than one component may be successful as they incorporate multiple approaches or are synergistic in their quest to improve psychosocial distress. However, complex interventions also have the potential to be less focused and may be taxing to the participant (Blue \& Black, 2005).

Among single-component interventions, most were alternative interventions. In fact, among all the included articles, the five interventions that used an alternative method as its sole component had a high proportion in achieving significance. In light of this, it should be noted that in all alternative interventions, outcome data collection was done immediately postintervention, with no longitudinal follow-up to test for sustained effectiveness. Short-term improvements in these creative arts (Walsh et al., 2004; Walsh et al., 2007b) and musical interventions (Lai, Li \& Lee, 2011) may be observed as they these activities provide focus and instant relief from stress, as opposed to other component types. Among the other component 
types, there were no observed patterns between post-test follow-up time (short-term versus longterm follow-up) and improvement in the psychological distress cluster.

\section{Approach.}

Across all the interventions, approach information was reported for all but one of the included studies. As previously described, the included studies largely consisted of targeted interventions. As such, the ability to draw associations between intervention approach and improvement in psychological distress was constrained. Among all targeted interventions, the number of studies yielding significant versus non-significant findings were evenly distributed. Three studies used a tailored approach, while two interventions contained content that was targeted as well as tailored to individual needs of the participant. Tailored interventions personalized the program to address participant needs, such as patient symptomology, treatment, and level of caregiver involvement (Kurtz et al., 2007; Porter et al., 2011). Among these five interventions, only two were significant in improving the psychological distress cluster. The low ratio of significant findings from tailored interventions is contradictory to findings among the existing intervention literature, which has generally supported that interventions that are tailored to the individual are more successful (Blue \& Black, 2005; Fredericks et al., 2010). Tailored interventions are thought to provide greater attention to individual differences (Blue \& Black, 2005).

\section{Mode: Strategy and Format.}

The majority of the included articles provided information pertaining to the strategy and format to which the intervention was delivered. Significant interventions in this review all incorporated a face-to-face strategy into its programme, either as the sole strategy or in combination with other modes. A meta-analysis by Northouse et al. (2010) found that caregiver 
interventions that were delivered face - to- face were more effective in improving coping compared to mixed strategies of delivery. All non-significant treatments also included a face-toface strategy in their program, wherein $80 \%$ used multiple strategies. As mentioned previously, the treatment strategy among the included studies were homogenous; as almost all the interventions used a face-to-face mode of delivery. As such, conclusions could not be drawn to link intervention strategies with positive psychological outcomes. Likewise, when comparing interventions that incorporated one strategy versus multiple strategies, no meaningful patterns of significance were apparent.

Results were also mixed when examining intervention format and its association with significant psychological distress outcome. Significant interventions were most frequently delivered using a one-to-one format. Close to a third of significant interventions used a dyadic approach, and only one delivered the program in a group format. Studies that did not generate significant results were frequently given in patient-caregiver dyads, while a third was given individually with the caregiver only. The caregiver intervention literature also contains mixed results pertaining to intervention format. One systematic review (Harding \& Higginson, 2003) presented varying results pertaining to the effectiveness of one-to-one interventions, where some studies showed significant improvements, some showed improvement in certain subsamples, and some found no significant differences at all. Intervention research investigating the influence dyadic interventions also presents opposing results. For instance, Northouse et al. (2010) found that interventions delivered to caregivers alone were associated with significantly better caregiver benefits than those that included both the patient and caregiver, whereas a different caregiver intervention review found that dyadic interventions contribute to the well-being of both patients and caregivers (Northouse et al., 2012) 


\section{Dose: Frequency, Amount and Duration.}

As reflected across all the included studies, significant interventions varied greatly in terms of its frequency, amount and duration. A comparison of longer and shorter dose strengths did not appear to produce improvements in psychological distress. Contrary to the results generated in this review, the literature supports that interventions that are higher in amount, frequency and duration may be linked to improved treatment effectiveness. In other words, interventions with more contact hours (Northouse et al., 2010; Northouse et al., 2012; Fan \& Sidani, 2009), more sessions (Fan \& Sidani, 2009; Fredericks et al., 2010; Northouse et al., 2010) and given over a longer period of time (Agurs-Collins et al., 1997; Brown, 1992; D’EramoMelkus, Wylie-Rosett \& Hargan 1992; Detsky et al., 1992; Fan \& Sidani, 2009) are more effective. In opposition to this, a meta-analysis of oncology caregiver interventions indicated that for some outcomes, such as caregiver burden, depression, and martial family relationship outcomes, interventions with more sessions were associated with significantly more negative outcomes. (Northouse et al., 2010). These opposing findings may reflect that although an increased intervention dose may have benefits, lengthy and frequent interventions may not be feasible or realistic and may result in fatigue; particularly among family members who must find time within their caregiving responsibilities (Blue \& Black, 2005; Murphy et al., 2007).

\section{Summary}

In essence, studies included in this systematic review were mostly quantitative and of moderate quality. Most studies that obtained a significant result did not have a comparison group; rather the intervention was only able to demonstrate significant time effects of the treatment. In contrast, the majority of interventions that did not report a significant improvement in 
psychological outcome used a comparison group, and were able to examine differences between groups as well as over time.

The sample characteristics among the included articles were largely Caucasian, female, and the partner or spouse of the individual with cancer. Most of the interventions were not specialized to cancer type or caregiver type (such as partner or other family caregiver), which may be problematic in addressing the specific needs of the caregiver.

The psychological outcomes across the included studies were most frequently conceptualized as anxiety and depression. Among these studies, most interventions were effective in improving anxiety, but a disproportionately low number of interventions were effective in decreasing depression.

Among the included studies, cognitive-behavioural and alternative methods were the most commonly used components. Alternative treatments were more commonly associated with significant reductions in the psychological distress cluster, although only a short-term follow-up assessment was made in these studies. The included studies largely comprised of similar approach (targeted) and mode of delivery (face-to-face), and as such no patterns were identified between effective and non-effective interventions. Likewise, interventions ranged greatly in dosing strength; therefore associations with significant outcomes could not be identified. Rationale was not given to support the dosing level of these programs among any of the articles, which has implications for the fidelity and integrity of the intervention. 


\section{Chapter 7}

\section{Implications, Limitations, Contributions and Conclusions}

In this chapter is a discussion of the implications, limitations, and contributions arising from this systematic review. Implications will be presented in terms of their contribution to theory, research, and practice.

\section{Implications}

\section{Theory}

Most studies did not describe whether the tested intervention was built within a guiding framework, although a number of stress and caregiving models exist in the literature. The inclusion of a theoretical framework is thought to inform and guide intervention development and advance knowledge (Fitzgerald \& Whall, 1996; McEwen \& Willis, 2011). A theoretical underpinning offers an understanding of the active treatment mechanisms that trigger the resulting outcomes (Sidani \& Braden, 2011). To this end, interventions should be guided by a guiding framework, as a means to facilitate the build of an effective treatment. Similarly, this systematic review provides a theoretical perspective of the characteristics associated with improved psychological outcome in oncology family caregivers. Specifically, this review provides a basis to identifying which treatment characteristics may contribute to the effectiveness and efficiency of an intervention, which can provide guidance in the development of future psychosocial programs aimed at this population.

Few studies provided a definition of psychological distress. Psychological distress was most commonly measured by anxiety and depression across the included studies, however, less commonly used were the conceptualization of hopelessness, psychological distress, stress, and mood as an outcome measure. Although anxiety and depressive symptoms are more commonly 
known, indicators such as hopelessness and stress, among others, were vague and require clarification. A theoretical discussion is required to better define and clarify differences between psychological distress concepts and identify possible inter-relationships. To this end, a more thorough examination is required to obtain consistency in the conceptualization and measurement of psychological distress as a concept.

\section{Research}

Enhanced qualitative work needs to be conducted in this research area. Qualitative detailing can also be valuable in supplementing or triangulating quantitative results to provide a more comprehensive and rigorous investigation. This review revealed that the vast majority of research is purely quantitative in nature, while minimal work has been done to explore the qualitative experience family caregivers have following an intervention. Further work needs to focus on identifying family caregivers' experiences with treatment programs and their perception and preferences of such interventions.

Future intervention research inquiries also need to explore more psychosocial programs that are effective in alleviating depression in oncology family members. Findings in this review demonstrate that depression was one of the most commonly measured psychological outcome of interest among the included studies. In spite of this, few interventions were effective in alleviating depression. This is concerning as depression continues to be an issue for many oncology caregivers and warrants further attention. Research needs to focus on identifying the strategies and content required to produce effective result, as well as build and evaluate such interventions.

More work also needs to be done to examine psychological distress beyond anxiety and depression. Further investigation of these other psychological outcomes may offer enhanced 
insight into to family caregiver experience, as well as shed light on other psychological issues other than anxiety and depression that may be overlooked in research and in practice. As previously stated, the results of this review indicate that most outcome measures of psychological distress were conceptualized as anxiety or depression in the study. In spite of this, a small number of other psychological distress concepts were identified, such as hopelessness, stress, and mood.

The results of this systematic review also indicate that more research is required to better understand the influence different treatment characteristics have on psychological outcome in family caregivers. Inquiry into psychosocial intervention in oncology may be a focused program area of research (Canadian Cancer Society, 2010b), as the prevalence of cancer is expected to grow (Canadian Cancer Society, 2013). In particular, more primary research needs to be conducted to build and evaluate new psychosocial interventions with varying treatment elements for effectiveness. An analysis of the relationships among intervention elements and the synergies that may exist may also be of focus. A qualitative exploration into caregivers' perceptions and preferences for intervention elements given in different dosages and methods of delivery are also required. Findings of this review indicate that single-component alternative interventions appear to trend towards short-term effectiveness in improving psychological distress, and are an alternative to traditional therapies (such as psycho-educational, cognitive-behavioural, or supportive treatments). In light of the small number of sample articles in this review, more work is needed to further understand and evaluate creative arts, massage, and musical interventions among caregivers who are caring for a loved one with cancer. Further work also needs to be done to identify the relationship and underlying mechanism of these alternative therapies that contribute to its success in alleviating psychological distress in caregivers. More research into 
other non-traditional, innovative treatments is also warranted. Moreover, as evidence in this review, a longitudinal analysis of such interventions is required to indicate the potential for sustained improvements in psychological distress.

Additionally, in terms of further analysis into the influence of various intervention elements, more interventions need to be built and tested with a variety of treatment strategies. Results of this review show the general homogeneity in treatment approach and mode; namely being targeted interventions and/or delivered face-to-face with participants. As this review indicated that the majority of interventions were not effective in producing statistically significant psychological outcome effects, further research needs to be done in the design and evaluation of a variety of different treatment elements in efforts to detect which characteristics may be more influential in producing improved outcomes.

As evidenced in this review, dosing information was frequently missing or not adequately reported on in the oncology caregiver literature. This information is required for practitioners and researchers alike who are interested in replicating the study, and is needed in order to enhance fidelity while achieving the intended outcomes. Researchers need to provide supporting rationale to justify the dose of the intervention as a means to support the integrity of study findings. The standardization of dose within intervention research is also warranted. As it currently stands, the great variation in an intervention's amount, frequency and duration makes it difficult to compare interventions as well as determine the ideal dose to which a treatment program is both effective and efficient for caregivers.

More research also needs to be done to identify the most optimal combinations of intervention characteristics for targeted populations. Rather than researching each intervention element in isolation, future inquiry into the study of intervention elements needs to examine what 
the ideal combination of characteristics are to improve psychological distress of oncology family caregivers. An intervention's approach, component, mode and dose need to be considered as a whole, and more investigation should be done to study the complex relationships and synergies that may exist when combining different treatment characteristics together. Furthermore, more research should be done to identify the ideal combination of treatment characteristics for specific caregiver populations, such as for partner caregivers, which may help to further address the specific complex needs they have.

\section{Practice}

The results of this systematic review have a number of practical implications to for health care providers. Across the included studies, a common theme was the lack of diverse cultural representation among samples. In light of this, practitioners must exercise caution when implementing psychosocial interventions with diverse ethnic groups, and be culturally sensitive when providing supportive care. When implementing treatments with oncology caregivers, practitioners may put more consideration into the cultural norms and values that may be at play which can influence ones' perception of the caregiving experience. In particular, when working with diverse populations, clinicians can assess how caregivers perceive their role in caring for their family member with cancer, and their interpretation of the cancer or illness experience. Practitioners should also be aware of personal values and be vigilant in accommodating the different cultural values and norms that family members may have.

Additionally, findings of this systematic review illustrate that the majority of caregivers were the partner or spouse of the patient. As such, it may be beneficial to direct interventions that are specially designed for partner-caregivers, as partners may have different needs and caregiving experiences than other family members (Badr et al.2010). In the practice setting, 
clinicians can tailor supportive care to the specific needs of partner-caregivers. Rather than providing partners with general psychosocial treatments, clinicians may incorporate treatment content specific to the needs of partners. Organizations can also offer programs that are specifically designed for oncology partner-caregivers. Moreover, across the included studies, most interventions that were aimed towards partner-caregivers were mainly given to those experiencing a gendered-type of cancer, such as breast or prostate cancers. Content in these interventions are oftentimes related to sexuality, body image, and communication, among others (Lewis et al., 2008; Northouse et al., 2007; McLean et al., 2008). Although these studies evaluated partner-specific interventions among gendered- cancer types, clinicians may choose to address these content areas when working with partners in non-gendered cancers as well, in efforts to meet the unique needs partners have.

Based on the results of this study, practitioners may also consider exploring alternative, non-traditional therapies for oncology caregivers. This systematic review indicated that several alternative interventions yielded positive psychological outcome among family members. These alternative therapies are often simple and feasible to incorporate (Walsh et al., 2004; Lai et al., 2011). Based on these findings, clinicians can further explore these non-traditional alternative therapies and be aware of such services in the community that are aimed at family caregivers. Interdisciplinary team members may also consider consulting these services or recommending such alternative therapies for family caregivers. Organizations may also further explore the benefit and feasibility of offering such treatments in comparison to traditional psychosocial care methods. Furthermore, as many of these alternative therapies were delivered by members of the multidisciplinary team, organizations may develop training programs for clinicians or a dedicated team to deliver certain alternative treatments to caregivers. 
Additionally, this review revealed that a large number of family members declined to participate and also dropped out of studies before completion. Family caregivers experience multiple stressors, and require practical methods to facilitate their participation in interventions (Walsh, 2004). Lack of time, patient treatment and illness demands, and other competing priorities oftentimes prevent family caregivers from participating in treatment programs (Cooley et al., 2003; Northouse et al., 2006). When organizing and implementing supportive treatments in the practice setting, clinicians need to build programs that are easily accessible for family caregivers to use. Treatment sessions should also be flexible to accommodate the lifestyle of family caregivers and strategies should be tailored to fit individual lifestyle needs as best as possible. In light of this, clinicians working with oncology caregivers may consider exploring methods of delivering treatments that are accommodating and best-suited to the needs of family members.

\section{Limitations}

This review is limited in that it included a small number of studies. As such, the extent to which this systematic review was able to identify relationships between intervention characteristics and psychological distress outcomes were limited. The intention of this systematic review was to provide both a narrative and statistical synthesis of the literature, however due to the lack of studies included in this systematic review, a more complex analysis of the data was not warranted to assess for linkages among intervention elements and psychological outcome. As such, inter-relationships and interactions among intervention elements could not be investigated. A limitation of having a purely descriptive method is that it provides a less rigorous analysis of the data (Burns \& Grove, 2009). To this end, another limitation to this systematic review is that 
in deconstructing the intervention into its elements, an exploration into the synergies among the intervention components was not explored.

Additionally, as some measures of psychological outcome were not frequently measured among the included studies (such as hopelessness, stress, mood, negative emotion, psychological distress), all psychological distress outcomes were grouped into one all-encompassing psychological distress cluster. This served to facilitate data synthesis, as a small number of articles measuring each psychological distress indicator did not derive any meaningful patterns. However, an issue with grouping together all the psychological distress outcomes in this systematic review is that details pertaining specifically to each psychological measure are lost. Although all the outcome measures are related to psychological distress, many of these distress measures can be different from one another. For instance, although anxiety and depression are related to psychological distress, both manifest and are characterized differently (American Psychiatric Association, 2000). Therefore, differences among various distress indicators may not be captured in this systematic review.

Due to the limited numbers of eligible studies, this systematic review also included studies that were lower in quality to be inclusive of the literature. Five articles that received low quality ratings were included in this review. This may reduce the overall quality level in this systematic review (Burns \& Grove, 2009; Higgins \& Green, 2011). Additionally, this review included various types of designs, including qualitative, quasi-experimental and randomized control trials. This is a shortcoming to the overall rigour of the systematic review, as comparing studies with different methodologies weakens the quality of the research evidence (Burns \& Grove 2009). 


\section{Contributions}

This review consisted of a comprehensive search strategy involving multiple electronic indexes, an additional hand search of reference lists and review articles was conducted, and guidance from a professional librarian. The eligibility criteria guiding this systematic review were broad and inclusive of varying research methods and designs. This allowed for the synthesis of both qualitative and quantitative methods of various designs, which provided a comprehensive review of literature in this area of interest within the last decade. Finally, this review was able to contribute to the oncology caregiver literature by being the first to systematically examine the literature addressing the relationship between oncology family caregivers' level of psychological distress following participation in interventions to reduce psychological distress and the characteristics of such interventions. This systematic review was able to amalgamate the results of multiple psychosocial interventions in efforts to provide a conclusion on the overall effect these treatments have on oncology caregivers (Bartolucci \& Hillegass, 2010). Moreover, a strength of examining the intervention elements is that it provides greater clarity on the functional components of the intervention and thier role as active ingredients in producing treatment outcomes (Michie, Fixsen, Grimshaw \& Eccles, 2009).

\section{Conclusions}

Cancer is an illness that is distressing not only the individual, but to family members as well. The prevalence of psychological distress is elevated within the caregiving population, and it is imperative to address this issue as they play a key role in the physical and psychosocial wellbeing of their loved one. This systematic review examined intervention characteristics that were associated with improved psychological distress in family caregivers of a loved one living with 
cancer. Although results were oftentimes mixed, this descriptive review offered a comprehensive look at the impact of oncology caregiver intervention literature on psychological outcome in the context of different intervention elements, as well as direction for further theoretical discussion, research, and practical application within this field. The present review provides a foundation to understanding the influence intervention characteristics have in developing more effective and efficient therapies, in efforts to address the issue of psychological distress among family caregivers. 
Appendix A: Literature Review Summary

\begin{tabular}{|c|c|c|c|c|c|}
\hline $\begin{array}{c}\text { Author, } \\
\text { Year of } \\
\text { Publication, } \\
\text { Title }\end{array}$ & $\begin{array}{c}\text { Study } \\
\text { Characteristics }\end{array}$ & $\begin{array}{c}\text { Sample } \\
\text { Characteristics Across } \\
\text { Included Studies }\end{array}$ & Findings & $\begin{array}{c}\text { Intervention } \\
\text { characteristics Across } \\
\text { Included Studies }\end{array}$ & $\begin{array}{c}\text { Quality } \\
\text { Assessment } \\
\text { Performed }\end{array}$ \\
\hline $\begin{array}{l}\text { Baik \& } \\
\text { Adams } \\
\text { (2011). } \\
\text { Improving } \\
\text { the well- } \\
\text { being of } \\
\text { couples } \\
\text { facing } \\
\text { cancer: A } \\
\text { review of } \\
\text { couples- } \\
\text { based } \\
\text { psychosocial } \\
\text { interventions }\end{array}$ & $\begin{array}{l}\text { Intervention } \\
\text { Outcome Measures: } \\
\text { Various outcomes } \\
\text { across studies, } \\
\text { including mental } \\
\text { health, psychological } \\
\text { adaptation, QOL, } \\
\text { coping dyadic level } \\
\text { outcomes (such as } \\
\text { relationship } \\
\text { functioning and } \\
\text { couples distress, and } \\
\text { sexual rehabilitation) } \\
\text { Study design: } \\
\text { Systematic review } \\
\text { Number of articles: } \\
\text { 14 } \\
\text { Included study } \\
\text { designs: } \\
\text { Experiential, quasi- } \\
\text { experimental, two } \\
\text { groups or one group } \\
\text { pre-post studies, case } \\
\text { study } \\
\text { Type of } \\
\text { interventions: } \\
\text { Psychosocial }\end{array}$ & $\begin{array}{l}\text { Age : Mean age varied } \\
\text { from late 40s to mid- } \\
80 \mathrm{~s} \\
\text { Gender: Not described } \\
\text { Race: Not described } \\
\text { Marital status: Not } \\
\text { described } \\
\text { Level of education: } \\
\text { Not described } \\
\text { Employment status: } \\
\text { Not described } \\
\text { Type and stage of } \\
\text { cancer: Sample } \\
\text { included various cancer } \\
\text { diagnoses, but largely } \\
\text { breast and prostate } \\
\text { cancer. Various stages. } \\
\text { Caregiver type: } \\
\text { Partners } \\
\text { Setting: Home setting }\end{array}$ & $\begin{array}{l}8 \text { studies indicate overall } \\
\text { improvement in patients and } 8 \\
\text { studies indicate overall } \\
\text { improvement in partner } \\
\text { caregivers. } 5 \text { studies suggest } \\
\text { partial improvement for patients } \\
\text { and } 3 \text { show partial improvements } \\
\text { for partners. Collectively, these } \\
\text { interventions suggest partial } \\
\text { effectiveness of psychosocial } \\
\text { interventions. }\end{array}$ & $\begin{array}{l}\text { Approach: Not described } \\
\text { Component: Sample } \\
\text { included interventions } \\
\text { using Psychotherapy, } \\
\text { education, and couples } \\
\text { therapy in the intervention; } \\
\text { most used a cognitive } \\
\text { behavioural component } \\
\text { Mode: Strategy: } \\
\text { Most were face-to face, } \\
\text { while two were conducted } \\
\text { via telephone } \\
\text { Format: Most interventions } \\
\text { were conducted with } \\
\text { individual couples, and two } \\
\text { were group interventions. } \\
\text { Dose: Varied among } \\
\text { interventions, ranging in } \\
\text { number of sessions, length } \\
\text { of each session, and } \\
\text { duration of the intervention }\end{array}$ & Yes \\
\hline
\end{tabular}




\begin{tabular}{|c|c|c|c|c|c|}
\hline & $\begin{array}{l}\text { interventions aimed } \\
\text { at couples only }\end{array}$ & & & & \\
\hline $\begin{array}{l}\text { Cochrane \& } \\
\text { Lewis } \\
\text { (2005). } \\
\text { Partner`s } \\
\text { Adjustment } \\
\text { to breast } \\
\text { cancer: A } \\
\text { critical } \\
\text { analysis of } \\
\text { interventions } \\
\text { studies. }\end{array}$ & $\begin{array}{l}\text { Intervention } \\
\text { Outcome Measures: } \\
\text { Partner`s adjustment } \\
\text { (mood or emotional } \\
\text { discomfort; marital } \\
\text { adjustment; social } \\
\text { support; sexual } \\
\text { satisfaction) } \\
\text { Study design: } \\
\text { Systematic review } \\
\text { Number of articles: } \\
4 \\
\text { Included study } \\
\text { designs: } \\
\text { Randomized control } \\
\text { trials, quasi- } \\
\text { experimental, clinical } \\
\text { case series }\end{array}$ & $\begin{array}{l}\text { Age : Not reported for } \\
\text { all included studies. For } \\
\text { those that did, age } \\
\text { ranged from } 30-70 \text {. } \\
\text { Gender: Not described } \\
\text { Race: Not described } \\
\text { Marital status: Not } \\
\text { described } \\
\text { Level of education: } \\
\text { Not described } \\
\text { Employment status: } \\
\text { Not described } \\
\text { Type and stage of } \\
\text { cancer: Breast cancer, } \\
\text { various stages included. } \\
\text { Caregiver type: } \\
\text { Partners }\end{array}$ & $\begin{array}{l}\text { Two studies reported statistically } \\
\text { significant differences but with } \\
\text { limited intervention efficacy. }\end{array}$ & $\begin{array}{l}\text { Approach: } 2 \text { interventions } \\
\text { were structured, } 2 \text { were } \\
\text { tailored to the individual } \\
\text { situation or group dynamic } \\
\text { Component: All } \\
\text { interventions included a } \\
\text { supportive component. } \\
\text { Other components } \\
\text { identified across studies } \\
\text { included education and } \\
\text { skills development } \\
\text { elements } \\
\text { Mode: } \\
\text { Strategy: Not clearly } \\
\text { described } \\
\text { Format: } 2 \text { interventions } \\
\text { used a group format, } 1 \text { was } \\
\text { dyadic, one was delivered } \\
\text { individually or in couples. } \\
\text { Dose: Number of sessions } \\
\text { ranged from 4-10 sessions. } \\
\text { Length and duration of } \\
\text { sessions not reported in all } \\
\text { intervention summaries }\end{array}$ & Yes \\
\hline $\begin{array}{l}\text { Harding \& } \\
\text { Higginson } \\
(2003) .\end{array}$ & $\begin{array}{l}\text { Intervention } \\
\text { Outcome Measures: } \\
\text { Non-specified } \\
\text { outcomes of interest. }\end{array}$ & $\begin{array}{l}\text { Age : Not described } \\
\text { Gender: Not described } \\
\text { Race: Not described } \\
\text { Marital status: }\end{array}$ & $\begin{array}{l}\text { Interventions were classified as } \\
\text { Home care, respite, social } \\
\text { networks and activity } \\
\text { enhancement, problem solving }\end{array}$ & $\begin{array}{l}\text { Approach: } \\
\text { Not described } \\
\text { Component: Included a } \\
\text { number of educational, }\end{array}$ & Yes \\
\hline
\end{tabular}




\begin{tabular}{|c|c|c|c|c|c|}
\hline $\begin{array}{l}\text { What is the } \\
\text { best way to } \\
\text { help } \\
\text { caregivers in } \\
\text { cancer and } \\
\text { palliative } \\
\text { care? A } \\
\text { systematic } \\
\text { review of } \\
\text { the literature } \\
\text { review of } \\
\text { interventions } \\
\text { and their } \\
\text { effectiveness. }\end{array}$ & $\begin{array}{l}\text { - Included studies } \\
\text { with all outcomes } \\
\text { Study design: } \\
\text { Systematic review } \\
\text { Number of articles: } \\
22 \\
\text { Included study } \\
\text { designs: } \\
\text { Not specified } \\
\text { Type of } \\
\text { interventions: } \\
\text { Interventions were } \\
\text { classified as Home } \\
\text { care, respite, social } \\
\text { networks and activity } \\
\text { enhancement, } \\
\text { problem solving and } \\
\text { education, and group } \\
\text { interventions }\end{array}$ & $\begin{array}{l}\text { Not described } \\
\text { Level of education: } \\
\text { Not described } \\
\text { Employment status: } \\
\text { Not described } \\
\text { Type and stage of } \\
\text { cancer: Palliative care } \\
\text { and cancer } \\
\text { Caregiver type: } \\
\text { Families and partners } \\
\text { Setting: } \\
\text { Home/community } \\
\text { setting }\end{array}$ & $\begin{array}{l}\text { and education, one to one and } \\
\text { group interventions. } \\
\text { Finding suggest lack of outcome } \\
\text { evaluation designs, small sample } \\
\text { sizes, and reliance of the } \\
\text { literature on intervention } \\
\text { descriptions and formative } \\
\text { evaluations. } \\
\text { Findings pertaining to } \\
\text { intervention characteristics: } \\
\text { One-to-one interventions: } \\
\text { Varying results pertaining to the } \\
\text { effectiveness of one-to -one } \\
\text { interventions. (some show } \\
\text { significant improvements, some } \\
\text { show improvement in certain } \\
\text { subsamples, some found no } \\
\text { significant differences) } \\
\text { Group work interventions: } \\
\text { Likewise, results across studies } \\
\text { related to the effectiveness of } \\
\text { these interventions varied, some } \\
\text { indicating improvements, some } \\
\text { with no differences, and one } \\
\text { reporting more negative feelings } \\
\text { following the intervention. }\end{array}$ & $\begin{array}{l}\text { skills training, and } \\
\text { supportive interventions in } \\
\text { sample } \\
\text { Mode: Strategy: Various } \\
\text { strategies used, such as } \\
\text { face-to-face delivery. } \\
\text { Intervention strategy } \\
\text { unclear in summary } \\
\text { description. } \\
\text { Format: } \\
10 \text { were group work } \\
\text { interventions, } 3 \text { were one to } \\
\text { one. } \\
\text { Dose: Description of dose } \\
\text { not consistently described } \\
\text { reported on across studies. }\end{array}$ & \\
\hline $\begin{array}{l}\text { Honea, } \\
\text { Brintnall, }\end{array}$ & $\begin{array}{l}\text { Intervention } \\
\text { Outcome Measures: }\end{array}$ & $\begin{array}{l}\text { Age : Not described } \\
\text { Gender: Not described }\end{array}$ & $\begin{array}{l}\text { Limited number of studies } \\
\text { addressing interventions for }\end{array}$ & $\begin{array}{l}\text { Approach: Not described } \\
\text { across included studies }\end{array}$ & Yes \\
\hline
\end{tabular}




\begin{tabular}{|c|c|c|c|c|c|}
\hline $\begin{array}{l}\text { Given, } \\
\text { Sherwood, } \\
\text { Colao, } \\
\text { Somers, \& } \\
\text { Northouse } \\
\text { (2008). } \\
\text { Nursing } \\
\text { assessment } \\
\text { and } \\
\text { interventions } \\
\text { to reduce } \\
\text { family } \\
\text { caregiver } \\
\text { burden and } \\
\text { strain. }\end{array}$ & $\begin{array}{l}\text { Family caregiver } \\
\text { strain and burden } \\
\text { Study design: } \\
\text { Systematic Review } \\
\text { Number of articles: } \\
12 \\
\text { Included study } \\
\text { designs: primary } \\
\text { intervention research } \\
\text { studies (design not } \\
\text { specified), systematic } \\
\text { reviews, meta- } \\
\text { analysis }\end{array}$ & $\begin{array}{l}\text { Race: Not described } \\
\text { Marital status: Not } \\
\text { described } \\
\text { Level of education: } \\
\text { Not described } \\
\text { Employment status: } \\
\text { Not described } \\
\text { Type and stage of } \\
\text { cancer: Not specified } \\
\text { Caregiver type: } \\
\text { families }\end{array}$ & $\begin{array}{l}\text { caregiver strain and burden in } \\
\text { oncology. } \\
\text { Interventions were classified into } \\
\text { categories: psycho-educational, } \\
\text { supportive, and psychotherapy/ } \\
\text { cognitive-behavioural, massage, } \\
\text { healing touch, respite care or } \\
\text { multi-component. } \\
\text { Interventions had a stronger } \\
\text { effect in reducing caregiver } \\
\text { burden when relationship and } \\
\text { issues between patients and } \\
\text { caregivers are addressed. } \\
\text { Findings pertaining to } \\
\text { intervention characteristics: } \\
\text { Multi-component interventions } \\
\text { may be more likely to be } \\
\text { effective at reducing burden, and } \\
\text { may be most valuable to } \\
\text { caregivers with higher burden } \\
\text { levels. } \\
\text { Interventions given in an } \\
\text { individualized format may be } \\
\text { more effective than when given } \\
\text { in a group. }\end{array}$ & $\begin{array}{l}\text { Component: Interventions } \\
\text { were classified into } \\
\text { categories: psycho- } \\
\text { educational, supportive, } \\
\text { and psychotherapy/ } \\
\text { cognitive-behavioural, } \\
\text { massage, healing touch, } \\
\text { respite care or multi- } \\
\text { component } \\
\text { Mode: Strategy: } \\
\text { Not described across } \\
\text { included studies } \\
\text { Format: Not described } \\
\text { across included studies } \\
\text { Dose: Not described across } \\
\text { included studies }\end{array}$ & \\
\hline $\begin{array}{l}\text { Hudson } \\
\text { (2004). A } \\
\text { critical } \\
\text { review of } \\
\text { supportive }\end{array}$ & $\begin{array}{l}\text { Intervention } \\
\text { Outcome Measures: } \\
\text { Non-specific } \\
\text { outcomes of interest- } \\
\text { Included studies with }\end{array}$ & $\begin{array}{l}\text { Age : Not described } \\
\text { Gender: Not described } \\
\text { Race: Not described } \\
\text { Marital status: Not } \\
\text { described }\end{array}$ & $\begin{array}{l}\text { In general, findings suggest a } \\
\text { small to moderate impact on } \\
\text { caregivers well-being. } \\
\text { Findings pertaining to }\end{array}$ & $\begin{array}{l}\text { Approach: Not clearly } \\
\text { described across } \\
\text { intervention descriptions. } \\
\text { Component: Included a } \\
\text { number of educational, }\end{array}$ & Yes \\
\hline
\end{tabular}




\begin{tabular}{|c|c|c|c|c|c|}
\hline $\begin{array}{l}\text { interventions } \\
\text { for family } \\
\text { caregivers of } \\
\text { patients with } \\
\text { palliative- } \\
\text { stage cancer. }\end{array}$ & $\begin{array}{l}\text { all outcomes } \\
\text { Study design: } \\
\text { Literature review } \\
\text { Number of articles: } \\
15 \\
\text { Included study } \\
\text { designs: Not } \\
\text { specified } \\
\text { Type of } \\
\text { interventions: } \\
\text { Supportive } \\
\text { interventions only }\end{array}$ & $\begin{array}{l}\text { Level of education: } \\
\text { Not described } \\
\text { Employment status: } \\
\text { Not described } \\
\text { Type and stage of } \\
\text { cancer: Palliative } \\
\text { cancer patients, various } \\
\text { cancer types } \\
\text { Caregiver type: } \\
\text { Family }\end{array}$ & $\begin{array}{l}\text { intervention characteristics: } \\
\text { Interventions that incorporate } \\
\text { multiple components are more } \\
\text { successful than single component } \\
\text { interventions in achieving } \\
\text { positive outcomes in caregivers. }\end{array}$ & $\begin{array}{l}\text { problem-solving, } \\
\text { supportive, and } \\
\text { combination interventions, } \\
\text { although component was } \\
\text { not clearly identified in all } \\
\text { intervention descriptions. } \\
\text { Mode: } \\
\text { Strategy: Not clearly } \\
\text { described across } \\
\text { intervention descriptions. } \\
\text { Format: Included a number } \\
\text { of group and individualized } \\
\text { interventions, however } \\
\text { format was not described } \\
\text { for all article summaries. } \\
\text { Dose: Not described in all } \\
\text { intervention descriptions. } \\
\text { For summaries that did } \\
\text { include a description, dose } \\
\text { of included interventions } \\
\text { ranged widely in terms of } \\
\text { frequency of interventions } \\
\text { sessions and duration of the } \\
\text { intervention. }\end{array}$ & \\
\hline $\begin{array}{l}\text { McCorkle \& } \\
\text { Pasacreta } \\
(2001) . \\
\text { Enhancing } \\
\text { Caregiver }\end{array}$ & $\begin{array}{l}\text { Intervention } \\
\text { Outcome Measures: } \\
\text { Non-specified } \\
\text { outcomes of interest. } \\
\text { Included studies with }\end{array}$ & $\begin{array}{l}\text { Age : Not described } \\
\text { Gender: Not described } \\
\text { Race: Not described } \\
\text { Marital status: Not } \\
\text { described }\end{array}$ & $\begin{array}{l}\text { Literature suggests that } \\
\text { Interventions that teach } \\
\text { caregivers about the physical and } \\
\text { psychological aspects of patient } \\
\text { care can have benefits to both the }\end{array}$ & $\begin{array}{l}\text { Approach: Not described } \\
\text { Component: Interventions } \\
\text { were categorized as being } \\
\text { informational or supportive } \\
\text { Mode: }\end{array}$ & No \\
\hline
\end{tabular}




\begin{tabular}{|c|c|c|c|c|c|}
\hline $\begin{array}{l}\text { outcomes in } \\
\text { palliative } \\
\text { care. }\end{array}$ & $\begin{array}{l}\text { all outcomes } \\
\text { Study design: } \\
\text { Literature review } \\
\text { Number of articles: } \\
13 \\
\text { Included study } \\
\text { designs: Not } \\
\text { described } \\
\text { Type of } \\
\text { interventions: } \\
\text { Interventions aimed } \\
\text { at palliative care } \\
\text { patients. }\end{array}$ & $\begin{array}{l}\text { Level of education: } \\
\text { Not described } \\
\text { Employment status: } \\
\text { Not described } \\
\text { Type and stage of } \\
\text { cancer: } \\
\text { Palliative stage, } \\
\text { various cancer types } \\
\text { Caregiver type: } \\
\text { Families }\end{array}$ & $\begin{array}{l}\text { caregiver and patient. } \\
\text { Interventions were categorized as } \\
\text { being informational or supportive }\end{array}$ & $\begin{array}{l}\text { Strategy: Inconsistently } \\
\text { reported on in intervention } \\
\text { descriptions. } \\
\text { Format: Not clearly } \\
\text { described in some } \\
\text { summaries. For those that } \\
\text { did, group, individual and } \\
\text { dyadic interventions were } \\
\text { identified. } \\
\text { Dose: Inconsistently } \\
\text { reported on in intervention } \\
\text { descriptions. }\end{array}$ & \\
\hline $\begin{array}{l}\text { Northouse, } \\
\text { Katapodi, } \\
\text { Song, Zhang, } \\
\text { \& Mood } \\
\text { (2010). } \\
\text { Interventions } \\
\text { with family } \\
\text { caregivers of } \\
\text { cancer } \\
\text { patients: } \\
\text { Meta- } \\
\text { analysis of } \\
\text { randomized } \\
\text { trials. }\end{array}$ & $\begin{array}{l}\text { Intervention } \\
\text { Outcome Measures } \\
\text { Not specified, but } \\
\text { outcomes were } \\
\text { classified into } \\
\text { outcome domain } \\
\text { including Illness } \\
\text { appraisal factors } \\
\text { (caregiver burden, } \\
\text { caregiver benefit, and } \\
\text { information needs); } \\
\text { coping resources } \\
\text { (coping strategies } \\
\text { and self-efficacy); or } \\
\text { quality of life } \\
\text { (physical } \\
\text { functioning, distress } \\
\text { and anxiety, }\end{array}$ & $\begin{array}{l}\text { Age : Ranged from } 18 \text { - } \\
92 \text { years ; mean age } \\
\text { was } 55 \text { years } \\
\text { Gender: } 64 \% \text { were } \\
\text { female, and } 36 \% \text { were } \\
\text { male across studies } \\
\text { Race: Majority of } \\
\text { sample participants } \\
\text { were White ( } 84 \%) \\
\text { Marital status: Not } \\
\text { described } \\
\text { Level of education: } \\
\text { Not described } \\
\text { Employment status: } \\
\text { Not described } \\
\text { Type and stage of } \\
\text { cancer: Various } \\
\text { cancers at various }\end{array}$ & $\begin{array}{l}\text { Interventions had small to } \\
\text { medium effects but significantly } \\
\text { reducing caregiver burden, } \\
\text { improved coping ability, } \\
\text { improved self-efficacy, and } \\
\text { quality of life. } \\
\text { Interventions improved stress and } \\
\text { anxiety but were not successful } \\
\text { in reducing caregiver depression } \\
\text { Findings pertaining to } \\
\text { intervention characteristics: } \\
\text { Face to face and group methods } \\
\text { resulted in better caregiver } \\
\text { coping compared to mixed } \\
\text { methods delivery. }\end{array}$ & $\begin{array}{l}\text { Approach: Not described } \\
\text { Component: Interventions } \\
\text { were classified as being } \\
\text { primarily psycho- } \\
\text { educational }(57.1 \%) \text {, skills } \\
\text { training }(25.7 \%) \text {, and } \\
\text { therapeutic counselling } \\
(17.1 \%) \text { in nature. A } \\
\text { number of interventions } \\
\text { also included a } \\
\text { combination of these } \\
\text { components. } \\
\text { Mode: } \\
\text { Strategy: Most were } \\
\text { delivered face-to-face } \\
\text { (68.6\%), and telephone } \\
\text { delivery (20\%) } \\
\text { Format: Most were }\end{array}$ & $\begin{array}{l}\text { Not } \\
\text { described. }\end{array}$ \\
\hline
\end{tabular}




\begin{tabular}{|c|c|c|c|c|c|}
\hline & $\begin{array}{l}\text { depression, martial- } \\
\text { family relationships, } \\
\text { and social } \\
\text { functioning). } \\
\text { Study design: Meta- } \\
\text { analysis } \\
\text { Number of articles: } \\
29 \\
\text { Included study } \\
\text { designs: } \\
\text { Randomized control } \\
\text { trials only } \\
\text { Type of } \\
\text { interventions: } \\
\text { Social, cognitive or } \\
\text { behaviourally based } \\
\text { interventions }\end{array}$ & $\begin{array}{l}\text { stages . } \\
\text { Caregiver type: } \\
\text { Families (spouses, adult } \\
\text { children, siblings, } \\
\text { friends) } \\
\text { Setting: }\end{array}$ & $\begin{array}{l}\text { Longer intervention horus and } \\
\text { more sessions were also } \\
\text { associated with improved coping. } \\
\text { In terms of caregiver burden, } \\
\text { depression, and martial family } \\
\text { relationship outcomes, } \\
\text { interventions with more sessions } \\
\text { were associated with } \\
\text { significantly more negative } \\
\text { outcomes. } \\
\text { Interventions delivered to } \\
\text { caregivers alone were associated } \\
\text { with significantly better caregiver } \\
\text { benefit than interventions that } \\
\text { included both the patient and } \\
\text { caregiver. }\end{array}$ & $\begin{array}{l}\text { delivered to patients and } \\
\text { caregivers as a unit }(62.9 \%) \\
\text { while } 37.5 \% \text { were } \\
\text { delivered to caregivers } \\
\text { only. } \\
\text { Dose: Total number of } \\
\text { hours ranged from } 1.7-18 \\
\text { hours (mean: } 7.5 \\
\text { hours). Total number of } \\
\text { sessions ranged from } 2-16 \\
\text { sessions (mean: } 6.7 \\
\text { sessions). Time frame of } \\
\text { the entire intervention had } \\
\text { a mean duration of } 7.8 \\
\text { weeks (excluding outliers). }\end{array}$ & \\
\hline $\begin{array}{l}\text { Northouse, } \\
\text { Williams, } \\
\text { Given, \& } \\
\text { McCorkle } \\
\text { (2012). } \\
\text { Psychosocial } \\
\text { care of } \\
\text { family } \\
\text { caregivers of } \\
\text { patients with } \\
\text { cancer. }\end{array}$ & $\begin{array}{l}\text { Intervention } \\
\text { Outcome Measures } \\
\text { Caregiver`s`well- } \\
\text { being } \\
\text { (burden, depression, } \\
\text { knowledge, caregiver } \\
\text { benefit, coping, self- } \\
\text { efficacy, physical } \\
\text { functioning, anxiety, } \\
\text { relationships, } \\
\text { psychological } \\
\text { distress) } \\
\text { Patient outcomes- } \\
\text { symptoms, mental } \\
\text { and physical health, } \\
\end{array}$ & $\begin{array}{l}\text { Age : Not described } \\
\text { Gender: } 61 \% \text { were } \\
\text { female, } 39 \% \text { were male } \\
\text { Race: Majority of } \\
\text { sample participants } \\
\text { were white }(84 \%) \\
\text { Marital status: Not } \\
\text { described } \\
\text { Level of education: } \\
\text { Not described } \\
\text { Employment status: } \\
\text { Not described } \\
\text { Type and stage of } \\
\text { cancer: Included } \\
\text { cancer (unspecified }\end{array}$ & $\begin{array}{l}\text { Interventions delivered to } \\
\text { oncology family caregivers can } \\
\text { reduce many negative effects and } \\
\text { improve caregivers` coping } \\
\text { skills, knowledge, and quality of } \\
\text { life. } \\
\text { Included meta-analyses reported } \\
\text { that interventions led to } \\
\text { significantly less burden, } \\
\text { depression and distress in } \\
\text { caregivers } \\
\text { These interventions also reduce } \\
\text { patients`symptoms, mortality, }\end{array}$ & $\begin{array}{l}\text { Approach: Not described } \\
\text { Component: Interventions } \\
\text { were classified as having a } \\
\text { psycho-educational, skills } \\
\text { training, or therapeutic } \\
\text { counselling component. } \\
\text { Mode: Strategy: Most were } \\
\text { delivered in face -to-face } \\
\text { sessions (69\%); others were } \\
\text { delivered by phone (20\%). } \\
\text { Format: Most were } \\
\text { delivered to patients and } \\
\text { family carers as a unit } \\
\text { (63\%) } \\
\text { Dose: Dose ranged }\end{array}$ & Yes \\
\hline
\end{tabular}




\begin{tabular}{|c|c|c|c|c|c|}
\hline & $\begin{array}{l}\text { mortality } \\
\text { Study design: } \\
\text { Systematic review } \\
\text { Number of articles: } \\
5 \\
\text { Included study } \\
\text { designs: Meta- } \\
\text { analyses of RCTs } \\
\text { Type of } \\
\text { interventions: } \\
\text { Psychosocial care } \\
\text { interventions }\end{array}$ & $\begin{array}{l}\text { type and stage) and } \\
\text { chronic illness patients } \\
\text { Caregiver type: } \\
\text { families; most were } \\
\text { spouses of the patient }\end{array}$ & $\begin{array}{l}\text { and improve patient`s physical } \\
\text { and mental health. } \\
\text { Interventions that included a } \\
\text { relationship focused } \\
\text { interventions had a more positive } \\
\text { effect on caregiver health } \\
\text { outcomes. } \\
\text { Findings pertaining to } \\
\text { intervention characteristics: } \\
\text { Longer interventions were more } \\
\text { likely to improve coping } \\
\text { outcomes compared to shorter } \\
\text { interventions. } \\
\text { Dyadic interventions aimed at the } \\
\text { patient and caregiver contribute } \\
\text { to the well-being of both the }\end{array}$ & $\begin{array}{l}\text { considerably and ranged } \\
\text { from } 1.7-18 \text { hours in length } \\
\text { and encompassed } 2-16 \\
\text { sessions }\end{array}$ & \\
\hline $\begin{array}{l}\text { Pasacreta \& } \\
\text { McCorkle } \\
(2000) \text {. } \\
\text { Cancer care: } \\
\text { Impact of } \\
\text { interventions } \\
\text { on caregiver } \\
\text { outcomes. }\end{array}$ & $\begin{array}{l}\text { Intervention } \\
\text { Outcome Measures: } \\
\text { Non-specified } \\
\text { outcomes of interest. } \\
\text { Included studies with } \\
\text { all outcomes. } \\
\text { (reviewed the design } \\
\text { and methodological } \\
\text { limitations across } \\
\text { studies) } \\
\text { Study design: } \\
\text { Systematic review } \\
\text { Number of articles: }\end{array}$ & $\begin{array}{l}\text { Age : Not described } \\
\text { Gender: Not described } \\
\text { Race: Not described } \\
\text { Marital status: Not } \\
\text { described } \\
\text { Level of education: } \\
\text { Not described } \\
\text { Employment status: } \\
\text { Not described } \\
\text { Type and stage of } \\
\text { cancer: Not specified } \\
\text { Caregiver type: } \\
\text { Families }\end{array}$ & $\begin{array}{l}\text { There was a lack of literature } \\
\text { describing interventions aimed at } \\
\text { family caregivers. Described } \\
\text { interventions in the literature lack } \\
\text { well-defined effects on } \\
\text { outcomes. Most studies used } \\
\text { small samples and lacked } \\
\text { randomization. } \\
\text { Many of the included studies had } \\
\text { selection bias. }\end{array}$ & $\begin{array}{l}\text { Approach: Not } \\
\text { consistently reported on } \\
\text { across intervention } \\
\text { summaries } \\
\text { Component: Interventions } \\
\text { were classified as } \\
\text { educational; support, } \\
\text { counselling and } \\
\text { psychotherapy; and hospice } \\
\text { and palliative home care } \\
\text { services. } \\
\text { Mode: Strategy: Not } \\
\text { consistently described }\end{array}$ & Yes \\
\hline
\end{tabular}




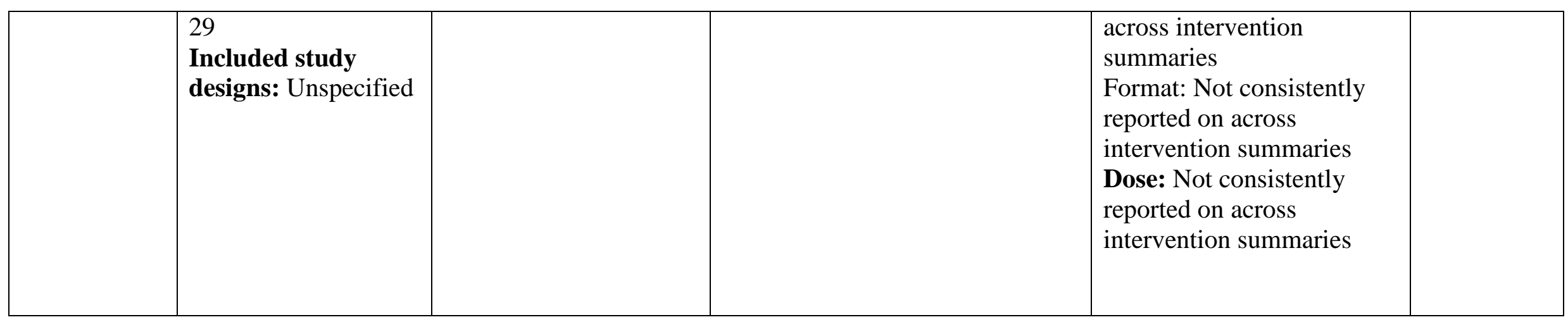




\section{Appendix B: Search Strategy}
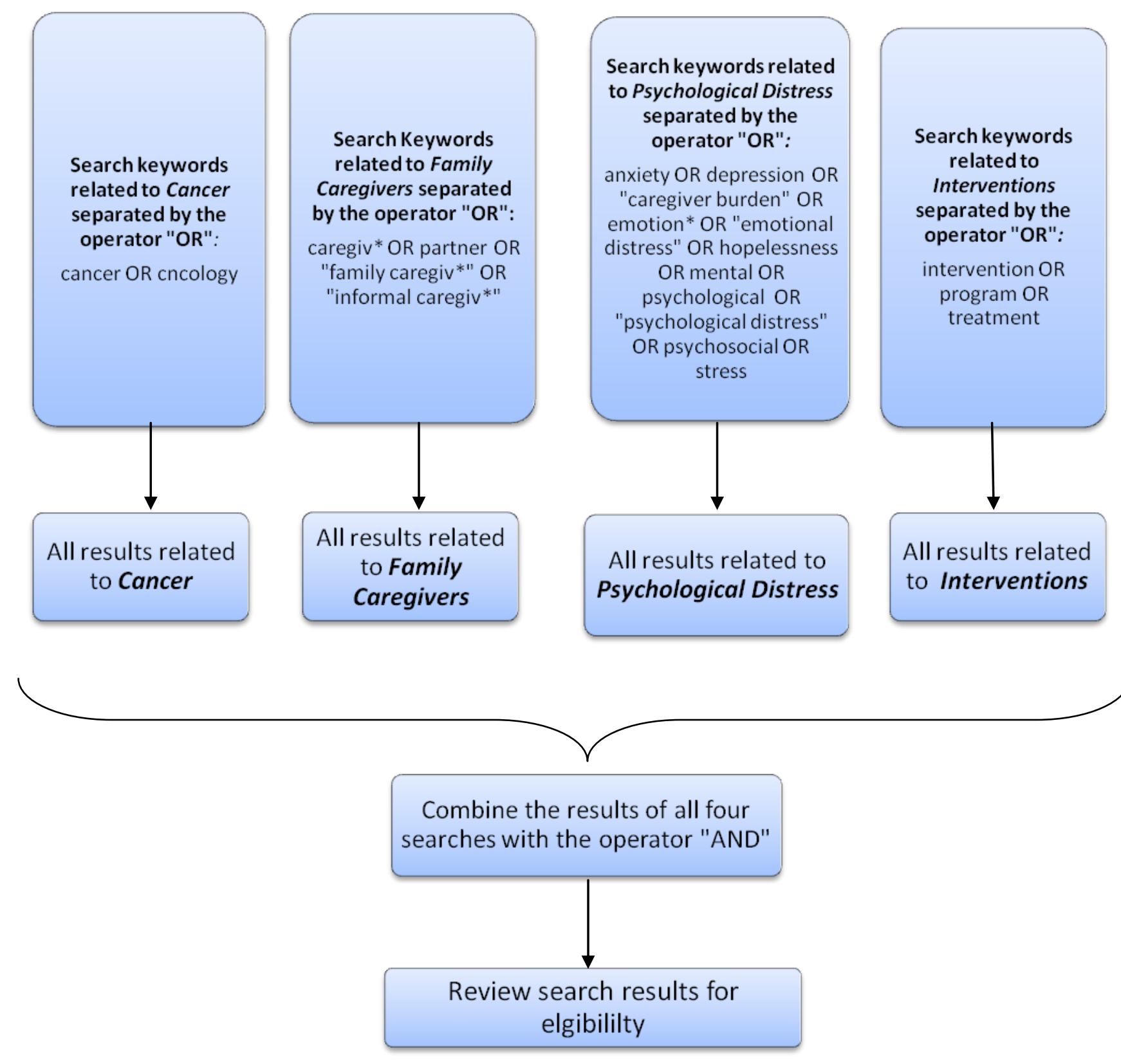

Repeat similar search strategies using CINAHL, EMBASE, MEDLINE, Proquest Nursing and PsychINFO 


\section{Appendix C: AMSTAR}

Table 2: AMSTAR is a measurement tool created to assess the methodological quality of systematic reviews.

\begin{tabular}{|c|c|}
\hline $\begin{array}{l}\text { 1. Was an 'a priori' design provided? } \\
\text { The research question and inclusion criteria should be established before the conduct of the review. }\end{array}$ & $\begin{array}{l}\square \text { Yes } \\
\square \text { No } \\
\square \text { Can't answer } \\
\square \text { Not applicable }\end{array}$ \\
\hline $\begin{array}{l}\text { 2. Was there duplicate study selection and data extraction? } \\
\text { There should be at least two independent data extractors and a consensus procedure for disagreements should be in place. }\end{array}$ & $\begin{array}{l}\square \text { Yes } \\
\square \text { No } \\
\square \text { Can't answer } \\
\square \text { Not applicable }\end{array}$ \\
\hline $\begin{array}{l}\text { 3. Was a comprehensive literature search performed? } \\
\text { At least two electronic sources should be searched. The report must include years and databases used (e.g. Central, EMBASE, } \\
\text { and MEDLINE). Key words and/or MESH terms must be stated and where feasible the search strategy should be provided. All } \\
\text { searches should be supplemented by consulting current contents, reviews, textbooks, specialized registers, or experts in the } \\
\text { particular field of study, and by reviewing the references in the studies found. }\end{array}$ & $\begin{array}{l}\square \text { Yes } \\
\square \text { No } \\
\square \text { Can't answer } \\
\square \text { Not applicable }\end{array}$ \\
\hline $\begin{array}{l}\text { 4. Was the status of publication (i.e. grey literature) used as an inclusion criterion? } \\
\text { The authors should state that they searched for reports regardless of their publication type. The authors should state whether } \\
\text { or not they excluded any reports (from the systematic review), based on their publication status, language etc. }\end{array}$ & $\begin{array}{l}\square \text { Yes } \\
\square \text { No } \\
\square \text { Can't answer } \\
\square \text { Not applicable }\end{array}$ \\
\hline $\begin{array}{l}\text { 5. Was a list of studies (included and excluded) provided? } \\
\text { A list of included and excluded studies should be provided. }\end{array}$ & $\begin{array}{l}\square \text { Yes } \\
\square \text { No } \\
\square \text { Can't answer } \\
\square \text { Not applicable }\end{array}$ \\
\hline $\begin{array}{l}\text { 6. Were the characteristics of the included studies provided? } \\
\text { In an aggregated form such as a table, data from the original studies should be provided on the participants, interventions and } \\
\text { outcomes. The ranges of characteristics in all the studies analyzed e.g. age, race, sex, relevant socioeconomic data, disease } \\
\text { status, duration, severity, or other diseases should be reported. }\end{array}$ & $\begin{array}{l}\square \text { Yes } \\
\square \text { No } \\
\square \text { Can't answer } \\
\square \text { Not applicable }\end{array}$ \\
\hline $\begin{array}{l}\text { 7. Was the scientific quality of the included studies assessed and documented? } \\
\text { 'A priori' methods of assessment should be provided (e.g., for effectiveness studies if the author(s) chose to include only } \\
\text { randomized, double-blind, placebo controlled studies, or allocation concealment as inclusion criteria); for other types of studies } \\
\text { alternative items will be relevant. }\end{array}$ & $\begin{array}{l}\square \text { Yes } \\
\square \text { No } \\
\square \text { Can't answer } \\
\square \text { Not applicable }\end{array}$ \\
\hline $\begin{array}{l}\text { 8. Was the scientific quality of the included studies used appropriately in formulating conclusions? } \\
\text { The results of the methodological rigor and scientific quality should be considered in the analysis and the conclusions of the } \\
\text { review, and explicity stated in formulating recommendations. }\end{array}$ & $\begin{array}{l}\square \text { Yes } \\
\square \text { No } \\
\square \text { Can't answer } \\
\square \text { Not applicable }\end{array}$ \\
\hline 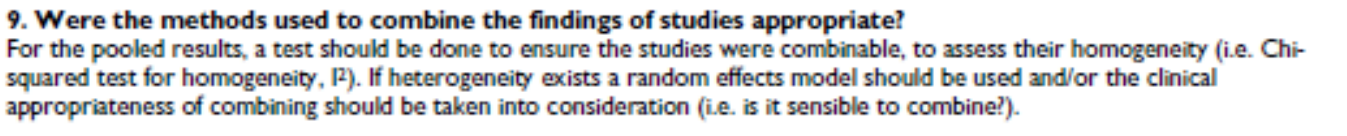 & $\begin{array}{l}\square \text { Yes } \\
\square \text { No } \\
\square \text { Can't answer } \\
\square \text { Not applicable }\end{array}$ \\
\hline $\begin{array}{l}\text { 10. Was the likelihood of publication bias assessed? } \\
\text { An assessment of publication bias should include a combination of graphical aids (e.g., funnel plot, other available tests) and/or } \\
\text { statistical tests (e.g., Egger regression test). }\end{array}$ & $\begin{array}{l}\square \text { Yes } \\
\square \text { No } \\
\square \text { Can't answer } \\
\square \text { Not applicable }\end{array}$ \\
\hline $\begin{array}{l}\text { 11. Was the conflict of interest stated? } \\
\text { Potential sources of support should be clearly acknowledged in both the systematic review and the included studies. }\end{array}$ & $\begin{array}{l}\square \text { Yes } \\
\square \text { No } \\
\square \text { Can't answer } \\
\square \text { Not applicable }\end{array}$ \\
\hline
\end{tabular}

Shea, B. J., Grimshaw, J. M., Wells, G. A., Boers, M., Andersson, N., Hamel, C., ... \& Bouter, L. M. (2007). Development of AMSTAR: a measurement tool to assess the methodological quality of systematic reviews. BMC medical research methodology, 7(1), 10. 


\section{Appendix D: PRISMA}

\begin{tabular}{|c|c|c|c|}
\hline Section/Topic & $\begin{array}{l}\text { Item } \\
\#\end{array}$ & Checklist Item & $\begin{array}{l}\text { Reported on } \\
\text { Page \# }\end{array}$ \\
\hline \multicolumn{4}{|l|}{ TITLE } \\
\hline Title & 1 & Identify the report as a systematic review, meta-analysis, or both. & \\
\hline \multicolumn{4}{|l|}{ ABSTRACT } \\
\hline Structured summary & 2 & $\begin{array}{l}\text { Provide a structured summary induding, as applicable: background; objectives; data sources, study } \\
\text { eligibility criteria, participants, and interventions; study appraisal and synthesis methods; results; } \\
\text { limitations; conclusions and implications of key findings; systematic review registration number. }\end{array}$ & \\
\hline \multicolumn{4}{|l|}{ INTRODUCTION } \\
\hline Rationale & 3 & Describe the rationale for the review in the context of what is already known. & \\
\hline Objectives & 4 & $\begin{array}{l}\text { Provide an explicit statement of questions being addressed with reference to participants, } \\
\text { interventions, comparisons, outcomes, and study design (PICOS). }\end{array}$ & \\
\hline \multicolumn{4}{|l|}{ METHODS } \\
\hline Protocol and registration & 5 & $\begin{array}{l}\text { Indicate if a review protocol exists, if and where it can be accessed (e.g., Web address), and, if } \\
\text { available, provide registration information including registration number. }\end{array}$ & \\
\hline Eligibility criteria & 6 & $\begin{array}{l}\text { Specify study characteristics (e.g., PICOS, length of follow-up) and report characteristics (e.g., } \\
\text { years considered, language, publication status) used as criteria for eligibility, giving rationale. }\end{array}$ & \\
\hline Information sources & 7 & $\begin{array}{l}\text { Describe all information sources (e.g., databases with dates of coverage, contact with study } \\
\text { authors to identify additional studies) in the search and date last searched. }\end{array}$ & \\
\hline Search & 8 & $\begin{array}{l}\text { Present full electronic search strategy for at least one database, including any limits used, such } \\
\text { that it could be repeated. }\end{array}$ & \\
\hline Study selection & 9 & $\begin{array}{l}\text { State the process for selecting studies (i.e., screening, eligibility, included in systematic review, } \\
\text { and, if applicable, included in the meta-analysis). }\end{array}$ & \\
\hline Data collection process & 10 & $\begin{array}{l}\text { Describe method of data extraction from reports (e.g., piloted forms, independently, in duplicate) } \\
\text { and any processes for obtaining and confirming data from investigators. }\end{array}$ & \\
\hline Data items & 11 & $\begin{array}{l}\text { List and define all variables for which data were sought (e.g., PICOS, funding sources) and any } \\
\text { assumptions and simplifications made. }\end{array}$ & \\
\hline $\begin{array}{l}\text { Risk of bias in individual } \\
\text { studies }\end{array}$ & 12 & $\begin{array}{l}\text { Describe methods used for assessing risk of bias of individual studies (including specification of } \\
\text { whether this was done at the study or outcome level), and how this information is to be used } \\
\text { in any data synthesis. }\end{array}$ & \\
\hline Summary measures & 13 & State the principal summary measures (e.g., risk ratio, difference in means). & \\
\hline Synthesis of results & 14 & $\begin{array}{l}\text { Describe the methods of handling data and combining results of studies, if done, including } \\
\text { measures of consistency (e.g., }\left.\right|^{2} \text { ) for each meta-analysis. }\end{array}$ & \\
\hline $\begin{array}{l}\text { Risk of bias across } \\
\text { studies }\end{array}$ & 15 & $\begin{array}{l}\text { Specify any assessment of risk of bias that may affect the cumulative evidence (e.g., publication } \\
\text { bias, selective reporting within studies). }\end{array}$ & \\
\hline Additional analyses & 16 & $\begin{array}{l}\text { Describe methods of additional analyses (e.g., sensitivity or subgroup analyses, meta-regression), if } \\
\text { done, indicating which were pre-specified. }\end{array}$ & \\
\hline \multicolumn{4}{|l|}{ RESULTS } \\
\hline Study selection & 17 & $\begin{array}{l}\text { Give numbers of studies screened, assessed for eligibility, and included in the review, with reasons } \\
\text { for exclusions at each stage, ideally with a flow diagram. }\end{array}$ & \\
\hline Study characteristics & 18 & $\begin{array}{l}\text { For each study, present characteristics for which data were extracted (e.g., study size, PICOS, } \\
\text { follow-up period) and provide the citations. }\end{array}$ & \\
\hline $\begin{array}{l}\text { Risk of bias within } \\
\text { studies }\end{array}$ & 19 & $\begin{array}{l}\text { Present data on risk of bias of each study and, if available, any outcome-level assessment (see } \\
\text { Item 12). }\end{array}$ & \\
\hline $\begin{array}{l}\text { Results of individual } \\
\text { studies }\end{array}$ & 20 & $\begin{array}{l}\text { For all outcomes considered (benefits or harms), present, for each study: (a) simple summary data } \\
\text { for each intervention group and (b) effect estimates and confidence intervals, ideally with a } \\
\text { forest plot. }\end{array}$ & \\
\hline Synthesis of results & 21 & $\begin{array}{l}\text { Present results of each meta-analysis done, including confidence intervals and measures of } \\
\text { consistency. }\end{array}$ & \\
\hline $\begin{array}{l}\text { Risk of bias across } \\
\text { studies }\end{array}$ & 22 & Present results of any assessment of risk of bias across studies (see Item 15). & \\
\hline Additional analysis & 23 & $\begin{array}{l}\text { Give results of additional analyses, if done (e.g., sensitivity or subgroup analyses, meta-regression } \\
\text { [see Item 16]). }\end{array}$ & \\
\hline \multicolumn{4}{|l|}{ DISCUSSION } \\
\hline Summary of evidence & 24 & $\begin{array}{l}\text { Summarize the main findings including the strength of evidence for each main outcome; consider } \\
\text { their relevance to key groups (e.g., health care providers, users, and policy makers). }\end{array}$ & \\
\hline Limitations & 25 & $\begin{array}{l}\text { Discuss limitations at study and outcome level (e.g., risk of bias), and at review level (e.g., } \\
\text { incomplete retrieval of identified research, reporting bias). }\end{array}$ & \\
\hline Conclusions & 26 & $\begin{array}{l}\text { Provide a general interpretation of the results in the context of other evidence, and implications } \\
\text { for future research. }\end{array}$ & \\
\hline \multicolumn{4}{|l|}{ FUNDING } \\
\hline Funding & 27 & $\begin{array}{l}\text { Describe sources of funding for the systematic review and other support (e.g., supply of data); } \\
\text { role of funders for the systematic review. }\end{array}$ & \\
\hline
\end{tabular}

Moher, D., Liberati, A., Tetzlaff, J., \& Altman, D. G. (2009). Preferred reporting items for systematic reviews and meta-analyses: The PRISMA statement. Annals of internal medicine, 151(4), 264-269. 


\section{Figure 1. Flow of information through the different phases of a systematic review.}

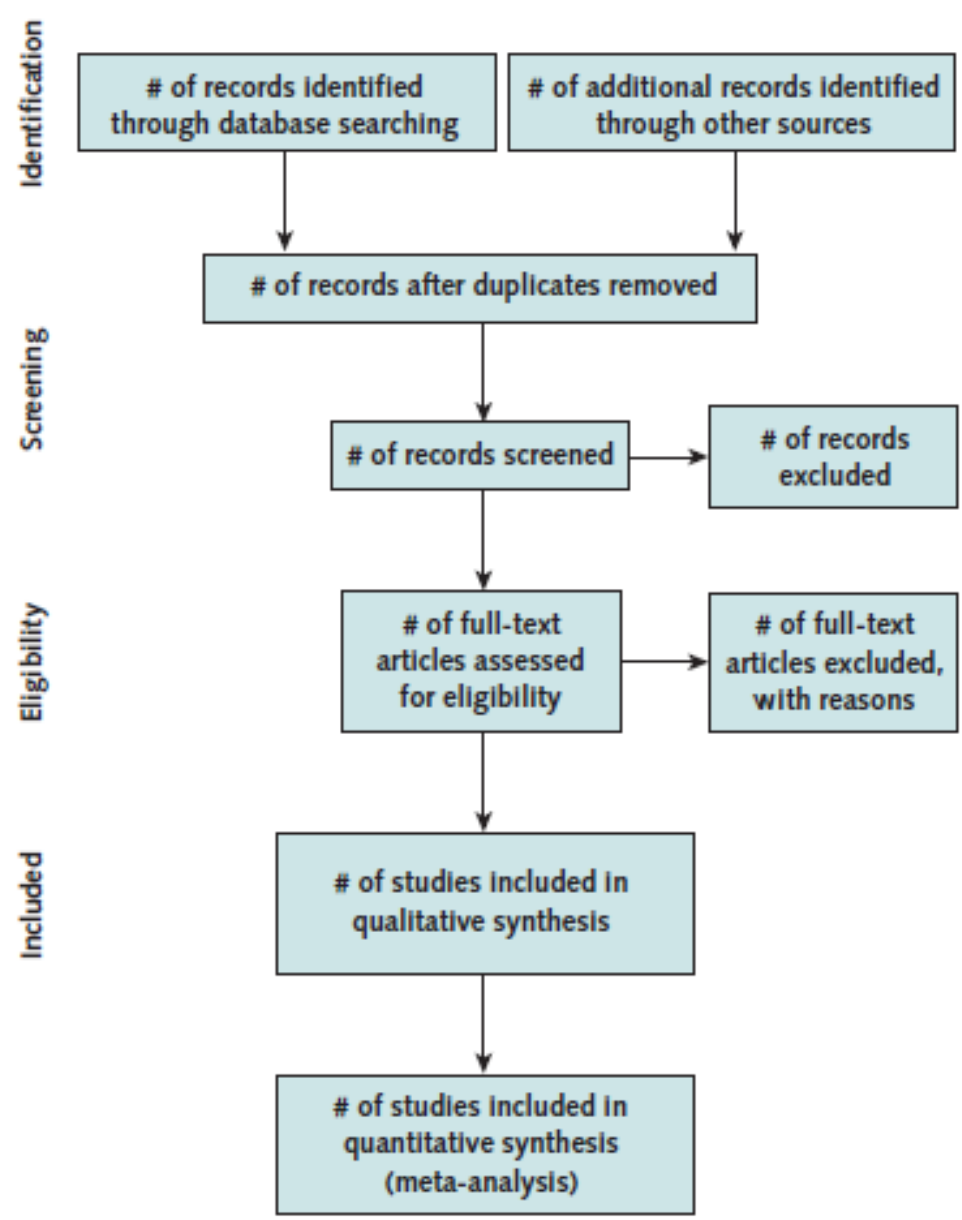

Moher, D., Liberati, A., Tetzlaff, J., \& Altman, D. G. (2009). Preferred reporting items for systematic reviews and meta-analyses: the PRISMA statement. Annals of internal medicine, 151(4), 264-269. 
Appendix E: Quality Assessment Tool for Quantitative Studies: EPHPP

\section{QUALITY ASSESSMENT TOOL FOR QUANTITATIVE STUDIES}

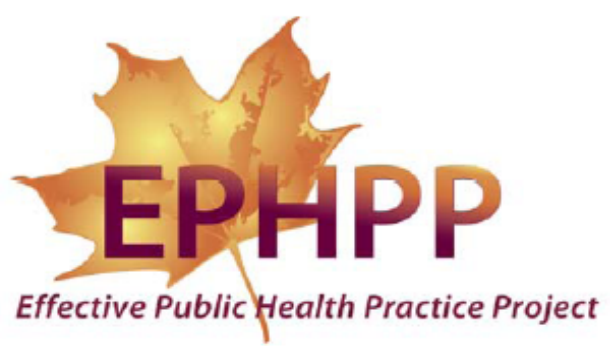

\section{COMPONENT RATINGS}

\section{A) SELECTION BIAS}

(01) Are the individuals selected to participate in the study likely to be representative of the target population?

$$
\begin{array}{ll}
1 & \text { Very likely } \\
2 & \text { Somewhat likely } \\
3 & \text { Not likely } \\
4 & \text { Can't tell }
\end{array}
$$

(02) What percentage of selected individuals agreed to participate?

$180-100 \%$ agreement

$260-79 \%$ agreement

3 less than $60 \%$ agreement

4 Not applicable

5 Can't tell

\begin{tabular}{|lccc|}
\hline RATE THIS SECTION & STRONG & MODERATE & WEAK \\
See dictionary & 1 & 2 & 3 \\
\hline
\end{tabular}

B) STUDY DESIGN

Indicate the study design

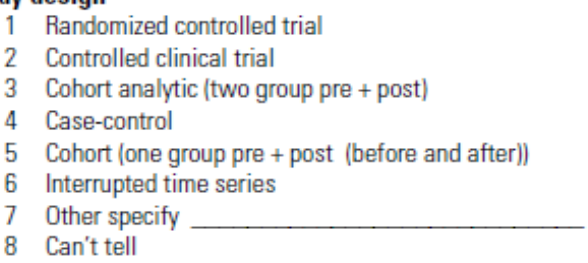

Was the study described as randomized? If NO, go to Component $\mathrm{C}$. No Yes

If Yes, was the method of randomization described? (See dictionary) No Yes

If Yes, was the method appropriate? (See dictionary) No Yes

\begin{tabular}{|lccc|}
\hline RATE THIS SECTION & STRONG & MODERATE & WEAK \\
See dictionary & 1 & 2 & 3 \\
\hline
\end{tabular}


C)

CONFOUNDERS

(01) Were there important differences between groups prior to the intervention?

$$
\begin{array}{ll}
1 & \text { Yes } \\
2 & \text { No } \\
3 & \text { Can't tell }
\end{array}
$$

The following are examples of confounders:

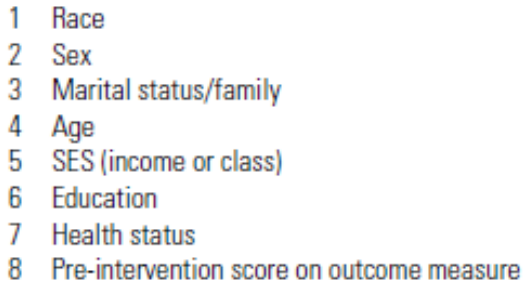

(02) If yes, indicate the percentage of relevant confounders that were controlled (either in the design (e.g. stratification, matching) or analysis)?

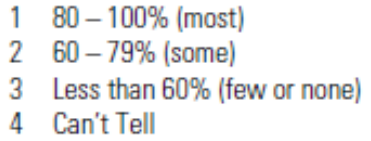

\begin{tabular}{|lccc|}
\hline RATE THIS SECTION & STRONG & MODERATE & WEAK \\
See dictionary & 1 & 2 & 3 \\
\hline
\end{tabular}

D) BLINDING

(01) Was (were) the outcome assessor(s) aware of the intervention or exposure status of participants?
1 Yes
2 No
3 Can't tell

(02) Were the study participants aware of the research question?
1 Yes
2 No
3 Can't tell

\begin{tabular}{|lccc|}
\hline RATE THIS SECTION & STRONG & MODERATE & WEAK \\
See dictionary & 1 & 2 & 3 \\
\hline
\end{tabular}

\section{E) DATA COLLECTION METHODS}

(01) Were data collection tools shown to be valid?
1 Yes
2 No
3 Can't tell

(02) Were data collection tools shown to be reliable?
1 Yes
2 No
3 Can't tell

\begin{tabular}{|lccc|}
\hline RATE THIS SECTION & STRONG & MODERATE & WEAK \\
See dictionary & 1 & 2 & 3 \\
\hline
\end{tabular}


(01) Were withdrawals and drop-outs reported in terms of numbers and/or reasons per group?

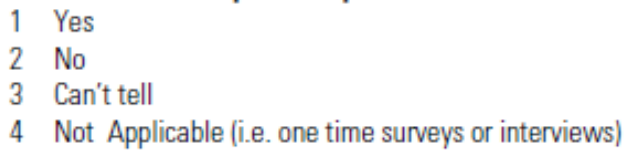

(02) Indicate the percentage of participants completing the study. (If the percentage differs by groups, record the lowest).

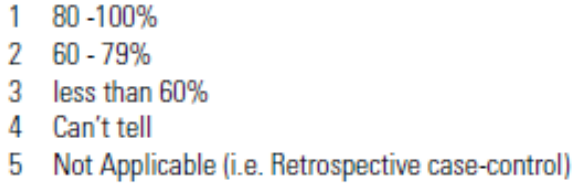

\begin{tabular}{|lcccc|}
\hline RATE THIS SECTION & STRONG & MODERATE & WEAK & \\
See dictionary & 1 & 2 & 3 & Not Applicable \\
\hline
\end{tabular}

\section{G) INTERVENTION INTEGRITY}

(01) What percentage of participants received the allocated intervention or exposure of interest?

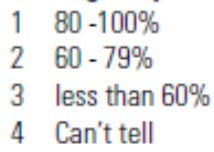

(02) Was the consistency of the intervention measured?

$$
\begin{array}{ll}
1 & \text { Yes } \\
2 & \text { No } \\
3 & \text { Can't tell }
\end{array}
$$

(03) Is it likely that subjects received an unintended intervention (contamination or co-intervention) that may influence the results?

$$
\begin{array}{ll}
4 & \text { Yes } \\
5 & \text { No } \\
6 & \text { Can't tell }
\end{array}
$$

\section{H) ANALYSES}

(01) Indicate the unit of allocation (circle one)

$$
\text { community organization/institution practice/office individual }
$$

(02) Indicate the unit of analysis (circle one)

$$
\text { community organization/institution practice/office individual }
$$

(03) Are the statistical methods appropriate for the study design?

$$
\begin{array}{ll}
1 & \text { Yes } \\
2 & \text { No } \\
3 & \text { Can't tell }
\end{array}
$$

(04) Is the analysis performed by intervention allocation status (i.e. intention to treat) rather than the actual intervention received?
1 Yes
2 No
3 Can't tell 
GLOBAL RATING

COMPONENT RATINGS

Please transcribe the information from the gray boxes on pages 1-4 onto this page. See dictionary on how to rate this section.

\begin{tabular}{|llccc|}
\hline A & SELECTION BIAS & STRONG & MODERATE & WEAK \\
\hline B & STUDY DESIGN & 1 & 2 & 3 \\
& & STRONG & MODERATE & WEAK \\
C & CONFOUNDERS & 1 & 2 & 3 \\
D & BLINDING & STRONG & MODERATE & WEAK \\
& & 1 & 2 & 3 \\
E & $\begin{array}{l}\text { DATA COLLECTION } \\
\text { METHOD }\end{array}$ & STRONG & MODERATE & WEAK \\
& & 1 & 2 & 3 \\
F & $\begin{array}{l}\text { WITHDRAWALS AND } \\
\text { DROPOUTS }\end{array}$ & STRONG & MODERATE & WEAK \\
& & 1 & 2 & 3 \\
\hline
\end{tabular}

GLOBAL RATING FOR THIS PAPER (circle one):

$\begin{array}{lll}1 & \text { STRONG } & \text { (no WEAK ratings) } \\ 2 & \text { MODERATE } & \text { (one WEAK rating) } \\ 3 & \text { WEAK } & \text { (two or more WEAK ratings) }\end{array}$

With both reviewers discussing the ratings:

Is there a discrepancy between the two reviewers with respect to the component $(\mathrm{A}-\mathrm{F})$ ratings?

No Yes

If yes, indicate the reason for the discrepancy
$1 \quad$ Oversight
2 Differences in interpretation of criteria
3 Differences in interpretation of study

$\begin{array}{lll}\text { Final decision of both reviewers (circle one): } & 1 & \text { STRONG } \\ & 2 & \text { MODERATE } \\ & 3 & \text { WEAK }\end{array}$

Effective Public Health Practice Project (EPHPP) (2010). Quality assessment tool for quantitative articles. Retrieved from http://www.ephpp.ca/tools.html 


\section{Appendix F: Quality Assessment Tool for Qualitative Studies: COREQ Checklist}

Table I Consolidated criteria for reporting qualitative studies (COREQ): 32-item checklist

\begin{tabular}{|c|c|}
\hline No Item & Guide questions/description \\
\hline \multicolumn{2}{|c|}{ Domain 1: Rescarch team and reflexivity } \\
\hline \multicolumn{2}{|c|}{ Personal Characteristics } \\
\hline 1. Interviewer/faditiator & Which author $/ \mathrm{s}$ conducted the interview or foas group? \\
\hline 2. Credentials & What were the researcher's credenrials? E.g. $P b D, M D$ \\
\hline 3. Occuparion & What was their occupation at the time of the study? \\
\hline 4. Gender & Was the researcher male or female? \\
\hline 5. Experience and training & What experience or training did the researcher have? \\
\hline \multicolumn{2}{|l|}{ Rdationship with participants } \\
\hline 6. Relationship established & Was a relationship established prior to study commencement? \\
\hline $\begin{array}{l}\text { 7. Participant knowledge of the } \\
\text { interviewer }\end{array}$ & $\begin{array}{l}\text { What did the participants know about the researcher? eg. persond goals, reasons for doing the } \\
\text { resear b }\end{array}$ \\
\hline 8. Interviewer characteristics & $\begin{array}{l}\text { What chanacteristics were reported about the interviewer/facilitator? } \mathrm{eg} \text {. Bias, awumptions, } \\
\text { reasons and intersts in the neseard topic }\end{array}$ \\
\hline \multicolumn{2}{|l|}{ Domain 2: study design } \\
\hline \multicolumn{2}{|c|}{ Theoretical framework } \\
\hline $\begin{array}{l}\text { 9. Methodological orientation and } \\
\text { Theory }\end{array}$ & 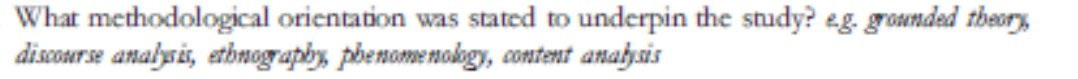 \\
\hline \multicolumn{2}{|l|}{ Partidipant selection } \\
\hline 10. Sampling & How were participants selected? eg. purperits, comenience, consecutits, mowball \\
\hline 11. Method of approadh & How were par ticipants approached? eg. face-to-fare, telepbons, mal', enal' \\
\hline 12. Sample size & How many participants were in the study? \\
\hline 13. Non-participarion & How many people refused to participare or dropped out? Reasons? \\
\hline \multicolumn{2}{|l|}{ Setring } \\
\hline 14. Serting of dara collection & Where was the dara collected? eg. bome, dinic, workplace \\
\hline 15. Presence of non-participants & Was anyone else present besides the participants and researchers? \\
\hline 16. Description of sample & What are the important characteristics of the sample? eg. demogrobic data, date \\
\hline \multicolumn{2}{|l|}{ Data collection } \\
\hline 17. Interview guide & Were questions, prompts, guides provided by the authors? Was it piloc tested? \\
\hline 18. Repeat interviews & Were repeat interviews car ried out? If yes, how many? \\
\hline 19. Audio/visual recording & Did the research use audio or visual recording to collect the data? \\
\hline 20. Field notes & Were field notes made during and/or after the interview or focus group? \\
\hline 21. Duration & What was the duration of the interviews or focus group? \\
\hline 22. Data saturation & Was data saruntion discussed? \\
\hline 23. Tenscripts returned & Were transcripts renurned to participants for comment and/or cor rection? \\
\hline \multicolumn{2}{|l|}{$\begin{array}{l}\text { Domain 3: analysis and findingsz } \\
\text { Dara analysis }\end{array}$} \\
\hline 24. Number of data coders & How many data coders coded the data? \\
\hline 25. Description of the coding tree & Did authors provide a description of the coding tree? \\
\hline 26. Derivation of themes & Were themes identified in advance or derived from the data? \\
\hline 27. Software & What softwate, if applicable, was used to manage the data? \\
\hline 28. Participant chedking & Did participants provide feedback on the findings? \\
\hline \multicolumn{2}{|l|}{ Reqorting } \\
\hline 29. Quotations presented & $\begin{array}{l}\text { Were participant quotations presented to illustate the themes / findings? Was each } \\
\text { quotation identified? e.g. partiajpant number }\end{array}$ \\
\hline 30. Data and findings consistent & Was there consistency between the data presented and the findings? \\
\hline 31. Clarity of major themes & Were major themes dearly presented in the findings? \\
\hline 32. Clarity of minor themes & Is there a description of diverse cases or discussion of minor themes? \\
\hline
\end{tabular}

Tong, A., Sainsbury, P., \& Craig, J. (2007). Consolidated criteria for reporting qualitative research (COREQ): a 32-item checklist for interviews and focus groups. International Journal for Quality in Health Care, 19(6), 349-357. 


\section{Appendix G: Excluded Articles}

\begin{tabular}{|l|l|}
\hline \multicolumn{1}{|c|}{ Author \& Title } & \multicolumn{1}{|c|}{ Reason for Exclusion } \\
\hline $\begin{array}{l}\text { Badger et al., 2004 } \\
\text { A case study of telephone interpersonal } \\
\text { counseling for women With breast cancer } \\
\text { and their partners. }\end{array}$ & Case study. \\
\hline $\begin{array}{l}\text { Badger et al., 2011 } \\
\text { Psychosocial interventions to improve } \\
\text { quality of life in prostate cancer survivors } \\
\text { and their intimate or family partners. }\end{array}$ & $\begin{array}{l}\text { Sample consists of caregivers and cancer } \\
\text { survivors. }\end{array}$ \\
\hline $\begin{array}{l}\text { Baucom et al., 2009 } \\
\text { A couple-based intervention for female } \\
\text { breast cancer. }\end{array}$ & Psych distress not an outcome. \\
\hline $\begin{array}{l}\text { Chambers et al., 2009 } \\
\text { Beating the blues after cancer: randomised } \\
\text { controlled trial of a tele-based } \\
\text { psychological intervention for } \\
\text { high distress patients and carers. }\end{array}$ & $\begin{array}{l}\text { Described the intervention only - did not evaluate } \\
\text { outcomes. }\end{array}$ \\
\hline $\begin{array}{l}\text { Choi, 2007 } \\
\text { The effect of music and muscle relaxation } \\
\text { on anxiety, fatigue, and quality of life in } \\
\text { family caregivers of hospice patients. }\end{array}$ & Thesis. \\
\hline $\begin{array}{l}\text { Creedle, et al., 2012 } \\
\text { The impact of education on caregiver } \\
\text { burden on two inpatient oncology units. }\end{array}$ & Psychological distress not an outcome. \\
\hline $\begin{array}{l}\text { Lambert et al., 2012 } \\
\text { A pilot randomized controlled trial of the } \\
\text { feasibility of a self-directed coping skills } \\
\text { intervention for couples facing prostate } \\
\text { cancer. }\end{array}$ & $\begin{array}{l}\text { Described the rationale and design of the } \\
\text { interventions, but did not evaluate outcomes. }\end{array}$ \\
\hline $\begin{array}{l}\text { Manne et al., 2005 } \\
\text { Couple-focused group intervention for } \\
\text { women with early stage breast cancer. }\end{array}$ & Only measured patient outcomes. \\
\hline $\begin{array}{l}\text { Northouse et al., 2010 } \\
\text { Interventions with family caregivers of } \\
\text { cancer patients meta-analysis of randomized } \\
\text { trials }\end{array}$ & Meta-analysis. \\
\hline $\begin{array}{l}\text { Pereira et al., 2012 } \\
\text { Anxiety, depression, traumatic stress and } \\
\text { quality of life in colorectal cancer after } \\
\text { different treatments: A study with }\end{array}$ & Intervention is not psychosocial. \\
\hline
\end{tabular}




\begin{tabular}{|l|l|}
\hline Portuguese patients and their partners. & \\
\hline $\begin{array}{l}\text { Shaw et al., 2012 } \\
\text { Family connect: A randomised controlled } \\
\text { for cancer carers. }\end{array}$ & Conference abstract. \\
\hline $\begin{array}{l}\text { Sherman et al., 2009 } \\
\text { Differences in Physical, Emotional, and } \\
\text { Social Adjustment of Intimate, Family, and } \\
\text { Nonfamily Patient-Partner Dyads Based on } \\
\text { a Breast Cancer Intervention Study }\end{array}$ & Intervention is not psychosocial. \\
\hline
\end{tabular}


Appendix H: Table of Included Studies

\begin{tabular}{|c|c|c|c|c|c|}
\hline \multicolumn{6}{|c|}{ Qualitative Article } \\
\hline $\begin{array}{c}\text { Author, Year } \\
\text { of } \\
\text { Publication } \\
\end{array}$ & $\begin{array}{c}\text { Study } \\
\text { characteristics }\end{array}$ & $\begin{array}{c}\text { Sample } \\
\text { characteristics }\end{array}$ & $\begin{array}{c}\text { Intervention } \\
\text { components }\end{array}$ & $\begin{array}{c}\text { Measurement } \\
\text { tool }\end{array}$ & $\begin{array}{l}\text { Findings related to } \\
\text { psychological distress }\end{array}$ \\
\hline $\begin{array}{l}\text { Arnaert et al., } \\
2010\end{array}$ & $\begin{array}{l}\text { Purpose: To } \\
\text { explore } \\
\text { the experiences of } \\
\text { cancer patients" } \\
\text { relatives who } \\
\text { attended a "Skills } \\
\text { for Healing Retreat } \\
\text { Weekend" } \\
\text { Study design: } \\
\text { Prospective } \\
\text { qualitative } \\
\text { explorative design } \\
\text { Quality rating: } \\
\text { Strong } \\
\text { Fidelity described: } \\
\text { No }\end{array}$ & $\begin{array}{l}\text { Caregiver sample size: } \\
8 \\
\text { Country: Canada } \\
\text { Setting: Clinic } \\
\text { Caregivers' average } \\
\text { age: } 53 \text { years } \\
\text { Caregiver sex: } 87.5 \% \\
\text { Female } \\
\text { Cancer type: } \\
\text { Varied (not specified) } \\
\text { Cancer stage: Ranged } \\
\text { from stage III to stage } \\
\text { IV } \\
\text { Caregiver type: } \\
\text { Family: } \\
\text { Included wife, partner, } \\
\text { niece, daughter and } \\
\text { close friend (did not } \\
\text { provide further details) }\end{array}$ & $\begin{array}{l}\text { Component: } \\
\text { Combined (psycho- } \\
\text { education, supportive, } \\
\text { and alternative } \\
\text { techniques) } \\
\text { Approach: Targeted } \\
\text { Mode: } \\
\text { Strategy: Face to face } \\
\text { Format: Group } \\
\text { Dose: } \\
\text { Amount: Unclear } \\
\text { Frequency: Delivered } \\
\text { once } \\
\text { Duration: Delivered } \\
\text { over } 2.5 \text { days }\end{array}$ & $\begin{array}{l}\text { (None) } \\
\text { Follow-up time: } \\
4 \text { weeks post- } \\
\text { retreat }\end{array}$ & $\begin{array}{l}\text { Theme: } \\
\text { "Beyond the retreat: } \\
\text { Enduring effects- } \\
\text { Emotional and spiritual } \\
\text { healing". } \\
\text { The intervention } \\
\text { contributed to a } \\
\text { process of emotional } \\
\text { and spiritual healing } \\
\text { for many of the } \\
\text { participants. }\end{array}$ \\
\hline \multicolumn{6}{|c|}{ Quantitative and Mixed Methods Articles } \\
\hline \multicolumn{6}{|c|}{ Studies yielding Significant Psychological Distress Findings } \\
\hline \multicolumn{6}{|c|}{ Strong Quality Rating } \\
\hline $\begin{array}{l}\text { Cameron et } \\
\text { al., } 2003\end{array}$ & $\begin{array}{l}\text { Purpose: To } \\
\text { evaluate a brief } \\
\text { problem-solving } \\
\text { intervention for }\end{array}$ & $\begin{array}{l}\text { Caregiver sample size: } \\
34 \\
\text { Country: Canada } \\
\text { Setting: Clinic }\end{array}$ & $\begin{array}{l}\text { Component: } \\
\text { Cognitive-behavioural } \\
\text { Approach: Targeted } \\
\text { Mode: }\end{array}$ & $\begin{array}{l}\text { Profile of Mood } \\
\text { States (POMS) } \\
\text { Follow-up time: }\end{array}$ & $\begin{array}{l}\text { Type of test: Paired t- } \\
\text { test } \\
\text { Statistical }\end{array}$ \\
\hline
\end{tabular}




\begin{tabular}{|c|c|c|c|c|c|}
\hline & $\begin{array}{l}\text { family caregivers to } \\
\text { individuals with } \\
\text { advanced cancer. } \\
\text { Study design: } \\
\text { Quantitative, Quasi- } \\
\text { experimental } \\
\text { Quality rating: } \\
\text { Strong } \\
\text { Fidelity described: } \\
\text { No } \\
\text { Psychological } \\
\text { distress outcomes: } \\
\text { Depression, } \\
\text { emotional tension } \\
\text { (anxiety) mood }\end{array}$ & $\begin{array}{l}\text { Caregivers' average } \\
\text { age : } 53.6 \text { years } \\
\text { Caregiver sex: } 68 \% \\
\text { Female } \\
\text { Cancer type: Varied } \\
\text { (GI, lung, and others) } \\
\text { Cancer stage: } \\
\text { Advanced } \\
\text { Caregiver type: } \\
\text { Family: } \\
\text { - Spouses }(73.5 \%) \\
\text { - Other (26.5\%) } \\
\text { Power analysis } \\
\text { calculation: No }\end{array}$ & $\begin{array}{l}\text { Strategy: Combined } \\
\text { (face-to-face, booklet, } \\
\text { presentation [either on } \\
\text { a laptop or flipchart]) } \\
\text { Format: one to one } \\
\text { Dose: } \\
\text { Amount: } 60 \text { minutes } \\
\text { Frequency: Delivered } \\
\text { once } \\
\text { Duration: Delivered in } \\
\text { one day }\end{array}$ & $\begin{array}{l}\text { Post-test } 4 \text { weeks } \\
\text { after receiving } \\
\text { the intervention }\end{array}$ & $\begin{array}{l}\text { significance reached? } \\
\text { Only emotional tension } \\
\text { (anxiety) reached } \\
\text { statistical significance } \\
(\mathrm{p}=0.024) \text {. } \\
\text { No significant } \\
\text { improvement was } \\
\text { observed in depression } \\
\text { and mood. }\end{array}$ \\
\hline $\begin{array}{l}\text { Northouse et } \\
\text { al., } 2007\end{array}$ & $\begin{array}{l}\text { Purpose: To } \\
\text { determine whether a } \\
\text { family-based } \\
\text { intervention } \\
\text { could improve } \\
\text { appraisal variables } \\
\text { (appraisal of illness } \\
\text { or caregiving, } \\
\text { uncertainty, } \\
\text { hopelessness), } \\
\text { coping resources } \\
\text { (coping strategies, } \\
\text { self-efficacy, } \\
\text { communication), } \\
\text { symptom distress, } \\
\text { and quality of life in } \\
\text { men with prostate }\end{array}$ & $\begin{array}{l}\text { Caregiver sample size: } \\
263 \\
\text { Country: US } \\
\text { Setting: Clinic } \\
\text { Caregivers' average } \\
\text { age : } 59 \text { years (SD=9.7) } \\
\text { Caregiver sex: } 100 \% \\
\text { Female } \\
\text { Cancer type: Prostate } \\
\text { Cancer stage: Varied- } \\
\text { did not specify } \\
\text { Caregiver type: } \\
\text { Partners (100\%) } \\
\text { Power analysis } \\
\text { calculation: No }\end{array}$ & $\begin{array}{l}\text { Component: } \\
\text { Combined (supportive, } \\
\text { educational) } \\
\text { Approach: Targeted } \\
\text { and tailored } \\
\text { Mode: } \\
\text { Strategy: Face to face, } \\
\text { phone } \\
\text { Format: Dyadic } \\
\text { Dose: } \\
\text { Amount: Average of } \\
66 \text { minutes } \\
\text { Frequency: Delivered } \\
\text { twice over a month } \\
\text { Duration: Delivered } \\
\text { over } 4 \text { months }\end{array}$ & $\begin{array}{l}\text { Beck } \\
\text { Hopelessness } \\
\text { Scale (BHS) } \\
\text { Follow-up time: } \\
\text { Follow-up at } 4 \\
\text { months, } \\
8 \text { months, and } \\
12 \text { months post- } \\
\text { intervention }\end{array}$ & $\begin{array}{l}\text { Type of test: Random } \\
\text { regression analysis } \\
\text { Statistical } \\
\text { significance reached? } \\
\text { Hopelessness reached } \\
\text { statistical significance } \\
\text { ( } \mathrm{p}=0.03 \text { ) at } 4 \text { months } \\
\text { follow-up only. }\end{array}$ \\
\hline
\end{tabular}




\begin{tabular}{|c|c|c|c|c|c|}
\hline & $\begin{array}{l}\text { cancer and their } \\
\text { spouses. } \\
\text { Study design: } \\
\text { Quantitative, RCT } \\
\text { Quality rating: } \\
\text { Strong } \\
\text { Fidelity described: } \\
\text { Yes } \\
\text { Psychological } \\
\text { distress outcomes: } \\
\text { Hopelessness }\end{array}$ & & & & \\
\hline \multicolumn{6}{|c|}{ Moderate Quality Rating } \\
\hline $\begin{array}{l}\text { Lai, Li \& Lee, } \\
2011\end{array}$ & $\begin{array}{l}\text { Purpose: To } \\
\text { compare the effects } \\
\text { of music } \\
\text { intervention with } \\
\text { nursing presence } \\
\text { and recorded music } \\
\text { on blood volume } \\
\text { pulse amplitude, the } \\
\text { low/high frequency } \\
\text { ratio component of } \\
\text { heart rate } \\
\text { variability, } \\
\text { depression, anxiety } \\
\text { and sleep quality in } \\
\text { cancer patient } \\
\text { caregivers; and to } \\
\text { compare the } \\
\text { participants } \\
\text { evaluation of these } \\
\text { two forms of }\end{array}$ & $\begin{array}{l}\text { Caregiver sample size: } \\
34 \\
\text { Country: Taiwan } \\
\text { Setting: Home } \\
\text { Caregivers' average } \\
\text { age : } 44.9 \text { years } \\
\text { (SD=9.03) } \\
\text { Caregiver sex: } \\
\text { Cancer type: Varied- } \\
\text { GU, GI, head and neck, } \\
\text { lung } \\
\text { Cancer stage: Varied- } \\
\text { Stage II, stage I, and } \\
\text { stage III } \\
\text { Caregiver type: } \\
\text { Family: } \\
\text { - Spouse (38.2\%) } \\
\text { - Parent }(38.2 \%) \\
\text { - Child (23.5\%) } \\
\text { Power analysis }\end{array}$ & $\begin{array}{l}\text { Component: } \\
\text { Alternative (music) } \\
\text { Approach: Targeted } \\
\text { Mode: } \\
\text { Strategy: Combined } \\
\text { (face to face, music } \\
\text { audiofile) } \\
\text { Format: one to one } \\
\text { Dose: } \\
\text { Amount: } 30 \text { minutes } \\
\text { Frequency: } 1 \text { time } \\
\text { Duration: } 1 \text { day }\end{array}$ & $\begin{array}{l}\text { Taiwanese } \\
\text { Depression Scale } \\
\text { State-Trait } \\
\text { Anxiety } \\
\text { Inventory (STAI) } \\
\text { Follow-up time: } \\
\text { Post-test } \\
\text { following the } \\
\text { intervention }\end{array}$ & $\begin{array}{l}\text { Type of test: } \\
\text { Wilcoxon rank signed } \\
\text { test and Friedman test } \\
\text { Statistical } \\
\text { significance reached? } \\
\text { Anxiety }(\mathrm{p}<0.001) \text { and } \\
\text { depression }(\mathrm{p}<0.001) \\
\text { scores both reached } \\
\text { statistical significance. }\end{array}$ \\
\hline
\end{tabular}




\begin{tabular}{|c|c|c|c|c|c|}
\hline & $\begin{array}{l}\text { musical } \\
\text { interventions. } \\
\text { Study design: } \\
\text { Quantitative, RCT } \\
\text { Quality rating: } \\
\text { Moderate } \\
\text { Fidelity described: } \\
\text { No } \\
\text { Psychological } \\
\text { distress outcomes: } \\
\text { Anxiety, depression }\end{array}$ & calculation: Yes & & & \\
\hline $\begin{array}{l}\text { Lewis et al., } \\
2008\end{array}$ & $\begin{array}{l}\text { Purpose: The } \\
\text { purpose of this pilot } \\
\text { study was to } \\
\text { evaluate the short- } \\
\text { term impact of a 5- } \\
\text { session, } \\
\text { clinic-based, } \\
\text { educational } \\
\text { counseling } \\
\text { intervention for } \\
\text { spouses whose wife } \\
\text { was recently } \\
\text { diagnosed } \\
\text { with early stage } \\
\text { breast cancer. } \\
\text { Study design: } \\
\text { Mixed methods } \\
\text { Quality rating: } \\
\text { Moderate } \\
\text { Fidelity described: } \\
\text { Yes } \\
\text { Psychological }\end{array}$ & $\begin{array}{l}\text { Caregiver sample size: } \\
20 \\
\text { Country: US } \\
\text { Setting: Clinic } \\
\text { Caregivers' average } \\
\text { age : } 54 \text { years (SD= } \\
9.5) \\
\text { Caregiver sex: } 100 \% \\
\text { Male } \\
\text { Cancer type: Breast } \\
\text { Cancer stage: Early } \\
\text { Caregiver type: } \\
\text { Partners (100\%) } \\
\text { Power analysis } \\
\text { calculation: No }\end{array}$ & $\begin{array}{l}\text { Component: } \\
\text { Combined (supportive, } \\
\text { educational) } \\
\text { Approach: targeted } \\
\text { Mode: } \\
\text { Strategy: face to face } \\
\text { Format: one to one } \\
\text { Dose: } \\
\text { Amount: } 60 \text { minutes } \\
\text { Frequency: } 2 \text { times } \\
\text { over a month } \\
\text { Duration: Delivered } \\
\text { over } 10 \text { weeks ( } 70 \\
\text { days) }\end{array}$ & $\begin{array}{l}\text { Center for } \\
\text { Epidemiological } \\
\text { Studies- } \\
\text { Depression Scale } \\
\text { (CES-D) } \\
\text { State-Trait } \\
\text { Anxiety Scale } \\
\text { (STAI-Y) } \\
\text { Follow-up time: } \\
\text { Post-test at exit } \\
\text { from program }\end{array}$ & $\begin{array}{l}\text { Type of test: } \\
\text { Wilcoxon rank signed } \\
\text { test } \\
\text { Statistical } \\
\text { significance reached? } \\
\text { Depressed mood } \\
(\mathrm{p}=0.001) \text { and anxiety } \\
((\mathrm{p}<0.001)) \text { both } \\
\text { reached statistical } \\
\text { significance. }\end{array}$ \\
\hline
\end{tabular}




\begin{tabular}{|c|c|c|c|c|c|}
\hline & $\begin{array}{l}\text { distress outcome: } \\
\text { Anxiety, depression }\end{array}$ & & & & \\
\hline $\begin{array}{l}\text { McLean et al., } \\
2008\end{array}$ & $\begin{array}{l}\text { Purpose: To } \\
\text { evaluate the } \\
\text { electiveness of a } \\
\text { couples } \\
\text { intervention in } \\
\text { improving marital } \\
\text { functioning in } \\
\text { advanced cancer } \\
\text { patients and their } \\
\text { spouse } \\
\text { caregivers. A } \\
\text { secondary objective } \\
\text { was to determine its } \\
\text { impact on other } \\
\text { symptoms of } \\
\text { psychosocial } \\
\text { distress and its } \\
\text { feasibility and } \\
\text { acceptability as a } \\
\text { clinical intervention. } \\
\text { Study design: } \\
\text { Quantitative, quasi- } \\
\text { experimental } \\
\text { Quality rating: } \\
\text { Moderate } \\
\text { Fidelity described: } \\
\text { Yes } \\
\text { Psychological } \\
\text { distress outcomes: } \\
\text { Depressive } \\
\text { symptoms, }\end{array}$ & $\begin{array}{l}\text { Caregiver sample size: } \\
16 \\
\text { Country: Canada } \\
\text { Setting: Clinic } \\
\text { Caregivers' average } \\
\text { age : } 48.1 \text { years } \\
\text { (SD=11.65) } \\
\text { Caregiver sex: } 56.25 \% \\
\text { Males } \\
\text { Cancer type: Varied- } \\
\text { Breast, head and neck, } \\
\text { leukemia, GI, } \\
\text { Gynecology } \\
\text { Cancer stage: } \\
\text { Advanced } \\
\text { Caregiver type: } \\
\text { Partner (100\%) } \\
\text { Power analysis } \\
\text { calculation: No }\end{array}$ & $\begin{array}{l}\text { Component: Unclear } \\
\text { Approach: Not } \\
\text { described } \\
\text { Mode: } \\
\text { Strategy: Face to face } \\
\text { Format: Dyadic } \\
\text { Dose: } \\
\text { Amount: Not } \\
\text { described } \\
\text { Frequency: average } \\
\text { number of sessions } \\
\text { delivered was } 11.56 \\
\text { sessions, but unclear } \\
\text { how many were } \\
\text { delivered per month. } \\
\text { Duration: Delivered } \\
\text { over two months }\end{array}$ & $\begin{array}{l}\text { Beck Depression } \\
\text { Inventory-II } \\
\text { (BDI-II] } \\
\text { Beck } \\
\text { Hopelessness } \\
\text { Scale } \\
\text { Follow-up time: } \\
\text { Post-test after } 4 \\
\text { sessions, } \\
8 \text { sessions, and } \\
3 \text { months post- } \\
\text { intervention }\end{array}$ & $\begin{array}{l}\text { Type of test: ANOVA } \\
\text { Statistical } \\
\text { significance reached? } \\
\text { Significance was } \\
\text { observed in depression } \\
\text { symptomology } \\
\text { (p=0.0454) at } 3 \text { months } \\
\text { post-intervention. } \\
\text { No significant } \\
\text { improvement was } \\
\text { observed in } \\
\text { hopelessness. }\end{array}$ \\
\hline
\end{tabular}




\begin{tabular}{|c|c|c|c|c|c|}
\hline & hopelessness & & & & \\
\hline $\begin{array}{l}\text { Porter et al, } \\
2011\end{array}$ & $\begin{array}{l}\text { Purpose: To test the } \\
\text { efficacy of a } \\
\text { caregiver-assisted } \\
\text { CST protocol in } \\
\text { a sample of patients } \\
\text { with lung cancer. } \\
\text { Study design: } \\
\text { Quantitative, RCT } \\
\text { Quality rating: } \\
\text { Moderate } \\
\text { Fidelity described: } \\
\text { Yes } \\
\text { Psychological } \\
\text { distress outcomes: } \\
\text { anxiety and } \\
\text { depression (using a } \\
\text { mood scoring tool } \\
\text { with anxiety and } \\
\text { depression } \\
\text { subscales) }\end{array}$ & $\begin{array}{l}\text { Caregiver sample size: } \\
233 \\
\text { Country: US } \\
\text { Setting: Community } \\
\text { oncology clinic } \\
\text { Caregivers' average } \\
\text { age : } 59.3 \text { (SD= } 12.3 \text { ) } \\
\text { Caregiver sex: } 52.8 \% \\
\text { Male } \\
\text { Cancer type: Lung } \\
\text { Cancer stage: Varied- } \\
\text { stage I, stage III, and } \\
\text { stage II } \\
\text { Caregiver type: } \\
\text { Family } \\
\text { - Spouse (76\%) } \\
\text { - Adult children } \\
\text { (14\%) } \\
\text { Siblings or Friends } \\
\quad(8 \%) \\
\text { Power analysis } \\
\text { calculation: No }\end{array}$ & $\begin{array}{l}\text { Component: } \\
\text { Combined (Cognitive } \\
\text { behavioural, } \\
\text { educational) } \\
\text { Approach: Tailored } \\
\text { Mode: } \\
\text { Strategy: Combined } \\
\text { (Telephone, audiotape, } \\
\text { handout) } \\
\text { Format: Dyadic } \\
\text { Dose: } \\
\text { Amount: } 45 \text { minutes } \\
\text { Frequency: Ranges } \\
\text { from weekly to } \\
\text { monthly. Average: bi- } \\
\text { weekly contact } \\
\text { Duration: Delivered } \\
\text { over eight months. }\end{array}$ & $\begin{array}{l}\text { Profile of Mood } \\
\text { States-B (POMS- } \\
\text { B) } \\
\text { Follow-up time: } \\
\text { Post-treatment } \\
\text { (immediately } \\
\text { after) and } \\
4 \text { months post- } \\
\text { treatment }\end{array}$ & $\begin{array}{l}\text { Type of test: } \\
\text { Hierarchical linear } \\
\text { modeling } \\
\text { Statistical } \\
\text { significance reached? } \\
\text { Significance was } \\
\text { observed in anxiety } \\
\text { (p=0.02) at } 4 \text { months } \\
\text { follow-up. } \\
\text { No significant } \\
\text { improvement was } \\
\text { observed in depression }\end{array}$ \\
\hline $\begin{array}{l}\text { Walsh et al, } \\
2007 b\end{array}$ & $\begin{array}{l}\text { Purpose: To test the } \\
\text { effects of an art- } \\
\text { making class } \\
\text { (AMC) } \\
\text { on reducing anxiety } \\
\text { and stress among } \\
\text { family caregivers of } \\
\text { patients with } \\
\text { cancer. } \\
\text { Study design: }\end{array}$ & $\begin{array}{l}\text { Caregiver sample size: } \\
69 \\
\text { Country: US } \\
\text { Setting: Hospitals, } \\
\text { residential facility } \\
\text { Caregivers' average } \\
\text { age : } 48 \text { years (SD= } \\
14.47) \\
\text { Caregiver sex: } 80 \% \\
\text { Female }\end{array}$ & $\begin{array}{l}\text { Component: } \\
\text { Alternative (Art- } \\
\text { making) } \\
\text { Approach: Targeted } \\
\text { Mode: } \\
\text { Strategy: Face to face } \\
\text { Format: One to one } \\
\text { Dose: } \\
\text { Amount: } 2 \text { hours } \\
\text { Frequency: twice a }\end{array}$ & $\begin{array}{l}\text { Beck Anxiety } \\
\text { Inventory (BAI) } \\
\text { Salivary Cortisol } \\
\text { (stress) } \\
\text { Follow-up time: } \\
\text { Post-treatment } \\
\text { (Not specified) }\end{array}$ & $\begin{array}{l}\text { Type of test: Paired t- } \\
\text { test and chi-square } \\
\text { analysis } \\
\text { Statistical } \\
\text { significance reached? } \\
\text { A statistically } \\
\text { significant decline in } \\
\text { anxiety was observed. }\end{array}$ \\
\hline
\end{tabular}




\begin{tabular}{|c|c|c|c|c|c|}
\hline & $\begin{array}{l}\text { Quantitative, quasi- } \\
\text { experimental } \\
\text { Quality rating: } \\
\text { Moderate } \\
\text { Fidelity described: } \\
\text { No } \\
\text { Psychological } \\
\text { distress outcomes: } \\
\text { Anxiety, stress }\end{array}$ & $\begin{array}{l}\text { Cancer type: Not } \\
\text { specified } \\
\text { Cancer stage: Not } \\
\text { specified } \\
\text { Caregiver type: } \\
\text { Family } \\
\text { - Adult daughter } \\
\quad(28 \%) \\
\text { - Wife }(23 \%) \\
\text { - mother }(16 \%) \\
\text { - other }(33 \%) \\
\text { Power analysis } \\
\text { calculation: No }\end{array}$ & $\begin{array}{l}\text { week (unclear) } \\
\text { Duration: Not } \\
\text { described }\end{array}$ & & $\begin{array}{l}\text { No significant } \\
\text { improvement was } \\
\text { observed in stress. }\end{array}$ \\
\hline \multicolumn{6}{|c|}{ Weak Quality Rating } \\
\hline $\begin{array}{l}\text { Birnie, } \\
\text { Garland \& } \\
\text { Carlson, } 2009\end{array}$ & $\begin{array}{l}\text { Purpose: To } \\
\text { examine the impact } \\
\text { of an 8-week MBSR } \\
\text { program for } 21 \\
\text { couples who } \\
\text { attended the } \\
\text { program together on } \\
\text { outcomes of mood } \\
\text { disturbance, } \\
\text { symptoms of stress, } \\
\text { and mindfulness. } \\
\text { Study design: } \\
\text { Quantitative, Quasi- } \\
\text { experimental } \\
\text { Quality rating: } \\
\text { Weak } \\
\text { Fidelity described: } \\
\text { No } \\
\text { Psychological }\end{array}$ & $\begin{array}{l}\text { Caregiver sample size: } \\
21 \\
\text { Country: Canada } \\
\text { Setting: Outpatient } \\
\text { cancer center } \\
\text { Caregivers' average } \\
\text { age : } 54 \text { years (SD= } \\
9.5) \\
\text { Caregiver sex: } 52.4 \% \\
\text { Male } \\
\text { Cancer type: Varied- } \\
\text { prostate, breast, and } \\
\text { colorectal } \\
\text { Cancer stage: Not } \\
\text { reported } \\
\text { Caregiver type: } \\
\text { Partners (100\%) } \\
\text { Power analysis } \\
\text { calculation: No }\end{array}$ & $\begin{array}{l}\text { Component: } \\
\text { Combined } \\
\text { (Educational, } \\
\text { cognitive-behavioural, } \\
\text { supportive) } \\
\text { Approach: Targeted } \\
\text { Mode: } \\
\text { Strategy: Combined } \\
\text { (face to face, } \\
\text { audiotape, booklet) } \\
\text { Format: Group } \\
\text { sessions } \\
\text { Dose: } \\
\text { Amount: } 8 \text { sessions } \\
\text { were } 90 \text { minutes; } 1 \\
\text { retreat was } 3 \text { hours } \\
\text { Frequency: Delivered } \\
4 \text { times over a month } \\
\text { Duration: } 2 \text { months }\end{array}$ & $\begin{array}{l}\text { Profile of Mood } \\
\text { States (POMS) } \\
\text { Calgary } \\
\text { Symptoms of } \\
\text { Stress Inventory } \\
\text { (C-SOSI) } \\
\text { Follow-up time: } \\
1 \text { post-test done } \\
\text { within two weeks } \\
\text { of completing the } \\
\text { intervention }\end{array}$ & $\begin{array}{l}\text { Type of test: ANOVA } \\
\text { Statistical } \\
\text { significance reached? } \\
\text { Anxiety ( } \mathrm{p}=0.01) \text { and } \\
\text { total mood score } \\
(\mathrm{p}=0.04) \text { reached } \\
\text { statistical significance. } \\
\text { No significant } \\
\text { improvement was } \\
\text { observed in depression. }\end{array}$ \\
\hline
\end{tabular}




\begin{tabular}{|c|c|c|c|c|c|}
\hline & $\begin{array}{l}\text { distress outcomes: } \\
\text { Mood, anxiety, } \\
\text { depression }\end{array}$ & & & & \\
\hline $\begin{array}{l}\text { Rexilius et al., } \\
2002\end{array}$ & $\begin{array}{l}\text { Purpose: To } \\
\text { examine the effect } \\
\text { of massage } \\
\text { therapy and Healing } \\
\text { Touch on anxiety, } \\
\text { depression, } \\
\text { subjective } \\
\text { caregiver burden, } \\
\text { and fatigue } \\
\text { experienced by } \\
\text { caregivers of } \\
\text { patients undergoing } \\
\text { autologous } \\
\text { hematopoietic } \\
\text { stem cell transplant. } \\
\text { Study design: } \\
\text { Quantitative, Quasi- } \\
\text { experimental } \\
\text { Quality rating: } \\
\text { Weak } \\
\text { Fidelity described: } \\
\text { No } \\
\text { Psychological } \\
\text { distress outcomes: } \\
\text { Anxiety, depression }\end{array}$ & $\begin{array}{l}\text { Caregiver sample size: } \\
36 \\
\text { Country: US } \\
\text { Setting: Outpatient } \\
\text { clinic } \\
\text { Caregivers' average } \\
\text { age: } 51.5 \text { years } \\
\text { Caregiver sex: } 72 \% \\
\text { Female } \\
\text { Cancer type: Not } \\
\text { specified } \\
\text { Cancer stage: Varied } \\
\text { (not specified) } \\
\text { Caregiver type: } \\
\text { Family } \\
\text { - Spouse/fiancé- } \\
\text { (72\%) } \\
\text { - Sister (17\%) } \\
\text { Power analysis } \\
\text { calculation: Yes }\end{array}$ & $\begin{array}{l}\text { Component: } \\
\text { Alternative (massage/ } \\
\text { healing touch) } \\
\text { Approach: Targeted } \\
\text { Mode: } \\
\text { Strategy: Face to face } \\
\text { Format: One to one } \\
\text { Dose: } \\
\text { Amount: } 30 \text { minutes } \\
\text { Frequency: } 6 \text { sessions } \\
\text { Duration: Delivered } \\
\text { over } 3 \text { weeks }\end{array}$ & $\begin{array}{l}\text { Beck Anxiety } \\
\text { Inventory (BAI) } \\
\text { Center for } \\
\text { Epidemiological } \\
\text { Studies- } \\
\text { Depression Scale } \\
\text { (CES-D) } \\
\text { Follow-up time: } \\
\text { Post-intervention } \\
\text { (not specified) }\end{array}$ & $\begin{array}{l}\text { Type of test: } \\
\text { ANCOVA and } \\
\text { ANOVA } \\
\text { Statistical } \\
\text { significance reached? } \\
\text { Significant decline in } \\
\text { anxiety }(\mathrm{p}<0.05) \text { and } \\
\text { depression }(\mathrm{p}<0.05) \\
\text { were observed in the } \\
\text { Massage intervention } \\
\text { group, but not in the } \\
\text { Healing Touch } \\
\text { intervention group. }\end{array}$ \\
\hline $\begin{array}{l}\text { Walsh, Martin } \\
\text { \& Schmidt, } \\
2004\end{array}$ & $\begin{array}{l}\text { Purpose: To test the } \\
\text { efficacy of a } \\
\text { creative-arts } \\
\text { intervention with }\end{array}$ & $\begin{array}{l}\text { Caregiver sample size: } \\
40 \\
\text { Country: US } \\
\text { Setting: Inpatient and }\end{array}$ & $\begin{array}{l}\text { Component: } \\
\text { Alternative (Creative } \\
\text { arts intervention) } \\
\text { Approach: Targeted }\end{array}$ & $\begin{array}{l}\text { Mini-Profile of } \\
\text { Mood States } \\
\text { (Mini-POMS) }\end{array}$ & $\begin{array}{l}\text { Type of test: Paired } \\
\text { samples t-test } \\
\text { Statistical }\end{array}$ \\
\hline
\end{tabular}




\begin{tabular}{|c|c|c|c|c|c|}
\hline & $\begin{array}{l}\text { family caregivers of } \\
\text { patients with cancer } \\
\text { Study design: } \\
\text { Quantitative, quasi- } \\
\text { experimental } \\
\text { Quality rating: } \\
\text { Weak } \\
\text { Fidelity described: } \\
\text { No } \\
\text { Psychological } \\
\text { distress outcomes: } \\
\text { Mood, anxiety, } \\
\text { affect (negative } \\
\text { emotion) }\end{array}$ & $\begin{array}{l}\text { outpatient } \\
\text { Caregivers' average } \\
\text { age : } 51.43 \text { years } \\
\text { (SD=15.38) } \\
\text { Caregiver sex: } 75 \% \\
\text { Females } \\
\text { Cancer type: Varied- } \\
\text { (not specified) } \\
\text { Cancer stage: Not } \\
\text { described } \\
\text { Caregiver type: } \\
\text { Family } \\
\text { - Spouses (70\%) } \\
\text { - Other (30\%) } \\
\text { Power analysis } \\
\text { calculation: No }\end{array}$ & $\begin{array}{l}\text { Mode: } \\
\text { Strategy: Face to face } \\
\text { Format: One to one } \\
\text { Dose: } \\
\text { Amount: Not } \\
\text { described } \\
\text { Frequency: Not } \\
\text { described } \\
\text { Duration: Not } \\
\text { described }\end{array}$ & $\begin{array}{l}\text { Beck Anxiety } \\
\text { Inventory (BAI) } \\
\text { Derogatis Affects } \\
\text { Balance Scale } \\
\text { Follow-up time: } \\
\text { Post-intervention } \\
\text { (Not specified) }\end{array}$ & $\begin{array}{l}\text { significance reached? } \\
\text { Anxiety }(\mathrm{p}<0.001) \\
\text { mood }(\mathrm{p}=0.001) \text { and } \\
\text { negative emotion } \\
(\mathrm{p}<0.001) \text { reached } \\
\text { statistical significance. }\end{array}$ \\
\hline \multicolumn{6}{|c|}{ Studies yielding Non-Significant Psychological Distress Findings } \\
\hline \multicolumn{6}{|c|}{ Strong Quality Rating } \\
\hline $\begin{array}{l}\text { McLean et al., } \\
2013\end{array}$ & $\begin{array}{l}\text { Purpose: To } \\
\text { evaluate the effect } \\
\text { of Emotionally } \\
\text { Focused Therapy } \\
\text { (EFT), modified for } \\
\text { the advanced cancer } \\
\text { population versus } \\
\text { standard care, on } \\
\text { marital functioning } \\
\text { and psychosocial } \\
\text { outcomes among } \\
\text { distressed couples }\end{array}$ & $\begin{array}{l}\text { Caregiver sample size: } \\
42 \\
\text { Country: Canada } \\
\text { Setting: Clinical } \\
\text { outpatient clinics } \\
\text { Caregivers' average } \\
\text { age : } 49.86 \text { years (SD= } \\
11.33 \text { ) } \\
\text { Caregiver sex: } 54.8 \% \\
\text { Male } \\
\text { Cancer type: Varied- } \\
\text { Blood, gynecology, }\end{array}$ & $\begin{array}{l}\text { Component: } \\
\text { Combined (Cognitive } \\
\text { behavioural, psycho- } \\
\text { educational) } \\
\text { Approach: Targeted } \\
\text { Mode: } \\
\text { Strategy: Face to face } \\
\text { Format: Dyadic } \\
\text { Dose: } \\
\text { Amount: } 60 \text { minutes } \\
\text { Frequency: Delivered } \\
\text { times over a month }\end{array}$ & $\begin{array}{l}\text { Beck Depression } \\
\text { Inventory-II } \\
\text { (BDI-II) } \\
\text { Beck } \\
\text { Hopelessness } \\
\text { Scale (BHS) } \\
\text { Follow-up time: } \\
\text { Post-intervention } \\
\text { (at the end of the } \\
\text { intervention) and }\end{array}$ & $\begin{array}{l}\text { Type of test: } \\
\text { ANCOVA } \\
\text { Statistical } \\
\text { significance reached? } \\
\text { No significant } \\
\text { improvement was } \\
\text { observed in depressive } \\
\text { symptomology or } \\
\text { hopelessness. }\end{array}$ \\
\hline
\end{tabular}




\begin{tabular}{|c|c|c|c|c|c|}
\hline & $\begin{array}{l}\text { Study design: } \\
\text { Quantitative, RCT } \\
\text { Quality rating: } \\
\text { Strong } \\
\text { Fidelity described: } \\
\text { Yes } \\
\text { Psychological } \\
\text { distress outcomes: } \\
\text { Depressive } \\
\text { symptoms, } \\
\text { hopelessness }\end{array}$ & $\begin{array}{l}\text { head and neck, breast, } \\
\text { lung, GU } \\
\text { Cancer stage: } \\
\text { Advanced } \\
\text { Caregiver type: } \\
\text { Partner (100\%) } \\
\text { Power analysis } \\
\text { calculation: Yes }\end{array}$ & $\begin{array}{l}\text { Duration: Delivered } \\
\text { over two months }\end{array}$ & $\begin{array}{l}\text { Three months } \\
\text { post-intervention }\end{array}$ & \\
\hline $\begin{array}{l}\text { Northouse et } \\
\text { al., } 2005\end{array}$ & $\begin{array}{l}\text { Purpose: The } \\
\text { purpose of this } \\
\text { study was to } \\
\text { determine if patients } \\
\text { with advanced } \\
\text { breast cancer and } \\
\text { their family } \\
\text { caregivers, who } \\
\text { participated in a } \\
\text { family based } \\
\text { intervention, report } \\
\text { better quality of life } \\
\text { and other } \\
\text { psychosocial } \\
\text { outcomes than } \\
\text { dyads who received } \\
\text { standard care alone } \\
\text { Study design: } \\
\text { Quantitative, RCT } \\
\text { Quality rating: } \\
\text { Strong }\end{array}$ & $\begin{array}{l}\text { Caregiver sample size: } \\
134 \\
\text { Country: US } \\
\text { Setting: Clinic } \\
\text { Caregivers' average } \\
\text { age: } 52 \text { years (SD=14) } \\
\text { Caregiver sex: not } \\
\text { reported } \\
\text { Cancer type: Breast } \\
\text { Cancer stage: } \\
\text { Advanced } \\
\text { Caregiver type: } \\
\text { Family } \\
\text { - Husbands (62\%) } \\
\text { - Adult child (16\%) } \\
\text { - Relative/Friend } \\
\text { - (13\%) } \\
\text { Power analysis } \\
\text { calculation: Not } \\
\text { described }\end{array}$ & $\begin{array}{l}\text { Component: } \\
\text { Combined } \\
\text { (information and } \\
\text { support) } \\
\text { Approach: Targeted } \\
\text { and Tailored } \\
\text { Mode: } \\
\text { Strategy: Combined } \\
\text { (face to face, } \\
\text { telephone) } \\
\text { Format: Dyadic } \\
\text { Dose: } \\
\text { Amount: Average } \\
\text { session was } 60 \\
\text { minutes } \\
\text { Frequency: Unclear } \\
\text { Duration: Unclear } \\
\text { Three home visits } \\
\text { spaced one month } \\
\text { apart, and two phone } \\
\text { calls. }\end{array}$ & $\begin{array}{l}\text { Beck } \\
\text { Hopelessness } \\
\text { Scale (BHS) } \\
\text { Follow-up time: } \\
3 \text { months (end of } \\
\text { home visits) and } \\
6 \text { months after } \\
\text { baseline (after } \\
\text { booster sessions } \\
\text { on exit from the } \\
\text { intervention) }\end{array}$ & $\begin{array}{l}\text { Type of test: ANOVA } \\
\text { Statistical } \\
\text { significance reached? } \\
\text { No significant } \\
\text { improvement was } \\
\text { observed in } \\
\text { hopelessness. }\end{array}$ \\
\hline
\end{tabular}




\begin{tabular}{|c|c|c|c|c|c|}
\hline & $\begin{array}{l}\text { Fidelity described: } \\
\text { Yes } \\
\text { Psychological } \\
\text { distress outcomes: } \\
\text { Hopelessness }\end{array}$ & & & & \\
\hline $\begin{array}{l}\text { Scott, Halford } \\
\text { \& Ward, } 2004\end{array}$ & $\begin{array}{l}\text { Purpose: To } \\
\text { evaluate the effects } \\
\text { of a couple-coping } \\
\text { training on } \\
\text { adjustment to } \\
\text { cancer. } \\
\text { Study design: } \\
\text { Quantitative, quasi- } \\
\text { experimental } \\
\text { Quality rating: } \\
\text { Strong } \\
\text { Fidelity described: } \\
\text { Yes } \\
\text { Psychological } \\
\text { distress outcomes: } \\
\text { Psychological } \\
\text { distress }\end{array}$ & $\begin{array}{l}\text { Caregiver sample size: } \\
94 \\
\text { Country: Australia } \\
\text { Setting: Clinic } \\
\text { Caregivers' average } \\
\text { age : } 53 \text { years (SD=10) } \\
\text { Caregiver sex: } 100 \% \\
\text { Male } \\
\text { Cancer type: Breast or } \\
\text { gynecological } \\
\text { Cancer stage: Early } \\
\text { Caregiver type: } \\
\text { Partner (100\%) } \\
\text { Power analysis } \\
\text { calculation: Not } \\
\text { described }\end{array}$ & $\begin{array}{l}\text { Component: } \\
\text { Combined } \\
\text { (educational, cognitive } \\
\text { behavioural, } \\
\text { supportive) } \\
\text { Approach: Targeted } \\
\text { Mode: } \\
\text { Strategy: Combined } \\
\text { (face to face, } \\
\text { telephone) } \\
\text { Format: Dyadic } \\
\text { Dose: } \\
\text { Amount: Ranged from } \\
30 \text { minutes to } 2 \text { hours } \\
\text { Frequency: Varied- } \\
\text { On average, about } \\
\text { once a month; ranged } \\
\text { up to } 5 \text { times in a } \\
\text { month } \\
\text { Duration: Delivered } \\
\text { over } 6 \text { months }\end{array}$ & $\begin{array}{l}\text { Psychosocial } \\
\text { Adjustment } \\
\text { to Illness Scale-- } \\
\text { Self Report } \\
\text { Follow-up time: } \\
\text { Post-intervention } \\
\text { (not specified), } \\
6 \text { months follow- } \\
\text { up and } 12 \\
\text { months follow- } \\
\text { up }\end{array}$ & $\begin{array}{l}\text { Type of test: } \\
\text { ANCOVA } \\
\text { Statistical } \\
\text { significance reached? } \\
\text { No significant } \\
\text { improvement was } \\
\text { observed in } \\
\text { psychological distress. }\end{array}$ \\
\hline $\begin{array}{l}\text { Walsh \& } \\
\text { Schmidt, } \\
2003\end{array}$ & $\begin{array}{l}\text { Purpose: To } \\
\text { determine the } \\
\text { feasibility of } \\
\text { conducting a brief } \\
\text { telephone }\end{array}$ & $\begin{array}{l}\text { Caregiver sample size: } \\
9 \\
\text { Country: US } \\
\text { Setting: Hospice (home } \\
\text { care) }\end{array}$ & $\begin{array}{l}\text { Component: } \\
\text { Educational } \\
\text { Approach: Targeted } \\
\text { Mode: } \\
\text { Strategy: Combined }\end{array}$ & $\begin{array}{l}\text { Center for } \\
\text { Epidemiological } \\
\text { Studies- } \\
\text { Depression } \\
\text { instrument }\end{array}$ & $\begin{array}{l}\text { Type of test: } \\
\text { Descriptive: Pre- and } \\
\text { post- intervention } \\
\text { scores were compared }\end{array}$ \\
\hline
\end{tabular}




\begin{tabular}{|c|c|c|c|c|c|}
\hline & $\begin{array}{l}\text { intervention, Tele- } \\
\text { Care II, for } \\
\text { caregivers of } \\
\text { hospice } \\
\text { patients. } \\
\text { Study design: } \\
\text { Quantitative, quasi- } \\
\text { experimental } \\
\text { Quality rating: } \\
\text { Strong } \\
\text { Fidelity described: } \\
\text { No } \\
\text { Psychological } \\
\text { distress outcomes: } \\
\text { Depression }\end{array}$ & $\begin{array}{l}\text { Caregivers' average } \\
\text { age : } 66 \text { years } \\
\text { Caregiver sex: } 80 \% \\
\text { Female } \\
\text { Cancer type: Not } \\
\text { specified } \\
\text { Cancer stage: } \\
\text { Advanced } \\
\text { Caregiver type: } \\
\text { Family } \\
\text { - Spouse/partner } \\
\quad \quad(64 \%) \\
\text { - Adult child (25\%) } \\
\text { - Other (12\%) } \\
\text { Power analysis } \\
\text { calculation: Not } \\
\text { described }\end{array}$ & $\begin{array}{l}\text { (telephone, workbook) } \\
\text { Format: one to one } \\
\text { Dose: } \\
\text { Amount: Not reported } \\
\text { Frequency: } 4 \text { times in } \\
\text { a month } \\
\text { Duration: Delivered } \\
\text { once a week over } 4 \\
\text { weeks }\end{array}$ & $\begin{array}{l}\text { Follow-up time: } \\
\text { Post- } \\
\text { intervention (not } \\
\text { specified) }\end{array}$ & $\begin{array}{l}\text { Statistical } \\
\text { significance reached? } \\
\text { Sample too small to } \\
\text { test for significance. }\end{array}$ \\
\hline \multicolumn{6}{|c|}{ Moderate Quality Rating } \\
\hline $\begin{array}{l}\text { Kuijer et al., } \\
2003\end{array}$ & $\begin{array}{l}\text { Purpose: To } \\
\text { evaluate a brief } \\
\text { counseling } \\
\text { program directed at } \\
\text { couples confronted } \\
\text { with cancer } \\
\text { Study design: } \\
\text { Quantitative, RCT } \\
\text { Quality rating: } \\
\text { Moderate } \\
\text { Fidelity described: } \\
\text { No } \\
\text { Psychological } \\
\text { distress outcomes: } \\
\text { Depression }\end{array}$ & $\begin{array}{l}\text { Caregiver sample size: } \\
59 \\
\text { Country: Netherlands } \\
\text { Setting: Inpatient } \\
\text { Caregivers' average } \\
\text { age: } 49.5 \text { (SD=11) } \\
\text { Caregiver sex: } 89.8 \% \\
\text { Female } \\
\text { Cancer type: Varied- } \\
\text { breast, intestinal, } \\
\text { Hodgkin disease, brain, } \\
\text { lung } \\
\text { Cancer stage: Varied- } \\
\text { did not specify } \\
\text { Caregiver type: }\end{array}$ & $\begin{array}{l}\text { Component: } \\
\text { Cognitive-behavioural } \\
\text { Approach: Targeted } \\
\text { Mode: } \\
\text { Strategy: Combined } \\
\text { (face to face, booklet) } \\
\text { Format: Dyadic } \\
\text { Dose: } \\
\text { Amount: } 90 \text { minutes } \\
\text { Frequency: } 2 \text { times a } \\
\text { months (5 biweekly } \\
\text { sessions) } \\
\text { Duration: Delivered } \\
\text { over } 10 \text { weeks }\end{array}$ & $\begin{array}{l}\text { Center of } \\
\text { Epidemiological } \\
\text { Studies- } \\
\text { Depression Scale } \\
\text { (CES-D) } \\
\text { Follow-up time: } \\
1 \text { week post- } \\
\text { intervention and } \\
3 \text { months post } \\
\text { intervention }\end{array}$ & $\begin{array}{l}\text { Type of test: ANOVA } \\
\text { Statistical } \\
\text { significance reached? } \\
\text { No significant } \\
\text { improvement was } \\
\text { observed in depression } \\
\text {. }\end{array}$ \\
\hline
\end{tabular}




\begin{tabular}{|c|c|c|c|c|c|}
\hline & & $\begin{array}{l}\text { Partners }(100 \%) \\
\text { Power analysis } \\
\text { calculation: Not } \\
\text { described }\end{array}$ & & & \\
\hline $\begin{array}{l}\text { Kurtz et al., } \\
2005\end{array}$ & $\begin{array}{l}\text { Purpose: To } \\
\text { investigate whether } \\
\text { a clinical nursing } \\
\text { intervention } \\
\text { focusing on teaching } \\
\text { family caregivers } \\
\text { and their cancer } \\
\text { patients skills to } \\
\text { better manage the } \\
\text { patients' symptoms } \\
\text { would reduce } \\
\text { caregiver depressive } \\
\text { symptomatology } \\
\text { Study design: } \\
\text { Quantitative, RCT } \\
\text { Quality rating: } \\
\text { Moderate } \\
\text { Fidelity described: } \\
\text { Yes } \\
\text { Psychological } \\
\text { distress outcomes: } \\
\text { Depression } \\
\text { symptomology }\end{array}$ & $\begin{array}{l}\text { Caregiver sample size: } \\
237 \\
\text { Country: US } \\
\text { Setting: } \\
\text { Comprehensive cancer } \\
\text { centres and community } \\
\text { oncology settings } \\
\text { Caregivers' average } \\
\text { age : } 55.2 \text { (SD=13.7) } \\
\text { Caregiver sex: } 126 \\
\text { (SD=53.5\%) } \\
\text { Cancer type: Varied- } \\
\text { Breast, lung, and others } \\
\text { Cancer stage: Varied- } \\
\text { late and early stage } \\
\text { Caregiver type: } \\
\text { Family (details not } \\
\text { provided) } \\
\text { Power analysis } \\
\text { calculation: Not } \\
\text { described }\end{array}$ & $\begin{array}{l}\text { Component: } \\
\text { Cognitive- } \\
\text { behavioural } \\
\text { Approach: Tailored } \\
\text { Mode: } \\
\text { Strategy: Combined } \\
\text { (in person, telephone) } \\
\text { Format: Dyadic } \\
\text { Dose: } \\
\text { Amount: Not reported } \\
\text { Frequency: } 2 \text { times } \\
\text { over a month (10 } \\
\text { contacts) } \\
\text { Duration: Delivered } \\
\text { over } 20 \text { weeks }\end{array}$ & $\begin{array}{l}\text { Center of } \\
\text { Epidemiological } \\
\text { Studies - } \\
\text { Depression Scale } \\
\text { (CES-D) } \\
\text { Follow-up time: } \\
10 \text { weeks into the } \\
\text { intervention and } \\
20 \text { weeks (end of } \\
\text { intervention) }\end{array}$ & $\begin{array}{l}\text { Type of test: Random } \\
\text { effects regression } \\
\text { analysis } \\
\text { Statistical } \\
\text { significance reached? } \\
\text { No significant } \\
\text { improvement was } \\
\text { observed in } \\
\text { depression.. }\end{array}$ \\
\hline $\begin{array}{l}\text { Lengacher et } \\
\text { al., } 2012\end{array}$ & $\begin{array}{l}\text { Purpose: To } \\
\text { investigate whether } \\
\text { a mindfulness-based } \\
\text { stress reduction } \\
\text { program for cancer }\end{array}$ & $\begin{array}{l}\text { Caregiver sample size: } \\
26 \\
\text { Country: US } \\
\text { Setting: Clinic } \\
\text { Caregivers' average }\end{array}$ & $\begin{array}{l}\text { Component: } \\
\text { Alternative (stress } \\
\text { reduction/ meditation) } \\
\text { Approach: Targeted } \\
\text { Mode: }\end{array}$ & $\begin{array}{l}\text { Perceived Stress } \\
\text { Scale } \\
\text { Center for } \\
\text { Epidemiological }\end{array}$ & $\begin{array}{l}\text { Type of test: Paired t- } \\
\text { test } \\
\text { Statistical } \\
\text { significance reached? }\end{array}$ \\
\hline
\end{tabular}




\begin{tabular}{|c|c|c|c|c|c|}
\hline & $\begin{array}{l}\text { (MBSR-C) } \\
\text { improved } \\
\text { psychological and } \\
\text { physical symptoms, } \\
\text { quality of life } \\
\text { (QOL), and stress } \\
\text { markers among } \\
\text { advanced-stage } \\
\text { cancer patients and } \\
\text { caregivers } \\
\text { Study design: } \\
\text { Quantitative, Quasi- } \\
\text { experimental } \\
\text { Quality rating: } \\
\text { Moderate } \\
\text { Fidelity described: } \\
\text { No } \\
\text { Psychological } \\
\text { distress outcomes: } \\
\text { Stress, depression, } \\
\text { anxiety, emotional } \\
\text { well-being }\end{array}$ & $\begin{array}{l}\text { age : } 51.5 \text { years }(\mathrm{SD}= \\
14.6) \\
\text { Caregiver sex: } 61.5 \% \\
\text { Female } \\
\text { Cancer type: Varied- } \\
\text { Breast, prostate, lung or } \\
\text { colon } \\
\text { Cancer stage: } \\
\text { Advanced } \\
\text { Caregiver type: } \\
\text { Family (details not } \\
\text { provided) } \\
\text { Power analysis } \\
\text { calculation: Not } \\
\text { described }\end{array}$ & $\begin{array}{l}\text { Strategy: Combined } \\
\text { (face to face, CD, } \\
\text { booklet) } \\
\text { Format: Dyadic } \\
\text { Dose: } \\
\text { Amount: Not clear } \\
\text { Frequency: Not clear } \\
\text { Duration: } 6 \text { weeks }\end{array}$ & $\begin{array}{l}\text { Studies } \\
\text { Depression Scale } \\
\text { (CES-D) } \\
\text { State-Trait } \\
\text { Anxiety } \\
\text { Inventory (STAI) } \\
\text { Medical } \\
\text { Outcomes } \\
\text { Studies Short- } \\
\text { Form } \\
\text { General Health } \\
\text { Survey (MOS } \\
\text { SF-36) } \\
\text { Follow-up time: } \\
\text { Pre- and post- } \\
\text { tests given at } \\
\text { week 1, week } 3 \\
\text { and week } 6\end{array}$ & $\begin{array}{l}\text { No significant } \\
\text { improvement was } \\
\text { observed in depression, } \\
\text { stress, anxiety and } \\
\text { emotional well-being. } \\
\text {. }\end{array}$ \\
\hline $\begin{array}{l}\text { Manne et al., } \\
2011\end{array}$ & $\begin{array}{l}\text { Purpose: To } \\
\text { examine the effects } \\
\text { of a five-session } \\
\text { Intimacy-Enhancing } \\
\text { Therapy (IET) vs. } \\
\text { Usual Care (UC) on } \\
\text { the } \\
\text { psychological and } \\
\text { relationship } \\
\text { functioning of men }\end{array}$ & $\begin{array}{l}\text { Caregiver sample size: } \\
71 \\
\text { Country: US } \\
\text { Setting: Cancer centers } \\
\text { Caregivers' average } \\
\text { age }: 55.7 \text { years } \\
(\mathrm{SD}=8.5) \\
\text { Caregiver sex: } 97.2 \% \\
\text { Female } \\
\text { Cancer type: Prostate }\end{array}$ & $\begin{array}{l}\text { Component: } \\
\text { Cognitive-behavioural } \\
\text { Approach: Targeted } \\
\text { Mode: } \\
\text { Strategy: face to face } \\
\text { Format: Dyadic } \\
\text { Dose: } \\
\text { Amount: } 90 \text { minutes } \\
\text { Frequency: } 5 \text { sessions } \\
\text { (unclear how many }\end{array}$ & $\begin{array}{l}\text { Psychological } \\
\text { Distress } \\
\text { scale of the } \\
\text { Mental Health } \\
\text { Inventory } \\
\text { Follow-up time: } \\
8 \text { weeks after } \\
\text { baseline } \\
\text { assessment (the }\end{array}$ & $\begin{array}{l}\text { Type of test: } \\
\text { ANCOVA } \\
\text { Statistical } \\
\text { significance reached? } \\
\text { No significant } \\
\text { improvement was } \\
\text { observed in } \\
\text { psychological distress. }\end{array}$ \\
\hline
\end{tabular}




\begin{tabular}{|c|c|c|c|c|c|}
\hline & $\begin{array}{l}\text { diagnosed with } \\
\text { localized prostate } \\
\text { cancer and their } \\
\text { partners } \\
\text { Study design: } \\
\text { Quantitative, RCT } \\
\text { Quality rating: } \\
\text { Moderate } \\
\text { Fidelity described: } \\
\text { Yes } \\
\text { Psychological } \\
\text { distress outcomes: } \\
\text { Psychological } \\
\text { distress }\end{array}$ & $\begin{array}{l}\text { Cancer stage: Early } \\
\text { Caregiver type: } \\
\text { Partner (100\%) } \\
\text { Power analysis } \\
\text { calculation: Not } \\
\text { described }\end{array}$ & $\begin{array}{l}\text { over a month) } \\
\text { Duration: Not } \\
\text { described }\end{array}$ & end of the trial) & \\
\hline $\begin{array}{l}\text { Porter et al., } \\
2009\end{array}$ & $\begin{array}{l}\text { Purpose: To test the } \\
\text { efficacy of a novel } \\
\text { partner-assisted } \\
\text { emotional disclosure } \\
\text { intervention in a } \\
\text { sample of patients } \\
\text { with gastrointestinal } \\
\text { (GI) cancer } \\
\text { Study design: } \\
\text { Quantitative, RCT } \\
\text { Quality rating: } \\
\text { Moderate } \\
\text { Fidelity described: } \\
\text { Yes } \\
\text { Psychological } \\
\text { distress outcomes: } \\
\text { Mood }\end{array}$ & $\begin{array}{l}\text { Caregiver sample size: } \\
130 \\
\text { Country: US } \\
\text { Setting: Clinic } \\
\text { Caregivers' average } \\
\text { age : } 59.3 \text { years }(12.3) \\
\text { Caregiver sex: } 71 \% \\
\text { female } \\
\text { Cancer type: GI } \\
\text { Cancer stage: Varied- } \\
\text { stage II-stage IV } \\
\text { Caregiver type: } \\
\text { Partner (100\%) } \\
\text { Power analysis } \\
\text { calculation: Not } \\
\text { described }\end{array}$ & $\begin{array}{l}\text { Component: } \\
\text { Cognitive-behavioural } \\
\text { Approach: Tailored } \\
\text { Mode: } \\
\text { Strategy: Combined } \\
\text { (face to face, handout) } \\
\text { Format: Dyadic } \\
\text { Dose: } \\
\text { Amount: Average time } \\
\text { of each session- } 52.5 \\
\text { minutes } \\
\text { Frequency: Unclear } \\
\text { Duration: Unclear }\end{array}$ & $\begin{array}{l}\text { Profile of Mood } \\
\text { States-Short } \\
\text { Form (POMS- } \\
\text { SF). } \\
\text { Follow-up time: } \\
\text { Post-intervention } \\
\text { (Not specified) }\end{array}$ & $\begin{array}{l}\text { Type of test: Multi- } \\
\text { level modelling } \\
\text { Statistical } \\
\text { significance reached? } \\
\text { No significant } \\
\text { improvement was } \\
\text { observed in total mood } \\
\text { score. }\end{array}$ \\
\hline Walsh et al., & Purpose: To & Caregiver sample size: & Component: & General Health & Type of test: \\
\hline
\end{tabular}




\begin{tabular}{|c|c|c|c|c|c|}
\hline $2007 \mathrm{a}$ & $\begin{array}{l}\text { evaluate the } \\
\text { effectiveness of } \\
\text { increased support } \\
\text { for distressed, } \\
\text { informal } \\
\text { carers of patients } \\
\text { receiving palliative } \\
\text { care. } \\
\text { Study design: } \\
\text { Quantitative, RCT } \\
\text { Quality rating: } \\
\text { Moderate } \\
\text { Fidelity described: } \\
\text { Yes } \\
\text { Psychological } \\
\text { distress outcomes: } \\
\text { Psychological } \\
\text { distress }\end{array}$ & $\begin{array}{l}271 \\
\text { Country: United } \\
\text { Kingdom } \\
\text { Setting: Community } \\
\text { palliative care } \\
\text { Caregivers' average } \\
\text { age : } 56.3 \text { years (SD= } \\
13.9) \\
\text { Caregiver sex: } 79 \% \\
\text { Female } \\
\text { Cancer type: Varied- } \\
\text { Lung, GI, GU, head } \\
\text { and neck, breast, other } \\
\text { Cancer stage: } \\
\text { Advanced } \\
\text { Caregiver type: } \\
\text { Family } \\
\text { - Spouses (50\%) } \\
\text { - Adult child (16.7\%) } \\
\text { - Sibling (16.7\%) } \\
\text { - Friend (16.7\%) } \\
\text { Power analysis } \\
\text { calculation: Yes }\end{array}$ & 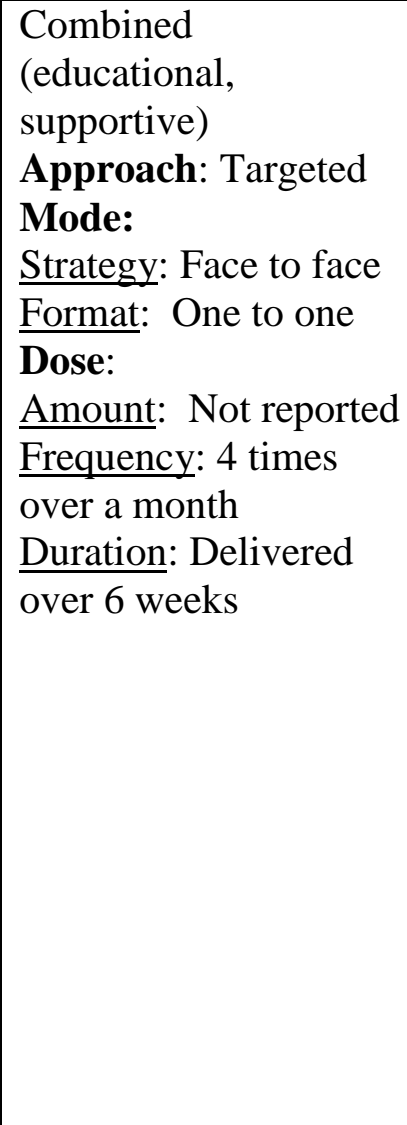 & $\begin{array}{l}\text { Questionnaire } \\
\text { (GHQ-28) } \\
\text { Follow-up time: } \\
\text { Follow-up at } 4 \\
\text { weeks, } \\
9 \text { weeks, and } \\
12 \text { weeks }\end{array}$ & $\begin{array}{l}\text { GLLAMM model } \\
\text { Statistical } \\
\text { significance reached? } \\
\text { No significant } \\
\text { improvement was } \\
\text { observed in } \\
\text { psychological distress. }\end{array}$ \\
\hline \multicolumn{6}{|c|}{ Weak Quality Rating } \\
\hline Carter, 2006 & $\begin{array}{l}\text { Purpose: To } \\
\text { explore the } \\
\text { feasibility and } \\
\text { effectiveness of the } \\
\text { Caregiver sleep } \\
\text { intervention (CASI) } \\
\text { in improving } \\
\text { caregiver sleep }\end{array}$ & $\begin{array}{l}\text { Caregiver sample size: } \\
30 \\
\text { Country: US } \\
\text { Setting: Community } \\
\text { oncology clinic } \\
\text { Caregivers' average } \\
\text { age }: 53 \text { years }(\mathrm{SD}=17) \\
\text { Caregiver sex: } 63 \%\end{array}$ & $\begin{array}{l}\text { Component: } \\
\text { Combination } \\
\text { (educational, } \\
\text { behavioral) } \\
\text { Approach: Targeted } \\
\text { Mode: } \\
\text { Strategy: Face to face } \\
\text { Format: one to one }\end{array}$ & $\begin{array}{l}\text { Center for } \\
\text { Epidemiological } \\
\text { Studies- } \\
\text { Depression Scale } \\
\text { (CES-D) } \\
\text { Follow-up time: } \\
1 \text { week post- }\end{array}$ & $\begin{array}{l}\text { Type of test: T-test } \\
\text { Statistical } \\
\text { significance reached? } \\
\text { Did not reach } \\
\text { statistical significance. }\end{array}$ \\
\hline
\end{tabular}




\begin{tabular}{|c|c|c|c|c|c|}
\hline & $\begin{array}{l}\text { quality, } \\
\text { depressive } \\
\text { symptoms, and } \\
\text { quality of life } \\
\text { Study design: } \\
\text { Quantitative, quasi- } \\
\text { experimental design } \\
\text { Quality rating: } \\
\text { Weak } \\
\text { Fidelity described: } \\
\text { Yes } \\
\text { Psychological } \\
\text { distress outcomes: } \\
\text { Depression }\end{array}$ & $\begin{array}{l}\text { Female } \\
\text { Cancer type: Not } \\
\text { reported } \\
\text { Cancer stage: Not } \\
\text { reported } \\
\text { Caregiver type: } \\
\text { Family } \\
\text { - Spouses }(57 \%) \\
\text { - Adult children } \\
\quad(30 \%) \\
\text { - Other (7\%) } \\
\text { Power analysis } \\
\text { calculation: No }\end{array}$ & $\begin{array}{l}\text { Dose: } \\
\text { Amount: } 1 \text { hour } \\
\text { Frequency: Delivered } \\
\text { twice } \\
\text { Duration: Delivered } \\
\text { over 1 month }\end{array}$ & $\begin{array}{l}\text { intervention } \\
\text { (week 3), } \\
3 \text { weeks post- } \\
\text { intervention } \\
\text { (booster), } \\
2 \text { months, } \\
3 \text { months, } \\
4 \text { months }\end{array}$ & \\
\hline $\begin{array}{l}\text { Hudson et al., } \\
2005\end{array}$ & $\begin{array}{l}\text { Purpose: To } \\
\text { evaluate a psycho- } \\
\text { educational } \\
\text { intervention for } \\
\text { family } \\
\text { caregivers of } \\
\text { patients dying of } \\
\text { cancer at home } \\
\text { Study design: } \\
\text { Quantitative, RCT } \\
\text { Quality rating: } \\
\text { Weak } \\
\text { Fidelity described: } \\
\text { No } \\
\text { Psychological } \\
\text { distress outcomes: } \\
\text { Anxiety, depression }\end{array}$ & $\begin{array}{l}\text { Caregiver sample size: } \\
106 \\
\text { Country: Australia } \\
\text { Setting: Community } \\
\text { home care } \\
\text { Caregivers' average } \\
\text { age }: 60.78 \text { (SD= } \\
13.98) \\
\text { Caregiver sex: } 65.1 \% \\
\text { Females } \\
\text { Cancer type: Varied } \\
\text { (not specified) } \\
\text { Cancer stage: } \\
\text { Advanced } \\
\text { Caregiver type: } \\
\text { Family } \\
\text { - Spouse/partner } \\
\quad(66.7 \%)\end{array}$ & $\begin{array}{l}\text { Component: } \\
\text { Combined } \\
\text { (educational, } \\
\text { supportive) } \\
\text { Approach: Targeted } \\
\text { Mode: } \\
\text { Strategy: Combined } \\
\text { (verbal [face to face], } \\
\text { booklet, audiotape) } \\
\text { Format: one to one } \\
\text { Dose: } \\
\text { Amount: Not reported } \\
\text { Frequency: } 3 \text { home } \\
\text { visits, } 1 \text { phone call } \\
\text { Duration: delivered } \\
\text { over } 3 \text { weeks }\end{array}$ & $\begin{array}{l}\text { Hospital Anxiety } \\
\text { and Depression } \\
\text { Scale } \\
\text { (HADS) } \\
\text { Follow-up time: } \\
5 \text { weeks post } \\
\text { intervention and } \\
8 \text { weeks after } \\
\text { patient's death. }\end{array}$ & $\begin{array}{l}\text { Type of test: ANOVA } \\
\text { and MANOVA } \\
\text { Statistical } \\
\text { significance reached? } \\
\text { No significant } \\
\text { improvement was } \\
\text { observed in anxiety } \\
\text { and depression. }\end{array}$ \\
\hline
\end{tabular}




\begin{tabular}{|l|l|l|l|l|}
\hline & $\begin{array}{l}\bullet \text { Adult child (7.8\%) } \\
\text { Power analysis } \\
\text { calculation: Not } \\
\text { calculated }\end{array}$ & & & \\
\hline
\end{tabular}




\section{Appendix I: Article Search Summary}
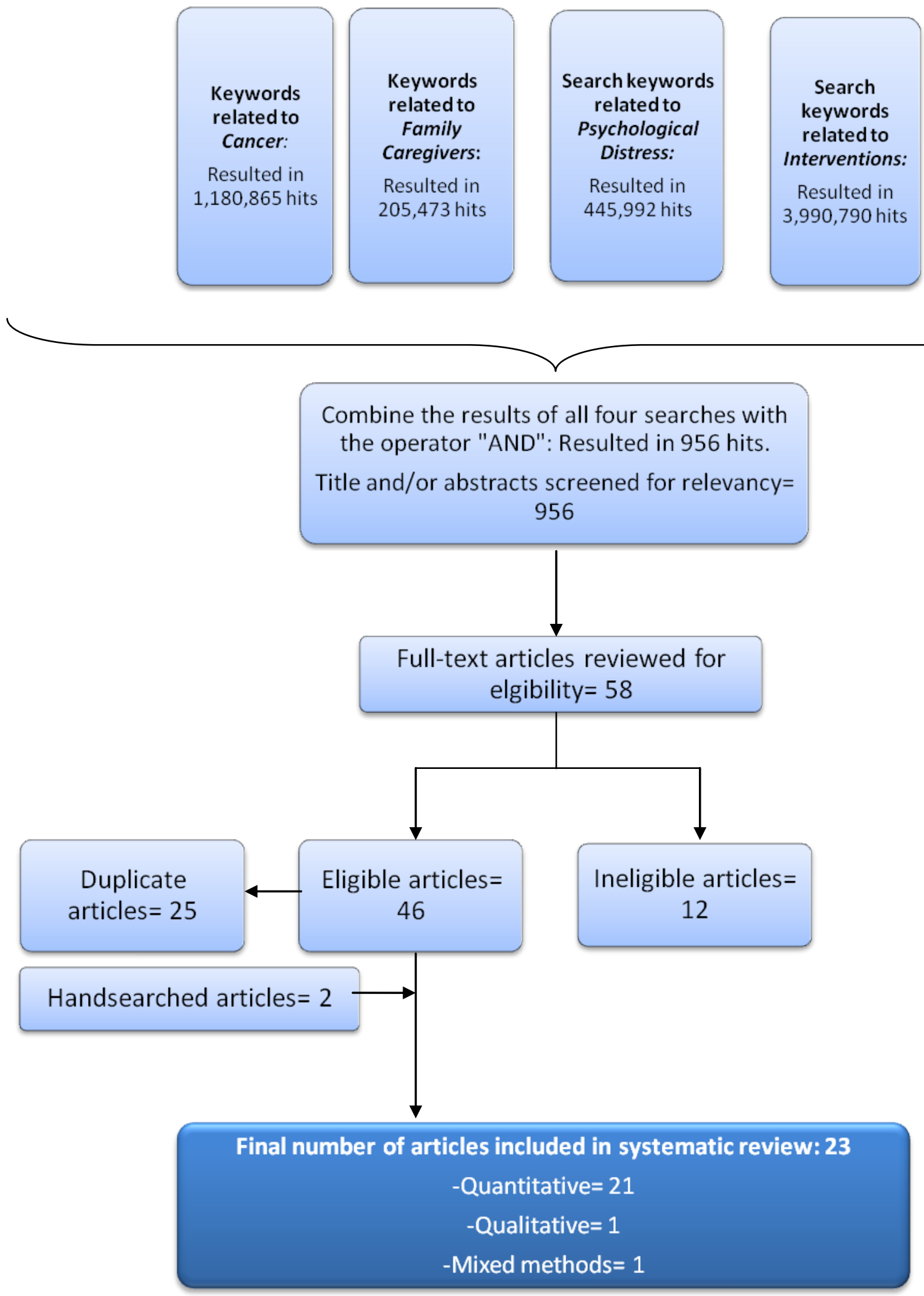


\section{Appendix J: Description of Studies}

\begin{tabular}{|l|l|l|}
\hline \multicolumn{2}{|l|}{ Description of Included Studies } \\
\hline Design & Quantitative & $91.3 \%$ \\
& $\bullet$ RCT & $\bullet 52.4 \%$ \\
& • Quasi-experimental & $\bullet 47.6 \%$ \\
& Qualitative & $4.3 \%$ \\
& Mixed Methods & $4.3 \%$ \\
\hline Location & United States & $52.2 \%$ \\
& Canada & $26.1 \%$ \\
& Australia & $8.7 \%$ \\
& Other & $12.9 \%$ \\
\hline Setting & Outpatient/Clinic & $87.0 \%$ \\
& Both Outpatient and Inpatient & $13.0 \%$ \\
\hline
\end{tabular}

\section{Appendix K: Strategies to Maintain Fidelity}

\begin{tabular}{|l|l|l|}
\hline Strategy & Frequency & Percent \\
\hline Training & 9 & $81.8 \%$ \\
\hline $\begin{array}{l}\text { Protocol/manual/scripted } \\
\text { sessions/checklists }\end{array}$ & 9 & $81.8 \%$ \\
\hline $\begin{array}{l}\text { Sessions } \\
\text { audiotaped/videotaped }\end{array}$ & 8 & $72.7 \%$ \\
\hline $\begin{array}{l}\text { Regular } \\
\text { meetings/discussion/debriefing } \\
\text { session }\end{array}$ & 7 & $63.6 \%$ \\
\hline $\begin{array}{l}\text { Regular } \\
\text { meetings/discussion/debriefing } \\
\text { session }\end{array}$ & 7 & $63.6 \%$ \\
\hline Review \& provide feedback & 6 & $54.5 \%$ \\
\hline Supervision/Observations & 5 & $45.4 \%$ \\
\hline $\begin{array}{l}\text { Delivered by limited number } \\
\text { of individuals }\end{array}$ & 2 & $18.2 \%$ \\
\hline Quality assurance coordinator & 1 & $9 \%$ \\
\hline
\end{tabular}

\section{Appendix L: Standardized Tools Assessing Psychological Distress}

\begin{tabular}{|l|l|l|}
\hline Tool & Frequency & $\begin{array}{l}\text { Percent } \\
\text { (Of 22 quantitative studies) }\end{array}$ \\
\hline $\begin{array}{l}\text { Center for Epidemiological } \\
\text { Studies-Depression Scale }\end{array}$ & 7 & $31.9 \%$ \\
\hline $\begin{array}{l}\text { Profile of Mood States } \\
\text { (POMS)/ } \\
\text { Mini-Profile of Mood States/ }\end{array}$ & 5 & $22.7 \%$ \\
\hline
\end{tabular}




\begin{tabular}{|c|c|c|}
\hline \multicolumn{3}{|l|}{$\begin{array}{l}\text { Profile of Mood States-Short } \\
\text { Form }\end{array}$} \\
\hline $\begin{array}{l}\text { Beck Hopelessness } \\
\text { Scale(BHS) }\end{array}$ & 4 & $18.1 \%$ \\
\hline Beck Anxiety Inventory (BAI) & 3 & $13.6 \%$ \\
\hline $\begin{array}{l}\text { State-Trait Anxiety Scale } \\
\text { (STAI) }\end{array}$ & 3 & $13.6 \%$ \\
\hline $\begin{array}{l}\text { Beck Depression Inventory II } \\
\text { (BDI-II) }\end{array}$ & 2 & $9.01 \%$ \\
\hline $\begin{array}{l}\text { Calgary Symptoms of Stress } \\
\text { Inventory (C-SOSI) }\end{array}$ & 1 & $4.5 \%$ \\
\hline $\begin{array}{l}\text { Derogatis Affects Balance } \\
\text { Scale }\end{array}$ & 1 & $4.5 \%$ \\
\hline $\begin{array}{l}\text { General Health Questionnaire } \\
\text { (GHQ- 28) }\end{array}$ & 1 & $4.5 \%$ \\
\hline $\begin{array}{l}\text { Hogan Grief Reactions } \\
\text { Checklist- End of Life }\end{array}$ & 1 & $4.5 \%$ \\
\hline $\begin{array}{l}\text { Hospital Anxiety and } \\
\text { Depression Scale (HADS) }\end{array}$ & 1 & $4.5 \%$ \\
\hline $\begin{array}{l}\text { Medical Outcomes Short- } \\
\text { Form General Health Survey }\end{array}$ & 1 & $4.5 \%$ \\
\hline The Mental Health Inventory & 1 & $4.5 \%$ \\
\hline The Perceived Stress Scale & 1 & $4.5 \%$ \\
\hline Taiwanese Depression Scale & 1 & $4.5 \%$ \\
\hline Salivary Cortisol level & 1 & $4.5 \%$ \\
\hline
\end{tabular}

\section{Component}

\section{Appendix M: Component \& Mode Combinations}

\begin{tabular}{|l|l|}
\hline Combination & Frequency \\
\hline CBT+ Psycho-educational & 3 \\
\hline Psycho-educational+ Supportive & 5 \\
\hline CBT+ Psycho-educational+ Supportive & 2 \\
\hline Psycho-educational+ Alternative+ Supportive & 1 \\
\hline
\end{tabular}

Mode
\begin{tabular}{|l|l|}
\hline Combination & Frequency \\
\hline Face-to-face + booklet/information sheet & 2 \\
\hline Face-to-face + booklet + audiotape & 2 \\
\hline Face-to-face +audiotape & 1 \\
\hline Face-to-face + telephone & 3 \\
\hline Telephone + booklet & 1 \\
\hline Telephone + booklet + audiotape & 1 \\
\hline
\end{tabular}


Appendix N: Studies Yielding Statistically Significant Psychological Distress Findings

\begin{tabular}{|c|c|c|}
\hline $\begin{array}{l}\text { Author, Year of } \\
\text { Publication }\end{array}$ & Intervention components & $\begin{array}{l}\text { Findings related to psychological } \\
\text { distress }\end{array}$ \\
\hline \multicolumn{3}{|c|}{ Strong Quality Rating } \\
\hline Cameron, 2003 & $\begin{array}{l}\text { Component: Cognitive- } \\
\text { behavioural } \\
\text { Approach: Targeted } \\
\text { Mode: } \\
\text { Strategy: Combined (face-to-face, } \\
\text { booklet, presentation [either on a } \\
\text { laptop or flipchart]) } \\
\text { Format: one to one } \\
\text { Dose: } \\
\text { Amount: } 60 \text { minutes } \\
\text { Frequency: Delivered once } \\
\text { Duration: Delivered in one day }\end{array}$ & $\begin{array}{l}\text { Tool: Profile of Mood States } \\
\text { (POMS) } \\
\text { Type of test: Paired t-test } \\
\text { Statistical significance reached?: } \\
\text { Only emotional tension (anxiety) } \\
\text { reached statistical significance } \\
\text { (p=0.024). } \\
\text { No significant improvement was } \\
\text { observed in depression and mood. }\end{array}$ \\
\hline Northouse et al., 2007 & $\begin{array}{l}\text { Component: Combined } \\
\text { (supportive, educational) } \\
\text { Approach: Targeted and tailored } \\
\text { Mode: } \\
\text { Strategy: Face to face, phone } \\
\text { Format: Dyadic } \\
\text { Dose: } \\
\text { Amount: Average of } 66 \text { minutes } \\
\text { Frequency: Delivered twice over } \\
\text { a month } \\
\text { Duration: Delivered over } 4 \\
\text { months }\end{array}$ & $\begin{array}{l}\text { Tool: Beck Hopelessness Scale } \\
\text { (BHS) } \\
\text { Type of test: Random regression } \\
\text { analysis } \\
\text { Statistical significance reached?: } \\
\text { Hopelessness reached statistical } \\
\text { significance (p=0.03) at } 4 \text { months } \\
\text { follow-up only. }\end{array}$ \\
\hline \multicolumn{3}{|c|}{ Moderate Quality Rating } \\
\hline Lai, Li \& Lee, 2011 & $\begin{array}{l}\text { Component: Alternative (music) } \\
\text { Approach: Targeted } \\
\text { Mode: } \\
\text { Strategy: Combined (face to face, } \\
\text { music audiofile) } \\
\text { Format: one to one } \\
\text { Dose: } \\
\text { Amount: } 30 \text { minutes } \\
\text { Frequency: } 1 \text { time } \\
\text { Duration: } 1 \text { day }\end{array}$ & $\begin{array}{l}\text { Tool: Taiwanese Depression Scale } \\
\text { \& State-Trait Anxiety Inventory } \\
\text { (STAI) } \\
\text { Type of test: Wilcoxon rank signed } \\
\text { test and Friedman test } \\
\text { Statistical significance reached?: } \\
\text { Anxiety (p<0.001) and depression } \\
\text { (p<0.001) scores both reached } \\
\text { statistical significance. }\end{array}$ \\
\hline Lewis et al., 2008 & $\begin{array}{l}\text { Component: Combined } \\
\text { (supportive, educational) } \\
\text { Approach: targeted } \\
\text { Mode: }\end{array}$ & $\begin{array}{l}\text { Tool: Center for Epidemiological } \\
\text { Studies-Depression Scale (CES-D) } \\
\text { \& State-Trait Anxiety Scale } \\
\text { (STAI-Y) }\end{array}$ \\
\hline
\end{tabular}




\begin{tabular}{|c|c|c|}
\hline & $\begin{array}{l}\text { Strategy: face to face } \\
\text { Format: one to one } \\
\text { Dose: } \\
\text { Amount: } 60 \text { minutes } \\
\text { Frequency: } 2 \text { times over a month } \\
\text { Duration: Delivered over } 10 \\
\text { weeks (70 days) }\end{array}$ & $\begin{array}{l}\text { Type of test: Wilcoxon rank signed } \\
\text { test } \\
\text { Statistical significance reached: } \\
\text { Depressed } \operatorname{mood}(\mathrm{p}=0.001) \text { and } \\
\text { anxiety }((\mathrm{p}<0.001)) \text { both reached } \\
\text { statistical significance. }\end{array}$ \\
\hline McLean et al., 2008 & $\begin{array}{l}\text { Component: Unclear } \\
\text { Approach: Not described } \\
\text { Mode: } \\
\text { Strategy: Face to face } \\
\text { Format: Dyadic } \\
\text { Dose: } \\
\text { Amount: Not described } \\
\text { Frequency: average number of } \\
\text { sessions delivered was } 11.56 \\
\text { sessions, but unclear how many } \\
\text { were delivered per month. } \\
\text { Duration: Delivered over two } \\
\text { months }\end{array}$ & $\begin{array}{l}\text { Tool: Beck Depression Inventory- } \\
\text { II (BDI-II) \& Beck Hopelessness } \\
\text { Scale } \\
\text { Type of test: ANOVA } \\
\text { Statistical significance reached?: } \\
\text { Significance was observed in } \\
\text { depression symptomology } \\
\text { (p=0.0454) at } 3 \text { months post- } \\
\text { intervention. } \\
\text { No significant improvement was } \\
\text { observed in hopelessness. }\end{array}$ \\
\hline Porter et al, 2011 & $\begin{array}{l}\text { Component: Combined } \\
\text { (Cognitive behavioural, } \\
\text { educational) } \\
\text { Approach: Tailored } \\
\text { Mode: } \\
\text { Strategy: Combined (Telephone, } \\
\text { audiotape, handout) } \\
\text { Format: Dyadic } \\
\text { Dose: } \\
\text { Amount: } 45 \text { minutes } \\
\text { Frequency: Ranges from weekly } \\
\text { to monthly. Average: bi-weekly } \\
\text { contact } \\
\text { Duration: Delivered over eight } \\
\text { months. }\end{array}$ & $\begin{array}{l}\text { Tool: Profile of Mood } \\
\text { States-B (POMS-B) } \\
\text { Type of test: Hierarchical linear } \\
\text { modeling } \\
\text { Statistical significance reached?: } \\
\text { Significance was observed in } \\
\text { anxiety (p=0.02) at } 4 \text { months } \\
\text { follow-up. } \\
\text { No significant improvement was } \\
\text { observed in depression. }\end{array}$ \\
\hline Walsh et al, 2007b & $\begin{array}{l}\text { Component: Alternative (Art- } \\
\text { making) } \\
\text { Approach: Targeted } \\
\text { Mode: } \\
\text { Strategy: Face to face } \\
\text { Format: One to one } \\
\text { Dose: }\end{array}$ & $\begin{array}{l}\text { Tool: Beck Anxiety Inventory } \\
\text { (BAI) \& Salivary Cortisol (stress) } \\
\text { Type of test: Paired t-test and chi- } \\
\text { square analysis } \\
\text { Statistical significance reached?: }\end{array}$ \\
\hline
\end{tabular}




\begin{tabular}{|c|c|c|}
\hline & $\begin{array}{l}\text { Amount: } 2 \text { hours } \\
\text { Frequency: twice a week } \\
\text { (unclear) } \\
\text { Duration: Not described }\end{array}$ & $\begin{array}{l}\text { A statistically significant decline in } \\
\text { anxiety was observed. } \\
\text { No significant improvement was } \\
\text { observed in stress. }\end{array}$ \\
\hline \multicolumn{3}{|c|}{ Weak Quality Rating } \\
\hline $\begin{array}{l}\text { Birnie, Garland \& } \\
\text { Carlson, } 2009\end{array}$ & $\begin{array}{l}\text { Component: Combined } \\
\text { (Educational, cognitive- } \\
\text { behavioural, supportive) } \\
\text { Approach: Targeted } \\
\text { Mode: } \\
\text { Strategy: Combined (face to face, } \\
\text { audiotape, booklet) } \\
\text { Format: Group sessions } \\
\text { Dose: } \\
\text { Amount: } 8 \text { sessions were } 90 \\
\text { minutes; } 1 \text { retreat was } 3 \text { hours } \\
\text { Frequency: Delivered } 4 \text { times } \\
\text { over a month } \\
\text { Duration: } 2 \text { months }\end{array}$ & $\begin{array}{l}\text { Tool: Profile of Mood States } \\
\text { (POMS) \& Calgary Symptoms of } \\
\text { Stress Inventory } \\
\text { (C-SOSI) } \\
\text { Type of test: ANOVA } \\
\text { Statistical significance reached?: } \\
\text { Anxiety (p=0.01) and total mood } \\
\text { score (p=0.04) reached statistical } \\
\text { significance. } \\
\text { No significant improvement was } \\
\text { observed in depression. }\end{array}$ \\
\hline Rexilius et al., 2002 & $\begin{array}{l}\text { Component: Alternative } \\
\text { (Massage/ healing touch) } \\
\text { Approach: Targeted } \\
\text { Mode: } \\
\text { Strategy: Face to face } \\
\text { Format: One to one } \\
\text { Dose: } \\
\text { Amount: } 30 \text { minutes } \\
\text { Frequency: } 6 \text { sessions } \\
\text { Duration: Delivered over } 3 \text { weeks }\end{array}$ & $\begin{array}{l}\text { Tool: Beck Anxiety Inventory } \\
\text { (BAI) \& Center for } \\
\text { Epidemiological Studies- } \\
\text { Depression Scale (CES-D) } \\
\text { Type of test: ANCOVA and } \\
\text { ANOVA } \\
\text { Statistical significance reached? } \\
\text { Significant decline in anxiety } \\
\text { (p<0.05) and depression (p<0.05) } \\
\text { were observed in the Massage } \\
\text { intervention group, but not in the } \\
\text { Healing Touch intervention group. }\end{array}$ \\
\hline $\begin{array}{l}\text { Walsh, Martin \& } \\
\text { Schmidt, } 2004\end{array}$ & $\begin{array}{l}\text { Component: Alternative } \\
\text { (Creative arts intervention) } \\
\text { Approach: Targeted } \\
\text { Mode: } \\
\text { Strategy: Face to face } \\
\text { Format: One to one } \\
\text { Dose: } \\
\text { Amount: Not described } \\
\text { Frequency: Not described }\end{array}$ & $\begin{array}{l}\text { Tool: Mini-Profile of Mood States } \\
\text { (Mini-POMS) \& } \\
\text { Beck Anxiety Inventory (BAI) \& } \\
\text { Derogatis Affects Balance Scale } \\
\text { Type of test: Paired samples t-test } \\
\text { Statistical significance reached? } \\
\text { Anxiety }(\mathrm{p}<0.001), \text { mood }\end{array}$ \\
\hline
\end{tabular}




\begin{tabular}{|l|l|l|}
\hline & Duration: Not described & $\begin{array}{l}(\mathrm{p}=0.001) \text { and negative emotion } \\
(\mathrm{p}<0.001) \text { reached statistical } \\
\text { significance. }\end{array}$ \\
\hline
\end{tabular}




\section{References}

Agurs-Collins, T. D., Kumanyika, S. K., Ten Have, T. R., \& Adams-Campbell, L. L. (1997). A randomized controlled trial of weight reduction and exercise for diabetes management in older African-American subjects. Diabetes Care,20(10), 1503-1511.

American Cancer Society. (2011). What is cancer? Retrieved from http://www.cancer.org/Cancer/CancerBasics/what-is-cancer

American Psychiatric Association (2000). Diagnostic and statistical manual of mental disorders: DSM-IV-TR. American Psychiatric Publishing, Inc.

Armijo-Olivo, S., Stiles, C. R., Hagen, N. A., Biondo, P. D., \& Cummings, G. G. (2012). Assessment of study quality for systematic reviews: a comparison of the Cochrane Collaboration Risk of Bias Tool and the Effective Public Health Practice Project Quality Assessment Tool: methodological research. Journal of Evaluation in Clinical Practice, 18(1), 12-18.

Aranda, S. K., \& Hayman-White, K. (2001). Home caregivers of the person with advanced cancer: An Australian perspective. Cancer Nursing, 24(4), 300.

Arnaert, A., Gabos, T., Ballenas, V., \& Rutledge, R. D. (2010). Contributions of a retreat weekend to the healing and coping of cancer patients' relatives. Qualitative Health Research, 20(2), 197-208.

Badr, H., Carmack, C. L., Kashy, D. A., Cristofanilli, M., \& Revenson, T. A. (2010). Dyadic coping in metastatic breast cancer. Health Psychology, 29(2), 169-180. doi:10.1037/a0018165 
Baik, O. M., \& Adams, K. B. (2011). Improving the Well-Being of Couples Facing Cancer: A Review of Couples-Based Psychosocial Interventions. Journal of Marital and Family Therapy, 37(2), 250-266.

Bartolucci, A. A., \& Hillegass, W. B. (2010). Overview, strengths, and limitations of systematic reviews and meta-analyses. In Evidence-Based Practice: Toward Optimizing Clinical Outcomes (pp. 17-33). Springer Berlin Heidelberg.

Bellg, A. J., Borrelli, B., Resnick, B., Hecht, J., Minicucci, D. S., Ory, M., ... \& Czajkowski, S. (2004). Enhancing treatment fidelity in health behavior change studies: Best practices and recommendations from the NIH Behavior Change Consortium. Health Psychology, 23(5), 443.

Bero, L. A., Grilli, R., Grimshaw, J. M., Harvey, E., Oxman, A. D., \& Thomson, M. A. (1998). Closing the gap between research and practice: an overview of systematic reviews of interventions to promote the implementation of research findings. British Medical Journal 317(7156), 465-468.

Blackwood, B. (2006). Methodological issues in evaluating complex healthcare interventions. Journal of Advanced Nursing, 54(5), 612-622.

Blanchard, C. G., Albrecht, T. L., \& Ruckdeschel, J. C. (1997). The crisis of cancer:

Psychological impact on family caregivers. Oncology, 11(2), 189-195.

Blue, C. L., \& Black, D. R. (2005). Synthesis of intervention research to modify physical activity and dietary behaviors. Research and Theory for Nursing Practice, 19(1), 25-61.

Boaz, A., Baeza, J., \& Fraser, A. (2011). Effective implementation of research into practice: an overview of systematic reviews of the health literature. Bio-Med Central, 4(1), 212. 
Brown, S. A. (1992). Meta-analysis of diabetes patient education research: Variations in intervention effects across studies. Research in Nursing \& Health, 15(6), 409-419.

Bruner, D. W., \& Boyd, C. P. (1999). Assessing women's sexuality after cancer therapy: checking assumptions with the focus group technique. Cancer Nursing, 22(6), 438-447.

Buch, K., \& Bartley, S. (2002). Learning style and training delivery mode preference. Journal of Workplace Learning, 14(1), 5-10.

Bulechek G. M., Butcher H. K., \& Dochterman J. M. (2008). Nursing interventions classification (NIC). (5th ed. ed.). St. Louis, MI.: Mosby/Elsevier.

Burns, N. \& Grove, S. (2009). The practice of nursing research: Appraisal, synthesis and generation of evidence (6th ed.) St. Louis, MI: Elsevier Saunders.

Cameron, J.I., Franche, R.L., Cheung, A.M., \& Stewart, D.E. (2002). Lifestyle interference and emotional distress in family caregivers of advanced cancer patients. Cancer, 94 (2), 521527.

Cameron, J. I., Shin, J. L., Williams, D., \& Stewart, D. E. (2004). A brief problem-solving intervention for family caregivers to individuals with advanced cancer. Journal of Psychosomatic Research, 57(2), 137-143. doi: 10.1016/S0022-3999(03)00609-3

Canadian Cancer Society. (2010a). Coping if you're a caregiver. Retrieved from http://www.cancer.ca/Canadawide/About\%20cancer/Coping\%20with\%20cancer/Living\%20with\%20cancer/Coping\%2 0if\%20you\%20re\%20a\%20caregiver.aspx?sc_lang=en\#Responsibilities\%20and\%20conc erns

Canadian Cancer Society. (2010b). The fight for life: Nationwide strategic plan 2010-2015. Retrieved from 
http://www.cancer.ca/ /media/cancer.ca/CW/nationwide\%20strategic\%20plan/CCS\%20

Nationwide\%20Strategic\%20Plan\%20EN.pdf

Canadian Cancer Society. (2011). General cancer statistics at a glance. Retrieved from http://www.cancer.ca/Canadawide/About $\% 20$ cancer/Cancer\%20statistics/Stats\%20at\%20a\%20glance/General\%20can cer\%20stats.aspx?sc_lang=en

Canadian Cancer Society. (2013). Canadian cancer statistics. Retrieved from http://www.cancer.ca/en/cancer-information/cancer-101/canadian-cancer-statisticspublication/?region=on

Carlson, L. E., \& Bultz, B. D. (2003). Cancer distress screening: needs, models, and methods. Journal of Psychosomatic research, 55(5), 403-409.

Carpenito-Moyet, L. J. (2006). Nursing diagnosis: Application to clinical practice. Philadelphia, PA: Lippincott Williams \& Wilkins.

Carter, P. A. (2006). A brief behavioral sleep intervention for family caregivers of persons with cancer. Cancer Nursing, 29(2), 95.

Carter, P., \& Chang, B. (2000). Sleep and depression in caregivers. Cancer Nursing, 23(6), 410415.

Chambers, S. K., Schover, L., Halford, K., Clutton, S., Ferguson, M., Gordon, L., . . Dunn, J. (2008). ProsCan for couples: Randomised controlled trial of a couples-based sexuality intervention for men with localised prostate cancer who receive radical prostatectomy. BioMed Central Cancer, 8, 226. doi:10.1186/1471-2407-8-226 
Cochrane, B. B., \& Lewis, F. M. (2005). Partner's adjustment to breast cancer: a critical analysis of intervention studies. Health Psychology, 24(3), 327.

Cooley, M. E., Sarna, L., Brown, J. K., Williams, R. D., Chernecky, C., Padilla, G., \& Danao, L. L. (2003). Challenges of recruitment and retention in multisite clinical research. Cancer Nursing, 26(5), 376-386.

Czaja, S. J., \& Rubert, M. P. (2002). Telecommunications technology as an aid to family caregivers of persons with dementia. Psychosomatic medicine, 64(3), 469-476.

D'Eramo-Melkus, G. A., Wylie-Rosett, J., \& Hagan, J. A. (1992). Metabolic impact of education in NIDDM. Diabetes Care, 15(7), 864-869.

Detsky, A. S., Naylor, C. D., O'Rourke, K., McGeer, A. J., \& L'Abbé, K. A. (1992).

Incorporating variations in the quality of individual randomized trials into metaanalysis. Journal of Clinical Epidemiology, 45(3), 255-265.

Dijkstra, A. (2005). Working mechanisms of computer-tailored health education: Evidence from smoking cessation. Health Education Research, 20(5), 527-539.

Dilworth-Anderson, P., Williams, I. C., \& Gibson, B. E. (2002). Issues of race, ethnicity, and culture in caregiving research A 20-year review (1980-2000). The Gerontologist, 42(2), 237-272.

Effective Public Health Practice Project (EPHPP) (2010). Quality assessment tool for quantitative articles. Retrieved from http://www.ephpp.ca/tools.html

Ensel, W. M., \& Lin, N. (1991). The life stress paradigm and psychological distress. Journal of Health and Social Behavior, 321-341.

Fan, L., \& Sidani, S. (2009). Effectiveness of diabetes self-management education intervention elements: a meta-analysis. Canadian Journal of Diabetes, 33(1), 18-26. 
Fitzgerald, J. J., \& Whall, A.L. (1996). Conceptual models of nursing: Analysis and application. New Jersey, NJ: Prentice Hall.

Forman, S. G., \& Barakat, N. M. (2011). Cognitive-behavioral therapy in the schools: Bringing research to practice through effective implementation. Psychology in the Schools, 48(3), 283-296.

Fredericks, S., Guruge, S., Sidani, S., \& Wan, T. (2010). Postoperative patient education: a systematic review. Clinical Nursing Research, 19(2), 144-164.

Fredericks, S., Ibrahim, S., \& Puri, R. (2009). Coronary artery bypass graft surgery patient education: A systematic review. Progress in Cardiovascular Nursing, 24(4), 162-168.

Given, B. A., Given, C. W., \& Kozachik, S. (2001). Family support in advanced cancer. CA: A Cancer Journal for Clinicians, 51(4), 213-231.

Given, B., Sherwood, P. R., \& Given, C. W. (2008). What knowledge and skills do caregivers need?. Journal of Social Work Education, 44, 115-123.

Government of Canada. (2011). Canada and the United States: No two nations closer. Retrieved from http://www.canadainternational.gc.ca/can-am/Closer-etroites.aspx

Gross, C. P., Mallory, R., Heiat, A., \& Krumholz, H. M. (2002). Reporting the recruitment process in clinical trials: Who are these patients and how did they get there? Annals of Internal Medicine, 137(1), 10-16.

Grov, E.K., Dahl, A.A., Moum, T., \& Fossa, S.D. (2005). Anxiety, depression, and quality of life in caregivers of patients with cancer in late palliative phase. Annals of Oncology, 16, 11851191. doi:10.1093/annanc/mdi210 
Grunfeld, E., Coyle, D., Whelan, T., Clinch, J., Reyno, L., Earle, C.C., Willan, A., Viola, R., Coristine, M., Janz, T., \& Glossop, R. (2004). Family caregiver burden: Results of a longitudinal study of breast cancer patients and their principal caregivers. Canadian Medical Association Journal, 170 (12), 1795-1800.

Haley, W. E. (2003a). Family caregivers of elderly patients with cancer: understanding and minimizing the burden of care. Journal of Support Oncology, 1(4 Suppl 2), 25-9.

Haley, W. E. (2003b). The costs of family caregiving: Implications for geriatric oncology. Critical Reviews in Oncology/Hematology, 48, 151-158.

Hagedoorn, M., Sanderman, R., Bolks, H. N., Tuinstra, J., \& Coyne, J. C. (2008). Distress in couples coping with cancer: A meta-analysis and critical review of role and gender effects. Psychological Bulletin, 134(1), 1-30. doi:10.1037/0033-2909.134.1.1

Harding, R., \& Higginson, I. J. (2003). What is the best way to help caregivers in cancer and palliative care? A systematic literature review of interventions and their effectiveness. Palliative Medicine, 17(1), 63-74.

Harding, R., Higginson, I.J., Lean, C., Donaldson, N. Pearce, A., ... Taylor, L. (2004). Evaluation of a short-term group interventions for informal carers of patients attending a home palliative care service. Journal of Pain and Symptom Management, 27 (5), 396-408.

Harvey, L. A., Lin, C. W., Glinsky, J. V., \& De Wolf, A. (2008). The effectiveness of physical interventions for people with spinal cord injuries: A systematic review. Spinal Cord, 47(3), 184-195.

Helgeson, V. S., \& Cohen, S. (1996). Social support and adjustment to cancer: Reconciling descriptive, correlational, and intervention research. Health Psychology, 15(2), 135. 
Higgins JPT, Green S. (2011). Cochrane Handbook for Systematic Reviews of

Interventions Version 5.1.0. Retrieved from www.cochrane-handbook.org.

Holahan, C.J. \& Moos, R.H. (1981). Social support and psychological distress: A longitudinal analysis. Journal of Abnormal Psychology, 90 (4), 365-370.

Honea, N. J., Brintnall, R., Given, B., Sherwood, P., Colao, D. B., Somers, S. C., \& Northouse, L. L. (2008). Putting Evidence Into Practice®: nursing assessment and interventions to reduce family caregiver strain and burden. Clinical Journal of Oncology Nursing, 12(3), $507-516$.

Horner, S., Rew, L., \& Torres, R. (2006). Enhancing intervention fidelity: A means of strengthening study impact. Journal for Specialists in Pediatric Nursing, 11(2), 80-89.

Hudson, P. (2004). A critical review of supportive interventions for family caregivers of patients with palliative-stage cancer. Journal of Psychosocial Oncology, 22(4), 77-92. doi:10.1300/J077v22n04_05

Hudson, P. L., Aranda, S., \& Hayman-White, K. (2005). A psycho-educational intervention for family caregivers of patients receiving palliative care: a randomized controlled trial. Journal of Pain and Symptom Management, 30(4), 329-341.

James, K., Keegan-Wells, D., Hinds, P. S., Kelly, K. P., Bond, D., Hall, B., \& Speckhart, B. (2002). The care of my child with cancer: Parents' perceptions of caregiving demands. Journal of Pediatric Oncology Nursing, 19(6), 218-228.

Jepson, C., McCorkle, R., Adler, D., Nuamah, I., \& Lusk, E. (1999). Effects of home care on caregivers' psychosocial status. Journal of Nursing Scholarship,31(2), 115-120. 
Kayser, K., Watson, L.E., \& Andrade, J. T. (2007). Cancer as a "we-disease": Examining the process of coping from a relational perspective. Families, Systems, \& Health, 25 (4), 404418. doi: $10.1037 / 10917527.25 .4 .404$

Kessler, R.C. (1979). Stress, social status and psychological distress. Journal of Health and Social Behavior, 20, 259-272.

Kessler, R. C., Andrews, G., Colpe, L. J., Hiripi, E., Mroczek, D. K., Normand, S. L. T., ... \& Zaslavsky, A. M. (2002). Short screening scales to monitor population prevalences and trends in non-specific psychological distress. Psychological Medicine, 32(6), 959-976.

Kim, Y., Wellisch, D. K., Spillers, R. L., \& Crammer, C. (2006). Psychological distress of female cancer caregivers: effects of type of cancer and caregivers' spirituality. Supportive Care in Cancer, 15(12), 1367-1374.

Knight, B. G., Lutzky, S. M., \& Macofsky-Urban, F. (1993). A meta-analytic review of interventions for caregiver distress: Recommendations for future research. The Gerontologist, 33(2), 240-248.

Kozachik, S.L., Given, C.W., Given, B. A., Pierce, S,J., Azzouz, F., Rawl, S., \& Champion, V. L. (2001). Improving depressive symptoms among caregivers of patients with cancer: Results of a randomized control trial. Oncology Nursing Forum, 28 (7), 1149-1157.

Kuijer, R. G., Buunk, B. P., De Jong, G. M., Ybema, J. F., \& Sanderman, R. (2004). Effects of a brief intervention program for patients with cancer and their partners on feelings of inequity, relationship quality and psychological distress. Psycho-Oncology, 13(5), 321334. 
Kurtz, M. E., Kurtz, J., Given, C. W., \& Given, B. (2005). A randomized, controlled trial of a patient/caregiver symptom control intervention: Effects on depressive symptomatology of caregivers of cancer patients. Journal of Pain and Symptom Management, 30(2), 112-122.

Lai, H. L., Li, Y. M., \& Lee, L. H. (2011). Effects of music intervention with nursing presence and recorded music on psycho-physiological indices of cancer patient caregivers. Journal of Clinical Nursing, 21(5-6), 745-756.

Lauver, D.R., Ward, S.E., Heidrich, S.M., Keller, M.L., Bowers, B.J., Brennan, P.F., Kirchhoff, K.T., \& Wells, T.J. (2002). Patient-centred interventions. Research in Nursing \& Health, $25,246-255$.

Lengacher, C. A., Kip, K. E., Barta, M., Post-White, J., Jacobsen, P. B., Groer, M., ... \& Shelton, M. M. (2012). A pilot study evaluating the effect of mindfulness-based stress reduction on psychological status, physical status, salivary cortisol, and interleukin-6 among advanced-stage cancer patients and their caregivers. Journal of Holistic Nursing, 30(3), 170-185.

Lewis, F. M., Cochrane, B. B., Fletcher, K. A., Zahlis, E. H., Shands, M. E., Gralow, J. R., ... \& Schmitz, K. (2008). Helping her heal: A pilot study of an educational counseling intervention for spouses of women with breast cancer. Psycho-Oncology, 17(2), 131-137.

Lewis, S.M., Heitkemper, M.M., \& Dirksen, SR. (2006). Medical-surgical nursing in Canada: Assessment and management of clinical problems. Toronto, ON: Elsevier.

Majumdar, S. R., Lipton, H. L., \& Soumerai, S. B. (2011). Evaluating and improving physician prescribing. In Strom, B.L., Kimmel, S.E.., \& Henness, S. ( $5^{\text {th }}$ ed $)$. Pharmacoepidemiology (pp. 419-438). New Jersey, NJ: Wiley-Blackwell. 
Mancini, J., Baumstarkck-Barrau, K., Simeoni, M. C., Grob, J. J., Michel, G., Tarpin, C., . . Auquier, P. (2011). Quality of life in a heterogeneous sample of caregivers of cancer patients: An in-depth interview study. European Journal of Cancer Care, 20(4), 483-492.

Manne, S., \& Badr, H. (2008). Intimacy and relationship processes in couples' psychosocial adaptation to cancer. Cancer, 112(11 Suppl), 2541-2555. doi:10.1002/cncr.23450

Manne, S. L., Kissane, D. W., Nelson, C. J., Mulhall, J. P., Winkel, G., \& Zaider, T. (2011). Intimacy-Enhancing Psychological Intervention for Men Diagnosed with Prostate Cancer and Their Partners: A Pilot Study. The Journal of Sexual Medicine, 8(4), 1197-1209.

Mattila, E., Leino, K., Paavilainen, E., \& Åstedt-Kurki, P. (2009). Nursing intervention studies on patients and family members: A systematic literature review. Scandinavian Journal of Caring Sciences, 23(3), 611-622.

Martire, L. M., Lustig, A. P., Schulz, R.; Miller, G. E.; Helgeson, V. S. (2004). Is it beneficial to involve a family member? A meta-analysis of psychosocial interventions for chronic illness. Health Psychology, 23(6), 599-611.

McEwen, M. \& Willis, E. M. (2011). Theoretical basis for nursing. ( ${ }^{\text {ed }}$ ed.). Philadelphia, PA: Lippincott, Williams \& Wilkins.

Müller-Staub, M., Needham, I., Odenbreit, M., Ann Lavin, M., \& Van Achterberg, T. (2007). Improved quality of nursing documentation: Results of a nursing diagnoses, interventions, and outcomes implementation study. International Journal of Nursing Terminologies and Classifications, 18(1), 5-17. 
Murphy, M. R., Escamilla, M. I., Blackwell, P. H., Lucke, K. T., Miner-Williams, D., Shaw, V., \& Lewis, S. L. (2007). Assessment of caregivers' willingness to participate in an intervention research study. Research in Nursing \& Health,30(3), 347-355.

McCorkle, R., \& Pasacreta, J. V. (2001). Enhancing caregiver outcomes in palliative care. Cancer Control, 8(1), 36-45.

McCorkle, R., Robinson, L., Nuamah, I., Lev, E., \& Benoliel, J.Q. (1998). The effects of home nursing care for patients during terminal illness on the bereaved's psychological distress. Nursing Research, 47 (1), 2-10.

McLean, L. M., Jones, J. M., Rydall, A. C., Walsh, A., Esplen, M. J., Zimmermann, C., \& Rodin, G. M. (2008). A couples intervention for patients facing advanced cancer and their spouse caregivers: Outcomes of a pilot study. Psycho-Oncology, 17(11), 1152-1156.

McLean, L. M., Walton, T., Rodin, G., Esplen, M. J., \& Jones, J. M. (2013). A couple-based intervention for patients and caregivers facing end-stage cancer: Outcomes of a randomized controlled trial. Psycho-Oncology, 22(1), 28-38.

Medical Research Council. (2000). Developing and evaluating complex interventions: New guidance. Retrieved from www.mrc.ac.uk/complexinterventionsguidance

Michie, S., Fixsen, D., Grimshaw, J. M., \& Eccles, M. P. (2009). Specifying and reporting complex behaviour change interventions: the need for a scientific method. Implementation Science, 4(40), 1-6.

Moher, D., Liberati, A., Tetzlaff, J., \& Altman, D. G. (2009). Preferred reporting items for systematic reviews and meta-analyses: the PRISMA statement. Annals of internal medicine, 151(4), 264-269. 
National Comphrehensive Cancer Network. (2012) National Comprehensive Cancer Network's Clinical Practice Guidelines for Oncology: Distress Management. Retrieved from http://www.healthyohioprogram.org/ /media/HealthyOhio/ASSETS/Files/comprehensive $\% 20$ cancer/CCLC/NCCN-Distress.ashx

Nayak, B. K. (2010). Understanding the relevance of sample size calculation.Indian Journal of Ophthalmology, 58(6), 469-470. doi: 10.4103/0301-4738.71673

Needleman, C., \& Needleman, M. L. (1996). Qualitative methods for intervention research. American Journal of Industrial Medicine, 29(4), 329-337.

Northouse, L. L., Katapodi, M. C., Song, L., Zhang, L., \& Mood, D. W. (2010). Interventions with Family Caregivers of Cancer Patients: Meta-Analysis of Randomized Trials. CA: A Cancer Journal for Clinicians, 60(5), 317-339.

Northouse, L., Kershaw, T., Mood, D., \& Schafenacker, A. (2005). Effects of a family intervention on the quality of life of women with recurrent breast cancer and their family caregivers. Psycho-Oncology, 14(6), 478-491.

Northouse, L. L., Mood, D. W., Schafenacker, A., Montie, J. E., Sandler, H. M., Forman, J. D., ... \& Kershaw, T. (2007). Randomized clinical trial of a family intervention for prostate cancer patients and their spouses. Cancer, 110(12), 2809-2818.

Northouse, L. L., Rosset, T., Phillips, L., Mood, D., Schafenacker, A., \& Kershaw, T. (2006). Research with families facing cancer: the challenges of accrual and retention. Research in Nursing \& Health, 29(3), 199-211.

Northouse, L., Williams, A. L., Given, B., \& McCorkle, R. (2012). Psychosocial care for family caregivers of patients with cancer. Journal of Clinical Oncology,30(11), 1227-1234. 
Osse, B. H. P., Vernooij-Dassen, M. J. F. J., Schadé, E., \& Grol, R. P. T. M. (2006). Problems experienced by the informal caregivers of cancer patients and their needs for support. Cancer Nursing, 29(5), 378-388.

Pasacreta, J. V., \& Mccorkle, R. (2000). Cancer Care: Impact of Interventions on Caregiver Outcomes. Annual Review of Nursing Research, 18(1), 127-148.

Payne, S., Smith, P., \& Glass, S. (1999). Identifying the concerns of informal caregivers in palliative care. Palliative Medicine, 13, 37-44.

Polit, D. F., \& Beck, C. T. (2008). Nursing research: Generating and assessing evidence for nursing practice Lippincott Williams \& Wilkins.

Porter, L. S., Keefe, F. J., Garst, J., McBride, C. M., \& Baucom, D. (2008). Self-efficacy for managing pain, symptoms, and function in patients with lung cancer and their informal caregivers: Associations with symptoms and distress. Pain, 137(2), 306-315.

Porter, L. S., Keefe, F. J., Garst, J., Baucom, D. H., McBride, C. M., McKee, D. C., Sutton, L., Carson, K., Knowles, C., Rumble, M. \& Scipio, C. (2011). Caregiver-assisted coping skills training for lung cancer: Results of a randomized clinical trial. Journal of Pain and Symptom Management, 41(1), 1-13.

Porter, L. S., Keefe, F. J., Baucom, D. H., Hurwitz, H., Moser, B., Patterson, E., \& Kim, H. J. (2009). Partner-assisted emotional disclosure for patients with gastrointestinal cancer. Cancer, 115(S18), 4326-4338.

Rawl, S. M., Given, B. A., Given, C. W., Champion, V. L., Kozachik, S. L., Barton, D., ... \& Williams, S. D. (2002). Intervention to improve psychological functioning for newly diagnosed patients with cancer. Oncology Nursing Forum, 29, 6, 967-975. 
Redman, N. (2001). The practice of patient education. St. Louis, MI: Mosby.

Reed, D., Titler, M. G., Dochterman, J. M., Shever, L. L., Kanak, M., \& Picone, D. M. (2007). Measuring the dose of nursing intervention. International Journal of Nursing Terminologies and Classifications, 18(4), 121-130.

Rexilius, S. J., Mundt, C. A., Megel, M. E., \& Agrawal, S. (2002). Therapeutic effects of massage therapy and healing touch on caregivers of patients undergoing autologous hematopoietic stem cell transplant. Oncology Nursing Forum, 29 (3), E35-E44).

Ridner, S. H. (2004). Psychological distress: concept analysis. Journal of Advanced Nursing, 45(5), 536-545.

Ruddy, R., \& House, A. (2005). Meta-review of high-quality systematic reviews of interventions in key areas of liaison psychiatry. The British Journal of Psychiatry, 187(2), 109-120.

Santo, E.A.R.E., Gaíva, M.A.M., Espinosa, M.M., Barbosa, D.A., \& Belasco, A.G.S. (2011). Taking care of children with cancer: Evaluation of the caregivers' burden and quality of life. Rev.Latino-Am. Enfermagem,19(3), 515-22

Scott, J. L., Halford, W. K., \& Ward, B. G. (2004). United we stand? The effects of a couplecoping intervention on adjustment to early stage breast or gynecological cancer. Journal of Consulting and Clinical Psychology, 72(6), 1122-1135. doi:10.1037/0022-006X.72.6.1122

Schumacher, K. L., Stewart, B. J., Archbold, P. G., Dodd, M. J., \& Dibble, S. L. (2000). Family caregiving skill: Development of the concept. Research in Nursing \& Health, 23(3), 191203.

Selwood, A., Johnston, K., Katona,C., Lyketsos, C., \& Livingston, G. (2006). Systematic review of the effect of psychological interventions on family caregivers of people with dementia. Journal of Affective Disorders, 101, 75-89. 
Shea, B. J., Grimshaw, J. M., Wells, G. A., Boers, M., Andersson, N., Hamel, C., ... \& Bouter, L. M. (2007). Development of AMSTAR: a measurement tool to assess the methodological quality of systematic reviews. BMC medical research methodology, 7(1), 10.

Sidani, S. \& Braden C. J. (1998). Evaluating nursing interventions: A theory-driven approach. Thousand Oaks, CA: Sage Publications.

Sidani, S., \& Braden, C. J. (2011). Design, evaluation, and translation of nursing interventions. New Jersey, NJ: Wiley-Blackwell.

Sorensen, S., Piquart, M., \& Duberstein, P. (2002). How effective are interventions with caregivers? An updated meta-analysis. Gerontologist, 42, 356-372.

Stenberg, U., Ruland, C. M., \& Miaskowski, C. (2010). Review of the literature on the effects of caring for a patient with cancer. Psycho-Oncology, 19(10), 1013-1025.

Strong, V., Waters, R., Hibberd, C., Rush, R., Cargill, A., Storey, D., ... \& Sharpe, M. (2007). Emotional distress in cancer patients: the Edinburgh Cancer Centre symptom study. British Journal of Cancer, 96(6), 868-874.

Suhonen, R., Välimäki, M., \& Leino-Kilpi, H. (2008). A review of outcomes of individualised nursing interventions on adult patients. Journal of Clinical Nursing, 17(7), 843-860.

Swanson, E. A., Jensen, D. P., Specht, J., Johnson, M. L., Maas, M., \& Saylor, D. (1997). Caregiving: Concept analysis and outcomes. Research and Theory for Nursing Practice, $11(1), 65-76$.

Thompson, B. T., \& Schoenfeld, D. (2007). Usual care as the control group in clinical trials of nonpharmacologic interventions. Proceedings of the American Thoracic Society, 4(7), 577. 
Tong, A., Sainsbury, P., \& Craig, J. (2007). Consolidated criteria for reporting qualitative research (COREQ): a 32-item checklist for interviews and focus groups. International Journal for Quality in Health Care, 19(6), 349-357.

Toseland, R. W., Blanchard, C. G., \& McCallion, P. (1995). A problem solving intervention for caregivers of cancer patients. Social Science \& Medicine, 40(4), 517-528.

Trecartin, K., \& Carroll, D. L. (2011). Nursing interventions for family members waiting during cardiac procedures. Clinical Nursing Research, 20(3), 263.

Uman, L. S., Chambers, C. T., McGrath, P. J., \& Kisely, S. (2006). Psychological interventions for needle-related procedural pain and distress in children and adolescents. Cochrane Database Syst Rev, 4.

Ussher, J. M., Tim Wong, W. K., \& Perz, J. (2011). A qualitative analysis of changes in relationship dynamics and roles between people with cancer and their primary informal carer. Health, 15(6), 650-667. doi:10.1177/1363459310367440

Veit, C. T., \& Ware, J. E. (1983). The structure of psychological distress and well-being in general populations. Journal of consulting and clinical psychology,51(5), 730.

Walsh, S. M., Martin, S. C., \& Schmidt, L. A. (2004). Testing the efficacy of a creative arts intervention with family caregivers of patients with cancer. Journal of Nursing Scholarship, 36(3), 214-219.

Walsh, S.M., Radcliffe, A., Castillo, L.C., Kumar, A.M. \& Broschard, D.M.(2007). A pilot study to test the effects of art-making classes for family caregivers of patients with cancer. Oncology Nursing Forum, 34(1), 1- 8.

Walsh, S. M., \& Schmidt, L. A. (2003). Telephone support for caregivers of patients with cancer. Cancer Nursing, 26(6), 448-453. 
Walsh, K., Jones, L., Tookman, A., Mason, C., McLouglin, J.,Blizard, R., \& King, M. (2007). Reducing emotional distress in people caring for patients receiving specialist palliative care randomised trial. The British Journal of Psychiatry, 190(2), 142-147.

Weitzner, M., Jacobsen, P., Wagner, H., Friedland, J., \& Cox, C. (1999). The caregiver Quality of Life Index-Cancer (CQOLC) scale: Development and validation of an instrument to measure quality of life of the family caregiver of patients with cancer. Quality of Life Research, 8(1), 55-63.

Whitley, G. G. (1992). Concept analysis of anxiety. International Journal of Nursing Terminologies and Classifications, 3(3), 107-116.

Yates, P. (1999). Family coping: Issues and challenges for cancer nursing. Cancer Nursing, 22(1), 63-71.

Zabora, J., Brintzenhofeszoc, K., Curbow, B., Hooker, C., \& Piantadosi, S. (2001). The prevalence of psychological distress by cancer site. Psycho-Oncology, 10(1), 19 